\title{
Computer Modeling of Weld Joint Microstructure and Residual Stresses
}

\author{
by \\ $\mathrm{Ba} \mathrm{He}$ \\ B.Eng., Shanghai JiaoTong University, China, 1991 \\ A thesis submitted to \\ the Faculty of Graduate Studies and Research \\ in partial fulfillment of the requirements for the degree of
}

\begin{abstract}
Master of Applied Science
Department of Mechanical and Aerospace Engineering

Ottawa - Carleton Institute for Mechanical and Aerospace Engineering

Carleton University

Ottawa, Canada
\end{abstract}

August 2005

(C) Copyright

2005, Ba He 


$\begin{array}{ll}\begin{array}{l}\text { Library and } \\ \text { Archives Canada }\end{array} & \begin{array}{l}\text { Bibliothèque et } \\ \text { Archives Canada }\end{array} \\ \begin{array}{l}\text { Published Heritage } \\ \text { Branch }\end{array} & \begin{array}{l}\text { Direction du } \\ \text { Patrimoine de l'édition }\end{array} \\ \begin{array}{l}\text { 395 Wellington Street } \\ \text { Ottawa ON K1A ON4 } \\ \text { Canada }\end{array} & \begin{array}{l}\text { 395, rue Wellington } \\ \text { Ottawa ON K1A ON4 } \\ \text { Canada }\end{array}\end{array}$

Your file Votre référence ISBN: 0-494-10087-7

Our file Notre référence

ISBN: 0-494-10087-7

NOTICE:

The author has granted a nonexclusive license allowing Library and Archives Canada to reproduce, publish, archive, preserve, conserve, communicate to the public by telecommunication or on the Internet, loan, distribute and sell theses worldwide, for commercial or noncommercial purposes, in microform, paper, electronic and/or any other formats.

The author retains copyright ownership and moral rights in this thesis. Neither the thesis nor substantial extracts from it may be printed or otherwise reproduced without the author's permission.
AVIS:

L'auteur a accordé une licence non exclusive permettant à la Bibliothèque et Archives Canada de reproduire, publier, archiver, sauvegarder, conserver, transmettre au public par télécommunication ou par l'Internet, prêter, distribuer et vendre des thèses partout dans le monde, à des fins commerciales ou autres, sur support microforme, papier, électronique et/ou autres formats.

L'auteur conserve la propriété du droit d'auteur et des droits moraux qui protège cette thèse. $\mathrm{Ni}$ la thèse ni des extraits substantiels de celle-ci ne doivent être imprimés ou autrement reproduits sans son autorisation.
In compliance with the Canadian

Privacy Act some supporting forms may have been removed from this thesis.

While these forms may be included in the document page count, their removal does not represent any loss of content from the thesis.
Conformément à la loi canadienne sur la protection de la vie privée, quelques formulaires secondaires ont été enlevés de cette thèse.

Bien que ces formulaires aient inclus dans la pagination, il n'y aura aucun contenu manquant. 
The undersigned recommend to the Faculty of Graduate Studies and Research acceptance of the thesis

\title{
Computer Modeling of Weld Joint Microstructure and Residual Stresses
}

\author{
submitted by
}

\section{$\mathrm{Ba} \mathrm{He}$}

in partial fulfillment of the requirements for

the degree of

Master of Applied Science

Thesis Supervisor, J. A. Goldak

Thesis Co-Supervisor, X. Huang

Chair, Department of Mechanical and Aerospace Engineering

Carleton University 


\begin{abstract}
A systematic study of weld joint microstructure and residual stress development has been conducted using computer modeling.

The temperature field was obtained using a $2 \mathrm{D}$ thermal model. A prescribed temperature double ellipsoid was employed as the moving heat source in the weld pool to compute the weld joint temperature history. The computed temperature was in good agreement with the existing experimental value.

Weld metal (WM) and heat affected zone (HAZ) microstructure evolution in a low alloy steel weld joint was modeled using algebraic equations for thermodynamics and ordinary differential equations (ODEs) for kinetics based on the weld joint chemical composition, austenite phase grain size and thermal history calculated using the thermal model. A 2D model was used for the calculation of the volume fraction of microstructural constituents.

Modeling of residual stresses in a butt-welded plate and a T-joint was addressed by 3D modeling. The thermal load computed by the thermal model was used to solve the conservation of moment and equilibrium of forces momentum equation, constitutive equation of stress and strain and compatibility equation between strain and displacement for the residual stress and displacement fields. The effects of weld length, weld constraint and welding sequence on residual stresses were also investigated.
\end{abstract}


To my family, for their love and support. 


\section{Acknowledgments}

I would like to take this opportunity to thank my thesis supervisor Dr. John Goldak, for his support, ideas and motivation. He has provided me with a great deal of inspiration throughout the research. His guidance and encouragement have taught me how to overcome hardships in both academic and non academic situations.

I would like to extend special appreciation to my thesis co-supervisor, Dr. Xiao Huang for her assistance in the course of my research.

I would also like to extend my appreciation to Shaodong Wang, Lijiang Bai, Stanislav Tchernov, Jianguo Zhou and Dan Downey for the incredible support and help that they have provided me with. 


\section{Nomenclature}

$a_{1}, a_{2}, b, c$ Heat source distribution parameters parallel to coordinate axes $\xi, y, z$

$a^{*}, b^{*} \quad$ Stoichiometry constants

b Body force vector

$\mathbf{b}_{\mathbf{f}} \quad$ Sum of body forces and surface tractions vector

f Surface traction vector

$\mathbf{f}^{\mathrm{e}} \quad$ Element force vector

$f_{f} \quad$ Fractions of heat deposited in the front quadrant of a double ellipsoid

$f_{r} \quad$ Fractions of heat deposited in the rear quadrant of a double ellipsoid

$g \quad$ Grain size

$h \quad$ Convective coefficient

$k \quad$ Thermal conductivity

$k_{1} \quad$ Kinetic constant

$k_{2} \quad$ Constant for martensite volume fraction calculation

$k_{r} \quad$ Radiative coefficient

$k_{x}, k_{y}, k_{z} \quad$ Thermal conductivities in the $x, y$ and $z$ directions

$l_{s} \quad$ Side length of a column grain

$m, n \quad$ Semi-empirical coefficients

$p \quad$ Peclet number

$q_{f} \quad$ Power density in the front quadrant of a double ellipsoid 
$q_{r} \quad$ Power density in the rear quadrant of a double ellipsoid

$r$

$r_{c} \quad$ Critical plate tip radius of Widmanstatten ferrite

$t \quad$ Lag factor

$u, v, w \quad$ Displacement components of a point along $\mathrm{x}, \mathrm{y}$ and $\mathrm{z}$ axes

$u^{*} \quad$ Virtual displacement

$\mathbf{u}_{\mathbf{i}} \quad$ Nodal displacement

$v_{1} \quad$ Velocity

$x, y, z \quad$ Cartesian coordinate system

$A$

Area

$A_{e 1} \quad$ Lower critical temperature

$A_{e 3} \quad$ Upper critical temperature

$A^{*}, B^{*} \quad$ Constant for determining precipitate dissolution temperature

$A_{S} \quad$ Acicular ferrite start temperature

$B \quad$ Strain to displacement mapping matrix

$B_{S} \quad$ Bainite start temperature

$\bar{C} \quad$ Average carbon content in the steel

$C_{4} \quad$ Constant for determining Widmanstatten volume fraction

$C^{\alpha \gamma} \quad$ Paraequilibrium carbon content in the $\alpha$

$C^{\gamma \alpha} \quad$ Paraequilibrium carbon content in the $\gamma$ 


\begin{tabular}{|c|c|}
\hline$D$ & Material property matrix \\
\hline$D^{*}$ & Diffusivity of carbon in $\gamma$ phase \\
\hline$\vec{D}^{*}$ & Weighted average diffusivity of carbon in $\gamma$ \\
\hline$D^{e}$ & Elastic stiffness matrix \\
\hline$D^{p}$ & Plastic stiffness matrix \\
\hline$D^{t h}$ & Thermal stiffness matrix \\
\hline$D_{f}$ & Distance in the front portion of a double ellipsoid \\
\hline$D_{r}$ & Distance in the rear portion of a double ellipsoid \\
\hline$E$ & Young's modulus \\
\hline$E_{i}$ & Element relative error \\
\hline$E_{\text {tot }}$ & Total relative error \\
\hline$G$ & Grain size index number \\
\hline$G^{\prime}$ & Temperature gradient \\
\hline$G_{l}$ & Lengthening rate of Widmanstatten ferrite \\
\hline$H$ & Combined convective and radiative heat transfer coefficient \\
\hline$H_{t}$ & Half thickness of grain boundary ferrite \\
\hline$I$ & Welding current \\
\hline$J$ & Jacobian operator \\
\hline$K$ & Global stiffness matrix \\
\hline$K^{e}$ & Element stiffness matrix \\
\hline
\end{tabular}

viii 


$\begin{array}{ll}\bar{L}_{t n} & \text { Mean linear intercept } \\ M & \text { Moment of residual stress } \\ M_{s} & \text { Martensite start temperature } \\ N_{i} & \text { Basis function } \\ \mathbf{P} & \text { Nodal vector of external loads } \\ Q & \text { Energy input rate } \\ R & \text { Gas constant } \\ \mathbf{R}_{1} & \text { Residual } \\ R_{g} & \text { Growth rate of solidification } \\ \mathbf{R}_{\mathbf{f}} & \text { Resultant vector of nodal thermal loads } \\ R_{x}, R_{y}, R_{z} & \text { Heat flux in } x, y \text { and } z \text { directions } \\ S E & \text { Strain energy norm } \\ T & \text { Temperature } \\ T_{L} & \text { Liquidus temperature } \\ T_{m a x} & \text { Peak temperature in the weld pool } \\ T_{m e l t} & \text { Melting point of the steel } \\ T_{\infty} & \text { Ambient temperature } \\ T S & \text { Precipitate dissolution temperature } \\ T_{S} & \text { Solidus temperature } \\ V & \text { Welding voltage } \\ & \end{array}$




\begin{tabular}{|c|c|}
\hline$W_{S}$ & Widmanstatten ferrite start temperature \\
\hline$X_{a}$ & Volume fraction of acicular ferrite \\
\hline$X_{F}$ & Volume fraction of ferrite \\
\hline$X_{F E}$ & Equilibrium volume fraction of ferrite \\
\hline$X_{m}$ & Volume fraction of microphase \\
\hline$X_{M}$ & Volume fraction of martensite \\
\hline$X_{P}$ & Volume fraction of pearlite \\
\hline$X_{P E}$ & Equilibrium volume fraction of pearlite \\
\hline$X_{w}$ & Volume fraction of Widmanstatten ferrite \\
\hline$X_{\alpha}$ & Volume fraction of grain boundary ferrite \\
\hline$\alpha$ & Ferrite phase \\
\hline$\gamma$ & Austenite phase \\
\hline$\alpha_{1}$ & 1D parabolic thickening rate constant \\
\hline$\alpha_{a}$ & Acicular ferrite \\
\hline$\alpha_{w}$ & Widmanstatten ferrite \\
\hline$\epsilon$ & Infinitesimal strain \\
\hline$\epsilon_{1}$ & Degree of blackness \\
\hline$\epsilon^{*}$ & Virtual strain \\
\hline$\epsilon_{x x}, \epsilon_{y y}, \epsilon_{z z}$ & Normal strain components \\
\hline$\epsilon_{x y}, \epsilon_{y z}, \epsilon_{x z}$ & Shear strain components \\
\hline
\end{tabular}




\begin{tabular}{|c|c|}
\hline$\nu$ & Poisson's ratio \\
\hline$\rho$ & Density \\
\hline$\sigma$ & Cauchy stress \\
\hline$\sigma_{1}$ & Stefan-Boltzmann's constant \\
\hline$\sigma_{k}$ & Kinematically admissible stress \\
\hline$\sigma_{s}$ & Statically admissible stress \\
\hline$\sigma_{x x}, \sigma_{y y}, \sigma_{z z}$ & Normal stress components of $\mathrm{x}, \mathrm{y}$ and $\mathrm{z}$ planes \\
\hline$\sigma_{x y}, \sigma_{y z}, \sigma_{x z}$ & Shear stress components \\
\hline$\sigma_{2}$ & The second Piola-Kirchoff stress \\
\hline$\tau$ & Welding time \\
\hline$\Pi$ & Operator that assembles element stiffness into global stiffness \\
\hline$\Pi_{0}$ & Homogeneous statically admissible stress space \\
\hline$\Sigma_{0}$ & Homogeneous kinematically admissible stress space \\
\hline$\Omega$ & Physical domain of volume \\
\hline$\nabla$ & Gradient operator \\
\hline$\Delta E_{i}$ & Element error bound \\
\hline$\Delta E_{t o t}$ & Total error bound \\
\hline$\Delta T$ & Undercooling \\
\hline
\end{tabular}




\section{Contents}

Acceptance Sheet . . . . . . . . . . . . . . ii

Abstract ...................... iii

Dedication .................... iv

Acknowledgements . . . . . . . . . . . . . . . . v

Nomenclature . . . . . . . . . . . . . . . . . vi

Table of Contents . . . . . . . . . . . . . . . . . . xii

List of Tables . . . . . . . . . . . . . . . . . xv

List of Figures . . . . . . . . . . . . . . . . . . . xvi

1 Introduction 1

1.1 Background . . . . . . . . . . . . . . . . . 1

1.1.1 Development and Applications of Fusion Welding . . . . . . 1

1.1.2 Microstructure Evolution during Fusion Welding . . . . . . . . 4

1.1.3 Weld-Induced Residual Stress . . . . . . . . . . . . . 10 
1.1.4 Modeling of Weld Joint Microstructure and Residual Stress . . 13

1.2 Objectives and Organization of the Thesis . . . . . . . . . . 16

1.2 .1 Objectives of the Thesis . . . . . . . . . . . 16

1.2.2 Organization of the Thesis . . . . . . . . . . . 17

2 Thermal Behavior Modeling $\quad 19$

2.1 Heat Transfer Analysis . . . . . . . . . . . . . . . . . 19

2.1 Heat Source Model . . . . . . . . . . . . . . . . 20

2.1.2 Heat Transfer Governing Equations . . . . . . . . . . . . . . 24

2.1.3 Boundary and Initial Conditions . . . . . . . . . . . . . 25

2.2 Finite Element Method (FEM) Procedure . . . . . . . . . . . . 28

2.3 Model Description . . . . . . . . . . . . . . . . 30

2.3.1 Model Consideration . . . . . . . . . . . . . . . 30

2.3.2 Geometry of the Model . . . . . . . . . . . . . . . . . 31

2.3.3 Material Thermal Properties . . . . . . . . . . . . . . . 32

2.4 Testing Results and Validation . . . . . . . . . . . . . 35

2.4.1 Mesh Optimization ................. 35

2.4.2 Model Validation . . . . . . . . . . . . . . . 36

2.5 Sensitivity Study . . . . . . . . . . . . . . . . . . 39

3 Microstructure Evolution $\quad 41$

xiii 
3.1 Literature Review . . . . . . . . . . . . . . . . . . . 42

3.1.1 Characteristic Transformation Temperatures and Carbon Content 42

3.1 .2 Austenite Grain Size . . . . . . . . . . . . . . . . . . 46

3.1.3 Solidification ................... . . . 48

3.1.4 Solid State Phase Transformation in Weld Metal (WM) - Bhadeshia's Model ......................... 51

3.1.5 Microstructure Evolution in Heat Affected Zone - Khoral's Model 57

3.2 Implementation of Khoral's Model . . . . . . . . . . . . . . . 62

3.3 Simulation and Results . . . . . . . . . . . . . . . . . 64

3.3.1 Geometry and Chemical Composition of the Weld Joint . . . . 64

3.3 .2 Thermal History . . . . . . . . . . . . . 66

3.3.3 Microstructure Development . . . . . . . . . . . 68

4 Residual Stress Analysis $\quad 76$

4.1 Fundamental Concepts . . . . . . . . . . . . . 76

4.2 Theoretical Considerations . . . . . . . . . . . . . . 78

4.2.1 Governing Equations . . . . . . . . . . . . 78

4.2.2 Computation Procedure ................ 84

4.2 .3 Error Estimation . . . . . . . . . . . . . 86

4.3 Implementation of Residual Stress Analysis . . . . . . . . . . . . . 89

4.3.1 Model Construction . . . . . . . . . . . . . . . . 89 xiv 
4.3 .2 Material Properties . . . . . . . . . . . . . . . . . . 91

4.3.3 Results and Discussion . . . . . . . . . . . . . . . . 92

4.3.4 Parametric Study . . . . . . . . . . . . . . . . . 100

5 Conclusions and Future Work 106

5.1 Conclusions . . . . . . . . . . . . . . . . . . 106

5.2 Future Work . . . . . . . . . . . . . . . . . . . 108

$\begin{array}{ll}\text { A Material properties } & 109\end{array}$

$\begin{array}{ll}\text { Bibliography } & 114\end{array}$ 


\section{List of Tables}

2.1 Arc efficiency of various welding processes [11] . . . . . . . 23

2.2 Double ellipsoid parameters . . . . . . . . . . . . . . 33

2.3 Welding parameters for welding of $8 \mathrm{~mm}$ low carbon steel plates [46]. 37

3.1 Solubility products for carbides and nitrides in steels [51] . . . . . 45

3.2 Chemical composition of the base metal and the filler metal (wt\%). . 66

3.3 Characteristic temperatures of the base metal and the filler metal. . . 66

3.4 Temperature difference at one time step and cooling time $t_{8 / 5} \ldots \ldots 8$ 


\section{List of Figures}

1.1 Schematic diagram showing the four zones in a steel weld. . . . . . . 3

1.2 The iron-carbon phase diagram $[5] \ldots \ldots \ldots$

1.3 Optical micrograph of weld metal $[15] . \ldots \ldots . \ldots . \ldots$

1.4 SEM micrograph of HAZ $[15] \ldots \ldots \ldots$

1.5 Factors that contribute to weld-induced residual stress. . . . . . . . . 11

1.6 Residual stress measurement methods in steel [21]. . . . . . . . . . . 12

1.7 Relation of temperature, microstructure and stress. . . . . . . . . 16

2.1 Double ellipsoid configuration $[37] . \ldots \ldots \ldots . \ldots \ldots 22$

2.2 Geometry of the cross section. . . . . . . . . . . . . . 32

2.3 Mesh used in the calculation. . . . . . . . . . . . . . . 32

2.4 Temperature-dependent density $[43] . \ldots \ldots 33$

2.5 Temperature-dependent specific heat [44]. . . . . . . . . . . . 34

2.6 Temperature-dependent thermal conductivity [44] . . . . . . . . . 34

2.7 Temperature distribution in different meshes. . . . . . . . . . . . . . 35 xvii 
2.8 Temperature distribution at 222th step. . . . . . . . . . . . . . . . . 37

2.9 Transient temperature distribution. . . . . . . . . . . . . 38

2.10 Comparison of temperature at point a. . . . . . . . . . . . 38

2.11 Comparison of temperature at point b. . . . . . . . . . . . 39

2.12 Effect of thermal conductivity on temperature field. . . . . . . . . . 40

3.1 TTT diagram for weld deposits $[22] . \ldots \ldots \ldots$. . . . . . . 46

3.2 Schematic diagram of a columnar austenite grain. . . . . . . . . . 47

3.3 Solidification mode in steels $[9] . \ldots \ldots$. . . . . . . . . . . . 49

3.4 CCT diagram for weld metal of low-carbon steel $[9] \ldots . . . . . . . .50$

3.5 Schematic diagram of allotriomorphic ferrite formation. . . . . . . . 52

3.6 Schematic diagram of Widmanstatten ferrite formation. . . . . . . . 54

3.7 Schematic diagram of microphase calculation. . . . . . . . . . . 56

3.8 Mesh of the base metal. . . . . . . . . . . . . . 65

3.9 Geometry and mesh of the filler metal. . . . . . . . . . . . . 65

3.10 Temperature variation at different points. . . . . . . . . . 67

3.11 Volume fraction of ferrite. . . . . . . . . . . . . . . . . . . 69

3.12 Volume fraction of pearlite. . . . . . . . . . . . . . 69

3.13 Volume fraction of bainite. . . . . . . . . . . . . . . . 70

3.14 Volume fraction of martensite. . . . . . . . . . . . . 70

3.15 Temperature and microstructure development at point A. . . . . . . . 71 xviii 
3.16 Temperature development at point B, C and D. . . . . . . . . . 73

3.17 Microstructure development at point B. . . . . . . . . . . . . 73

3.18 CCT diagram of $0.17 \mathrm{C}$ wt\% carbon steel $[20] . \ldots . . . . . . . .74$

3.19 Microstructure development at point C . . . . . . . . . . . 75

3.20 Microstructure development at point D. . . . . . . . . . . . . . 75

4.1 Stress field and exact solution [68]. . . . . . . . . . . . . . . . 89

4.2 Geometry of the plate butt weld. . . . . . . . . . . . . . . . 90

4.3 Geometry of the T-joint. . . . . . . . . . . . . . . . . 91

4.4 Transient stress in weld metal and HAZ. . . . . . . . . . . . . . . . 93

4.5 Normal stress in the butt weld. . . . . . . . . . . . . . . . . . . 94

4.6 Effective stress in the butt weld. . . . . . . . . . . . . . . . 96

4.7 Effective plastic strain in the butt weld. . . . . . . . . . . . . . . . 97

4.8 Displacement in the weld joint. . . . . . . . . . . . . . . . . . 98

4.9 Stress distribution in the T-joint. . . . . . . . . . . . . . . . . 99

4.10 Comparison of longitudinal stress along $\mathrm{Z}$ direction. . . . . . . . . 101

4.11 Comparison of transverse stress along X direction. . . . . . . . . . . . 101

4.12 Nodal fixity of the model. . . . . . . . . . . . . . . . . . . 102

4.13 Longitudinal stress distribution for different constraints. . . . . . . . 103

4.14 Transverse stress distribution for different constraints. . . . . . . . . . 103

4.15 Comparison of T-joint longitudinal stress along Z direction. . . . . . . 104 
4.16 Comparison of T-joint transverse stress along X direction. . . . . . . 105

A.1 Temperature-dependent thermal conductivity [44] . . . . . . . . 109

A.2 Temperature-dependent specific heat [44]. . . . . . . . . . . . 110

A.3 Temperature-dependent coefficient of thermal expansion [45] . . . . . 110

A.4 Temperature-dependent bulk modulus [45] . . . . . . . . . . . 111

A.5 Temperature-dependent hardening modulus [45] . . . . . . . . . . . 111

A.6 Temperature-dependent Poisson's ratio [45] . . . . . . . . . . . . . . 112

A.7 Temperature-dependent shear modulus [45] . . . . . . . . . . 112

A.8 Temperature-dependent yield stress [45] . . . . . . . . . . . . . . 113

A.9 Temperature-dependent Young's modulus [45] . . . . . . . . . . . 113 


\section{Chapter 1}

\section{Introduction}

\section{$1.1 \quad$ Background}

\subsubsection{Development and Applications of Fusion Welding}

Welding is a technique used for joining metallic or nonmetallic parts usually through the application of heat or pressure. In accordance with the International Organization for Standardization (ISO), welding is divided into two groups [1]: Fusion welding and pressure welding. Fusion welding is welding without application of outer force in which the facing surface must be melted. By contrast, pressure welding is welding in which sufficient outer force is applied to cause more or less plastic deformation of both facing surfaces. Arc welding, gas welding, electroslag welding and high energy density welding belong to the first group, whereas forge welding, 
friction welding, ultrasonic welding and explosion welding belong to the latter group.

Before the invention of arc welding and resistance welding in the late 1880's, forge welding had been the only method of metallurgically joining metals for centuries. In the 20 th century, arc welding processes including shielded metal arc welding (SMAW), submerged-arc welding (SAW), gas tungsten arc welding (GTAW), gas metal arc welding (GMAW), and flux-cored arc welding (FCAW) were developed. Oxyacetylene welding was also developed during the same period as arc welding [2]. In addition, high energy density welding processes, i.e., electron beam welding and laser welding, as well as pressure welding processes, such as friction welding, ultrasonic welding and explosion welding were developed and applied commercially in modern industry.

A typical fusion weld joint consists of fusion zone (FZ), mushy zone, heat affected zone (HAZ), and unaffected base metal, as shown in Figure 1.1. Each zone is subject to a different thermal history. The FZ is the area where the peak temperature is higher than the melting point of the material being joined and the base metal and any filler metal are melted during welding, whereas the metal is just partially melted in the mushy zone. The HAZ is the region of the base metal that is not melted during the welding operation but whose physical properties are altered by the heat induced from the welding process.

The energy used for welding can originate from electrical sources, chemical sources, focused sources, mechanical sources, and solid state sources [3]. In many cases, welds 
are made using multipass welding techniques and procedures.

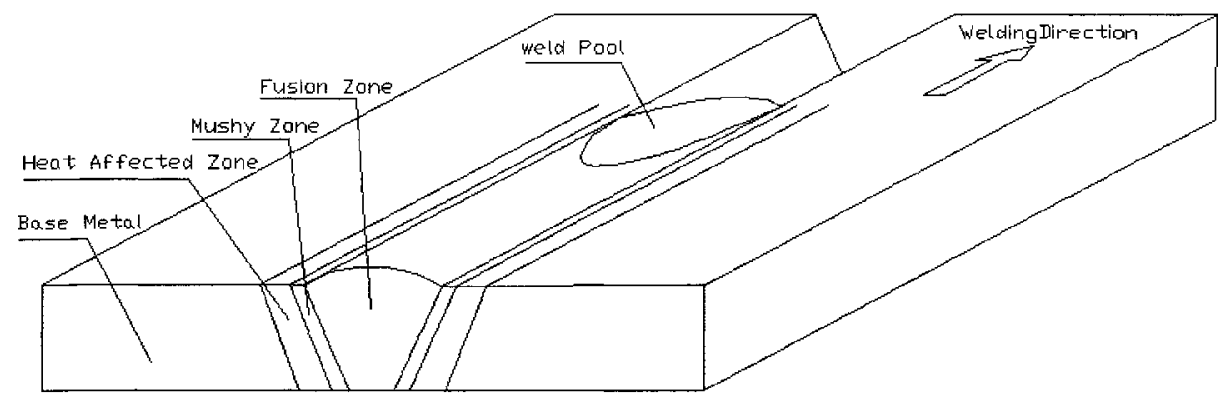

Figure 1.1: Schematic diagram showing the four zones in a steel weld.

Compared to other metal joining methods, fusion welding has the following advantages $[4]$ :

- Welded joints can have high joint efficiency. They are capable of carrying loads similar to those supported by the individual components from which they are built.

- They save weight. Components can be joined without adding appreciable mass or volume to the overall structure compared to processes such as mechanical fastening.

- Very thick sections or parts can be joined by employing multipass welding techniques and procedures.

- Welding is a versatile and relative low-cost process. 
- High productivity can be achieved with precise computer control led automatic operation.

Due to the advantages associated with fusion welding, it has served as one of the most important material joining techniques extensively employed in diverse industries such as petrochemical, transportation, aerospace, nuclear, bridge, machinery, etc. However, because of the intense localized heating, subsequent rapid cooling, and the possible defects created during welding, welded structures are by no means free from problems. Some examples of the problems are the deterioration of mechanical properties in the $\mathrm{FZ}$ and $\mathrm{HAZ}$, residual stress and distortion.

\subsubsection{Microstructure Evolution during Fusion Welding}

The microstructure of a weld determines the final performance of welded structures and it is greatly affected by the welding thermal cycle. When two components to be joined are subjected to a heat source, the mating surfaces are melted and the joint is formed with or without the addition of filler metal. The constituents and phase transformation of low alloy steel during welding can be best revealed from the iron-carbon phase diagram, as shown in Figure 1.2. There are several temperatures or critical points in the phase diagram which are important from the microstructural point of view. In equilibrium condition, the eutectoid reaction occurs at line P-S-K, which is called the lower critical temperature $A_{e 1}$; a transformation occurs between 
$\alpha$-iron and $\gamma$-iron at line GS which is called upper critical temperature $A_{e 3}$. In addition, EJ is the solidus line and $\mathrm{J}-\mathrm{B}-\mathrm{C}$ is the liquidus line. Other characteristic temperatures such as austenite grain coarsening (or precipitate dissolution) temperature (TS), Widmanstatten ferrite start temperature $\left(W_{s}\right)$, bainite start temperature $\left(B_{s}\right)$ and martensite start temperature $\left(M_{s}\right)$ are however not presented in the phase diagram.

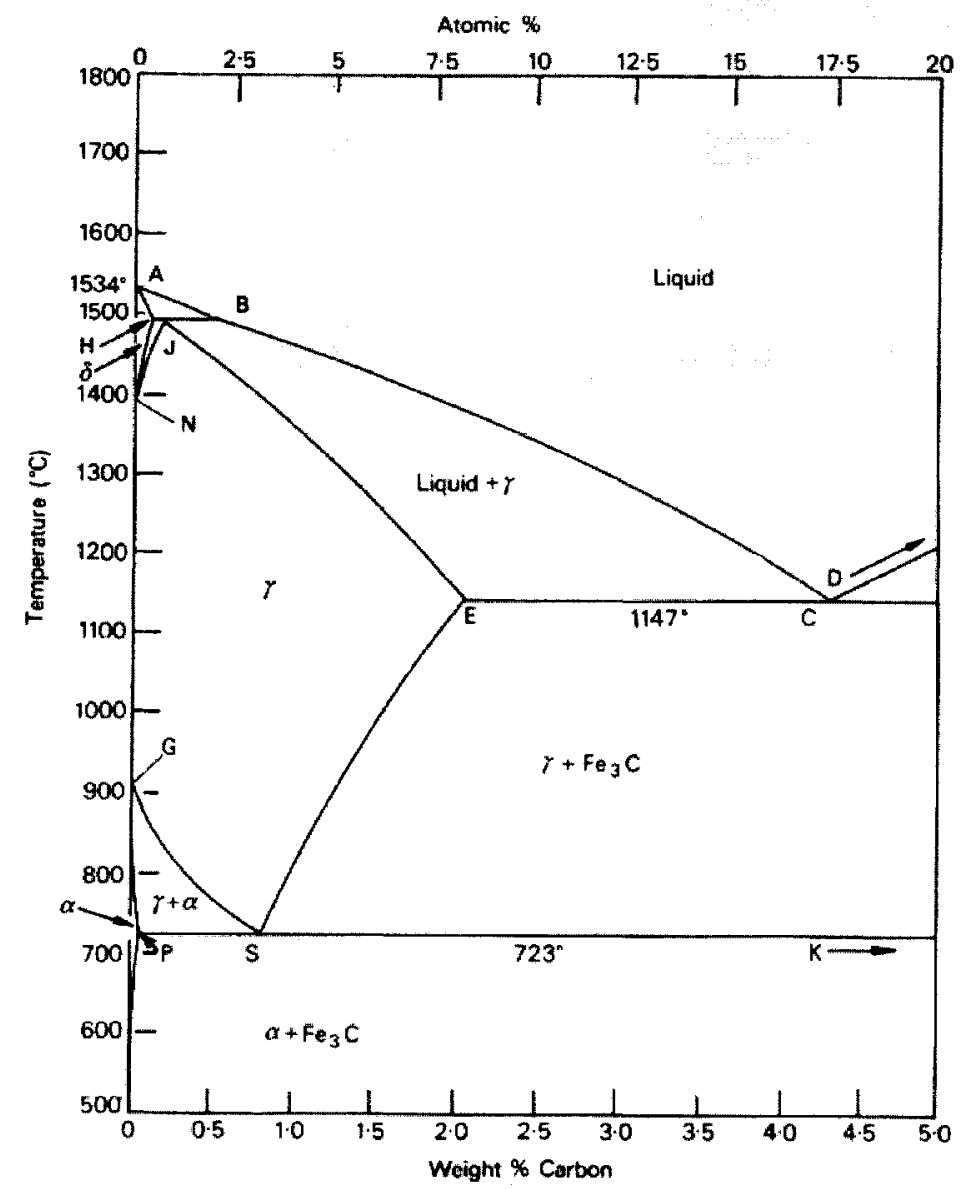

Figure 1.2: The iron-carbon phase diagram [5]. 
When heated, the fusion zone and mushy zone of a weld joint melt when the arc passes through. During the cooling cycle, various phase transformations occur including inclusion formation, solidification from liquid to $\delta$-ferrite, phase transformation of $\delta$ ferrite to austenite, and finally subsequent transformation of austenite to products such as $\alpha$-ferrite, pearlite, bainite, and/or martensite $[6,7]$.

Initial solidification of the fusion zone commonly occurs epitaxially at the partially melted grains in the base metal [8-11], in which the nucleation occurs by arranging atoms from the liquid metal upon the substrate grains without altering their existing crystallographic orientations [9]. Thus the FZ grain structure is primarily determined by the base metal grain structure and welding conditions. The solidification behavior of a weld pool is controlled by the solidification parameters, such as temperature gradient, growth rate and the resultant undercooling [12].

For low-alloy steels whose alloy element content is less than $5 \%$ in weight percent, the primary microstructure of weld metal at room temperature, i.e., as-deposited microstructure, consists of one or more of the following constituents [13]:

- Allotriomorphic ferrite $(\alpha)$ or grain boundary ferrite (GBF). These crystals which nucleate at the austenite grain boundaries.

- Widmanstatten ferrite $\left(\alpha_{w}\right)$ or side plate ferrite (WF). These plates nucleate at the $\gamma$-grain boundaries or the existing ferrite grain boundaries. 
- Acicular ferrite ( $\alpha_{a}$ or AF). These are crystals, which nucleate intragranularly at inclusions within the large columnar austenite grains [8]. AF can improve the toughness of weld joint due to its fine grain size and interlocking characteristics.

- Microphase including small amounts of martensite (M), retained austenite or degenerate pearlite $(\mathrm{P})$.

For multipass welds, both as-deposited and reheated weld metal (HAZ) regions are formed due to the deposition of subsequent weld passes depending on the plate thickness, welding process and parameters as well as the weld pass sequence. In the former case, the prior austenite grains are more equiaxed, while in the latter case very fine polygonal ferrite and low temperature transformation products may be formed [14]. The proportion of as-deposited and reheated weld metal has been considered an important factor in explaining, for example, weld metal toughness properties.

A weld metal morphology for SAE 1020 steel is illustrated at Figure 1.3. The weld was made by SAW using AWS EL $12 \mathrm{~K} \phi 3.2$ wire and the heat input is $1 \mathrm{kJmm}^{-1}$.

The temperature increases to a level that is higher than the lower critical temperature but lower than the melting point in the HAZ. After heating a low alloy steel weld joint to just above the upper critical temperature, the austenite grains form and grow slowly; when the temperature is further increased to above the grain coarsening temperature, the rate of growth increases sharply.

The HAZ can be further divided into three zones [16]: supercritical zone, inter- 


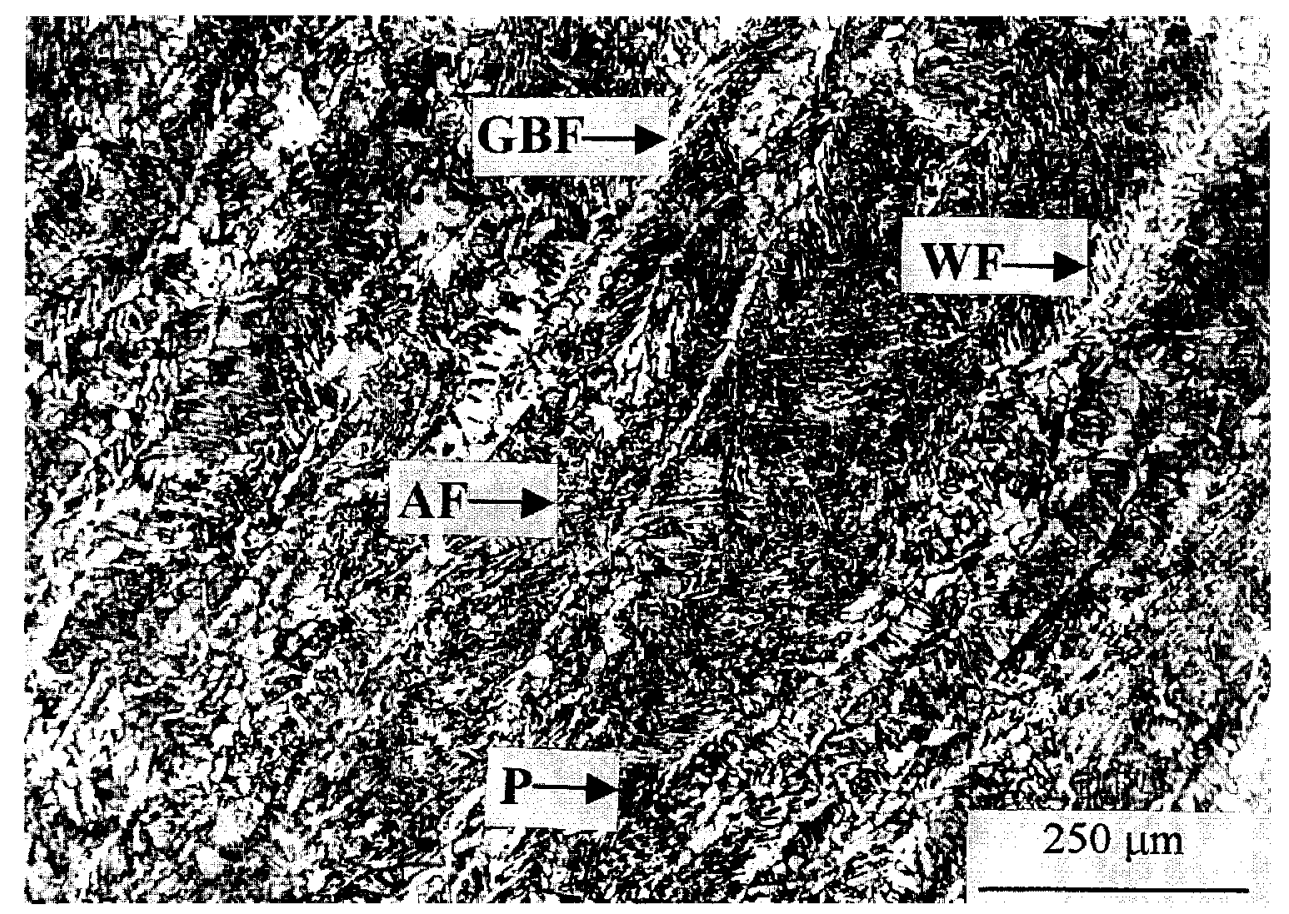

Figure 1.3: Optical micrograph of weld metal [15].

critical zone, and subcritical zone. The supercritical zone can be further subdivided into a grain growth (coarse-grained) region and a grain refined region. Microstructure in the coarse-grained region, depending on the carbon and alloy content of the steel, the grain size and the cooling rate, can be ferrite, pearlite, bainite, or martensite, or a mixture of these components and retained austenite [7]. In the grain refined region, due to the grain refining additives such as $\mathrm{Al}, \mathrm{Ti}, \mathrm{Nb}, \mathrm{V}$ and the lower peak temperature reached, the grain size is smaller than that of the parent metal. In the intercritical region, partial transformation may take place. However, the subcritical 
region does not undergo any observable microstructural change except that a small region of spheroidization may occur.

Figure 1.4 shows the HAZ microstructure of an SAE 1020 steel weld joint, where $\mathrm{PF}$ is ferrite, $\mathrm{P}$ is pearlite, $\mathrm{B}$ is bainite and $\mathrm{M}$ is martensite. The weld was made by SAW with $0.5 \mathrm{kJmm}^{-1}$ heat input and the initial ferrite ASTM grain size number was 4.5 .

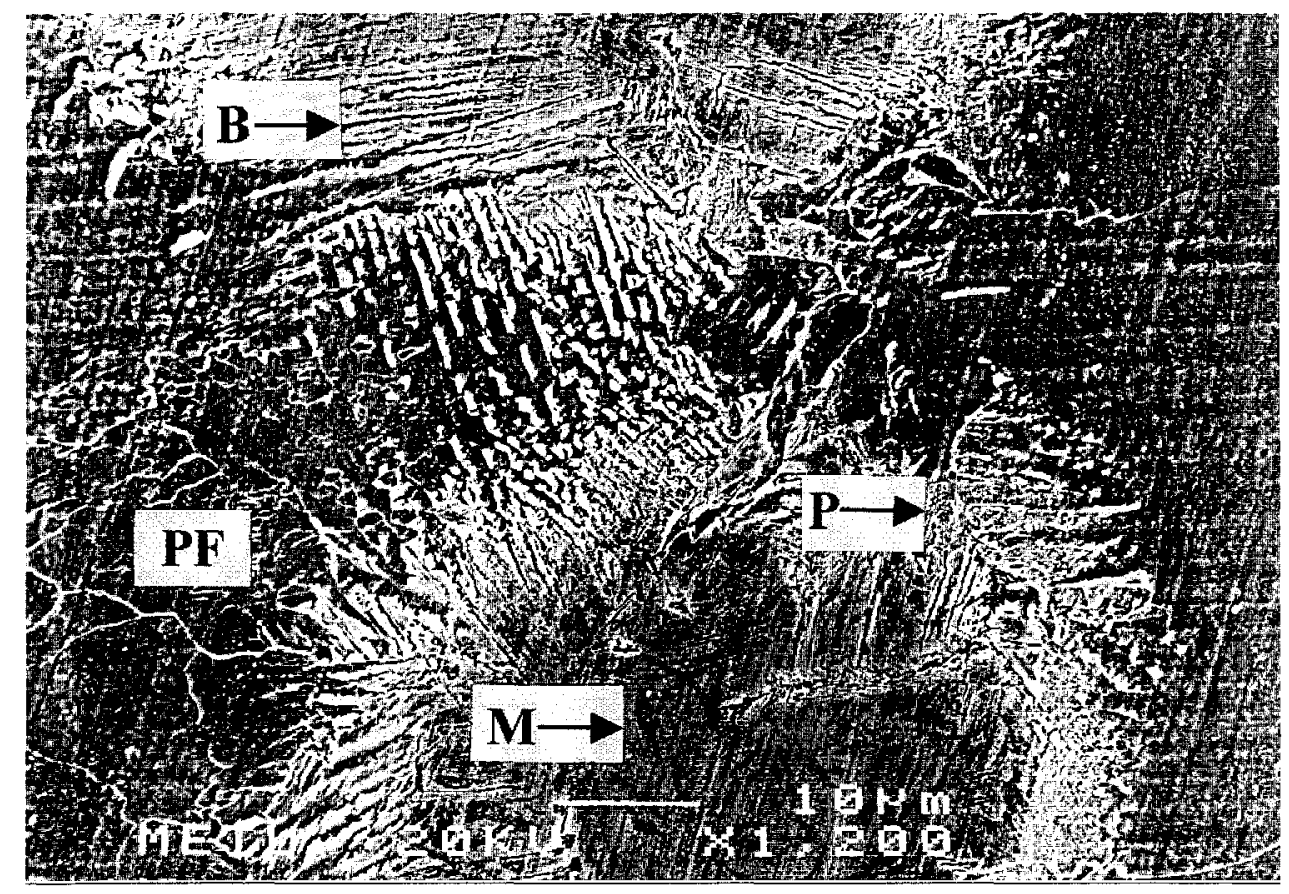

Figure 1.4: SEM micrograph of HAZ [15]. 


\subsubsection{Weld-Induced Residual Stress}

Due to the non-uniform temperature distribution throughout the joint during heating and cooling cycles, thermal strains, localized plastic deformation and the phase transformation can induce residual stress and distortion, which are unavoidable for a welding process. Several issues relate microstructure to the residual stress [1719]:

- They both correlate to the thermal history.

- They both offer useful information for evaluating crack initiation and propagation in and around the weld joint.

- From the microstructure, one can predict the thermal and mechanical constitutive properties of a weldment.

- The evolution of microstructure affects the thermal stress analysis of welds.

- From the microstructure and residual stress, one can predict weldment performance and the conditions that lead to failure.

It has long been recognized that residual stress is an important factor relevant to the weld joint performance. Residual stress and distortion may cause cracking and mismatching. High tensile residual stress reduces fatigue life and cause fractures under certain conditions. Compressive residual stress may reduce the buckling strength 
of structural components [20]. Therefore, the ability to determine the magnitude and distribution of residual stress is essential to evaluate the service performance of welded structures. Causes of residual stress involve thermal expansion, plastic deformation, shrinkage and phase transformation. Both intrinsic and extrinsic factors that contribute to weld-induced residual stress are listed in Figure 1.5.

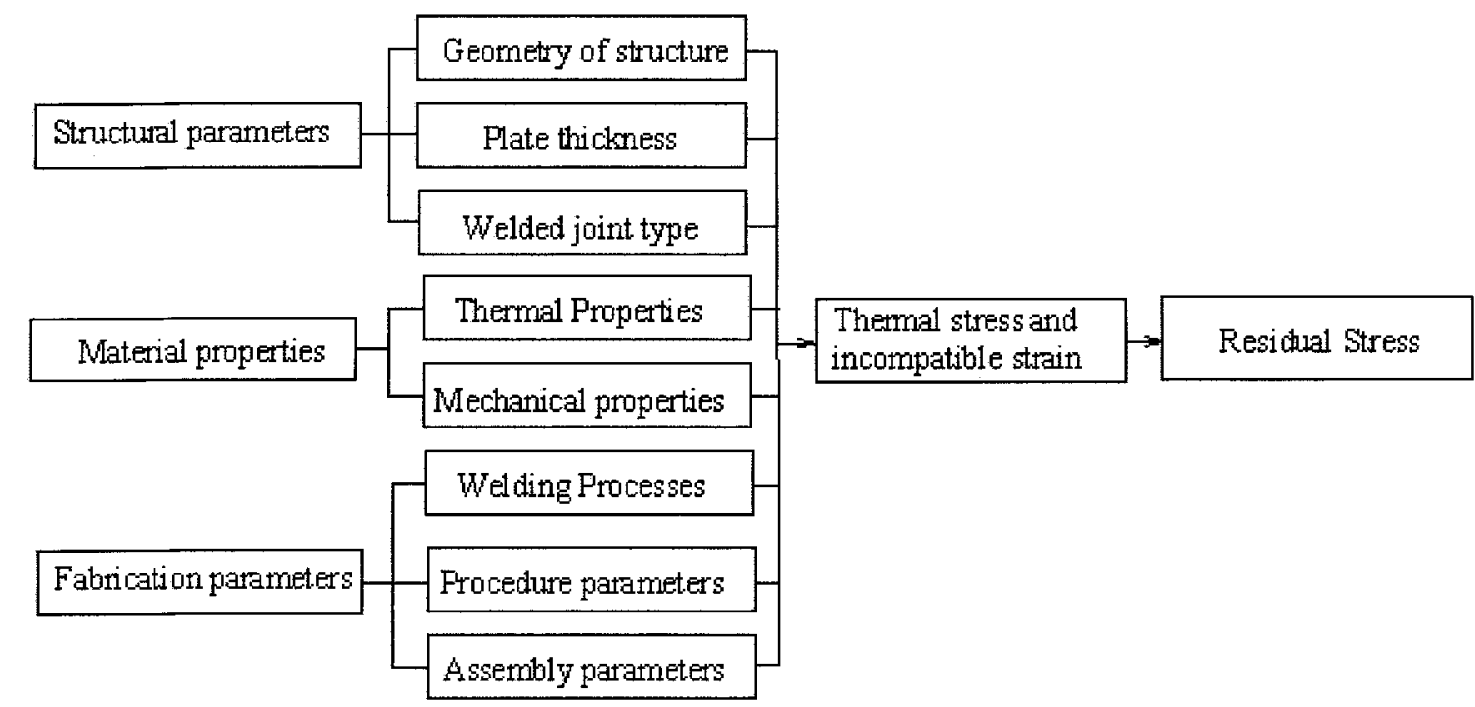

Figure 1.5: Factors that contribute to weld-induced residual stress.

Experimental measurement of residual stress can be divided into two categories: One is invasive (or destructive), e.g., hole drilling and strain gauge techniques; the other is non-invasive (or non-destructive), such as X-ray and neutron diffractions or supersonic waves. However, both categories obtain incomplete stress distributions 
and are time-consuming. Most non-destructive methods are usually restricted to near-surface depths down to about 1 to $2 \mathrm{~mm}$ in steels. Furthermore, fully destructive techniques, such as slotting, block removal, splitting and layering, destroy the specimen completely so no further measurement is possible. Figure 1.6 summarizes the residual stress measurement methods used in steels.

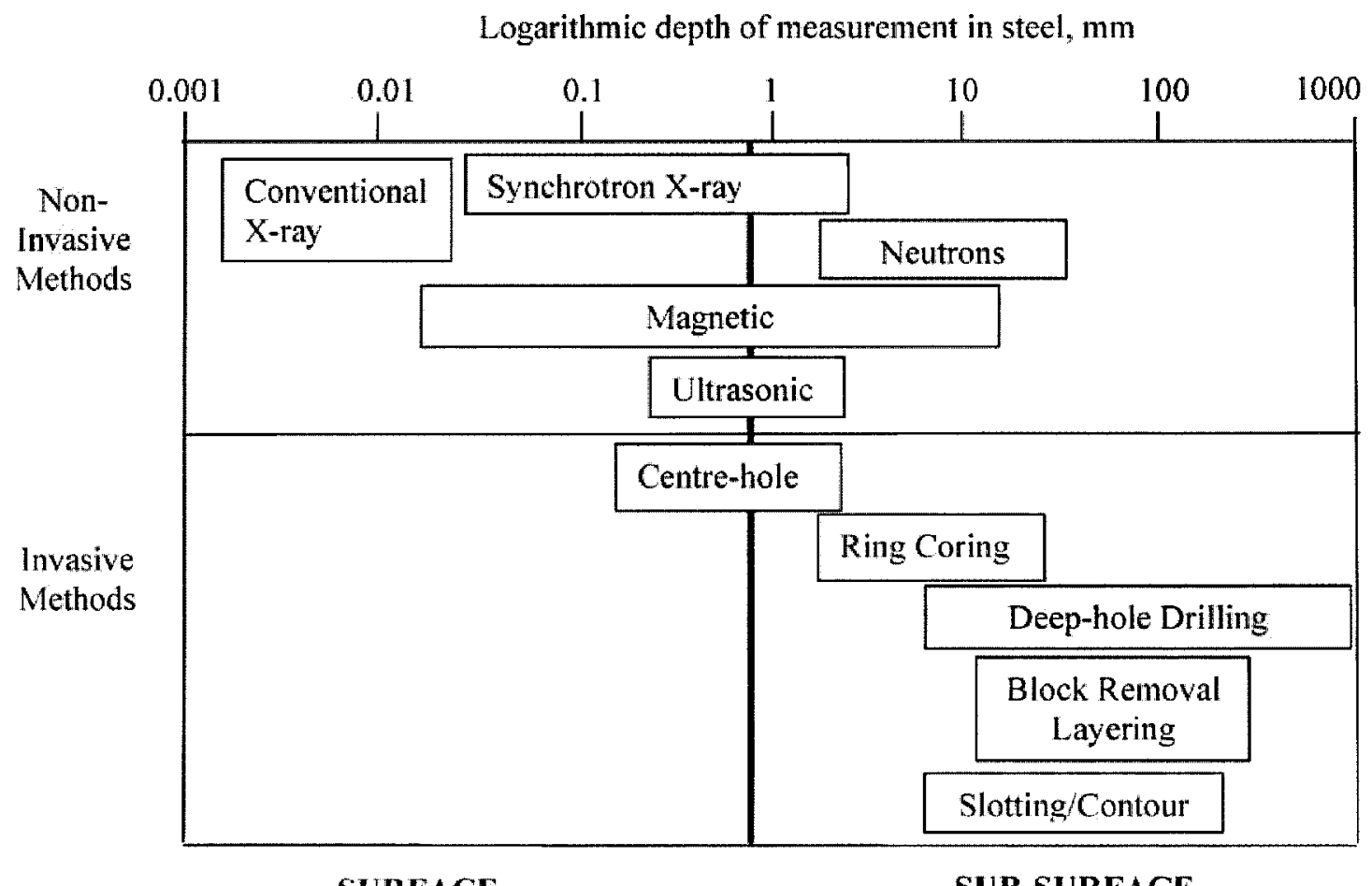

Figure 1.6: Residual stress measurement methods in steel [21]. 


\subsubsection{Modeling of Weld Joint Microstructure and Residual Stress}

Since the performance of a welded structure is largely dependent on weld microstructure and the residual stresses, large amounts of work and considerable progress has been made in the experimental and simulation of these two areas.

Computer-based welding simulation can predict the outcome of welding processes without the need for costly pre-production trials or experimentation, and has increasingly become an essential tool for welding and design engineers. Mathematical modeling of microstructure and stress have been carried out by using a set of differential or algebraic equations, which are derived from fundamental solidification, phase transformation and thermo-mechanical theories. A reliable numerical model provides quantitative relationships within the microstructure, residual stress and the key process parameters, such as welding current, welding speed and welding sequence, thus plays an important role in process development and service life prediction. However, accurate prediction is difficult because an arc welding process involves localized high temperature, temperature dependent material properties and a moving heat source.

Due to the complexity of the microstructural phenomena associated with weld FZ and HAZ, microstructure is usually examined experimentally and theoretical prediction using computer modeling has only received a little attention. However, computer modeling of microstructure in steel welds has been employed to estimate the influ- 
ence of variables such as composition on the deposit and HAZ characteristics since the late 1980s [8]. Currently, several models have been established for the microstructure evolution of welds. For example, Bhadeshia et al $[6,9,22]$ proposed a model for the microstructure evolution in the fusion zone of low alloy steel welds. At the same time, Khoral et al [7,23] employed another model to deal with the microstructure development in the heat affected zone. Both of the above models compute the volume fraction of the austenite products such as ferrite, pearlite, bainite and martensite. By contrast, V. Pavlyk et al [24] set up a model to simulate the solidification microstructure, i.e., the dendritic and cell morphology of columnar grains in the fusion zone.

Interest in developing analytical models of weld-induced stresses dates from the late 1930s [25]. The finite element analysis of residual stresses was first introduced in 1973 by Hibbitt and Marcal [26], followed by Rybicki [27] and Ueda [28] in 1977. The advance in computer technology promotes the implementation of computer simulation of welding process. The first attempt of computer analysis of thermal stresses during welding was conducted in 1961 by Tall [29]. However, due to the expensive computational demand, such as refined mesh for steep temperature gradient, small time step for convergence, and multipass welds, most of the computer modeling on residual stresses was limited to simple geometry and one or two dimensional (1D or 2D) models until the late 1980s. With the rapid development in computer compu- 
tational capacity, a complete three dimensional (3D) stress analysis is now possible. Also, many commercial computer software packages have been available for computing weld-induced residual stresses based on the thermo-elasto-plastic theory and FEM theory, such as ABAQUS [30], ANSYS [31], and ADINA [32].

For both microstructure and residual stress calculation, the thermal history of the weld is a prerequisite, i.e., the peak temperature and heating/cooling rate which control the phase changes and find microstructure. The relationship among temperature, microstructure and stress is shown in Figure 1.7. A reliable thermal model is needed in order to predict phase transformations and final products. Early mathematical representation of weldment heat flow in arc welding can be traced back to the 1940's by Rosenthal [33], and some of his analytical equations [34] are still widely used for welding thermal analysis even today. Finite element analysis of heat transfer in welds began in 1970s [26, 35], numerous up to date thermal analysis models have been built based on the heat conduction as well as convection theories.

In this study, the computational technique was based on the finite element method and it provides a prediction of temperature, microstructure and residual stress in a given weldment. A conduction model with combined convective and radiative boundary conditions was employed to solve the energy equations for the temperature distribution in a butt weld joint. The model was validated and showed to be in good agreement with the experimental data from the literature. Microstructural analysis 


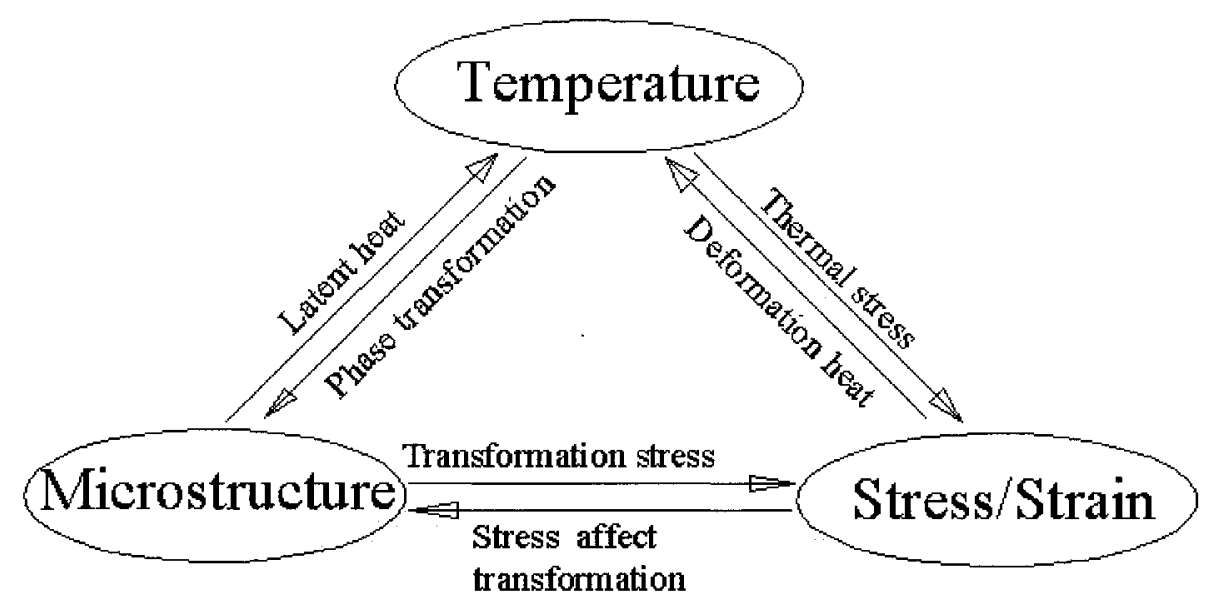

Figure 1.7: Relation of temperature, microstructure and stress.

was carried out with Bhadeshia model, which focuses on the microstructure of the FZ, and Khoral model, which deals with the microstructure of the HAZ. A thermo-elasticplastic model which incorporated phase transformation effect was used in residual stress analysis.

\subsection{Objectives and Organization of the Thesis}

\subsubsection{Objectives of the Thesis}

This study focuses on the mathematical modeling of the thermal history, microstructure evolution and residual stress development in low-alloy steel welded joints. 
Though much work in these areas has been done, metallurgical and mechanical phenomena associated with welding are still not well understood and research in theses areas continues. Further development of these models can help us obtain a clearer picture of the weld joint microstructures and weld-induced residual stress as well as further assist with the prediction of the properties and life of the welded structures.

The objectives of this thesis were to:

1. Set up a 2D transient thermal model to allow prediction of the temperature distribution in a butt weld joint cross section.

2. Construct a 2D microstructure model to predict the microstructure evolution for both weld metal and HAZ in a low alloy steel weld joint.

3. Construct a 3D residual stress model for a butt weld joint and a T-joint, and to solve for the residual stresses, plastic strains and displacement.

\subsubsection{Organization of the Thesis}

This thesis describes the approach used to determine the temperature distribution, predict the microstructure evolution and weld-induced residual stresses in low-alloy steel weld joints, using finite element method (FEM).

Chapter 1 gives a brief introduction on the development history and the advantages of welding process, the weld joint microstructure evolution, weld-induced resid- 
ual stress formation and measurement as well as an outline of the thesis.

Chapter 2 presents a $2 \mathrm{D}$ transient heat transfer model during welding. In this chapter, a double ellipsoid heat source model is presented in terms of prescribedtemperature. A set of conductive heat transfer equations with combined convective and radiative boundary conditions is solved for the temperature distribution, and the result is compared with the experimental data. In order to improve the accuracy, a mesh optimization was also proposed in this chapter.

Chapter 3 describes the theoretical modeling of microstructure evolution in both the weld metal and the HAZ in a butt weld joint cross section. Factors that affect the weld joint microstructure development, i.e., cooling rate, chemical composition and austenite grain size, are discussed.

Chapter 4 discusses the mathematical model for 3D weld-induced residual stresses. The conservation of momentum equation, the constitutive equation relating stress and strain, and the compatibility equation between strain and displacement with certain boundary conditions are solved for the displacement, plastic strain and stress in butt weld and T-joint specimens.

Chapter 5 presents the conclusions and some suggestions for future work. 


\section{Chapter 2}

\section{Thermal Behavior Modeling}

Heat transfer during welding does not only strongly affect the microstructure and the mechanical properties of the weld, but is also responsible for the weld residual stress and distortion. Furthermore, fluid flow in the arc plasma and the weld pool during welding can affect the occurrence of welding defects, such as slag inclusion, porosity, and cracks. Therefore an accurate prediction of the weld joint thermal cycle is a prerequisite for the modeling of microstructure evolution and residual stresses.

\subsection{Heat Transfer Analysis}

During arc welding, the heat generated by the electric power of a moving welding arc is transferred to the workpiece by thermal conduction, convection and radiation. At the same time, heat is absorbed by a temperature increase, viscous dissipation 
of the weld and loss to the surrounding environment, or it is transferred to the weld fixture or other attached components. To avoid the complexity of the arc physics and fluid mechanics of the weld pool, a double ellipsoid heat source model was employed in this analysis. In addition, because the finite element method (FEM) has the best capability for nonlinear analysis and electro-thermo-elasto-plastic analysis, and is the most compatible with CAD/CAM software packages, FEM code SimManTech developed by Goldak Technology Inc. was used for all simulations described in the following sections.

\subsubsection{Heat Source Model}

Since the pioneering work of Rosenthal [33], the welding heat source has often been modeled as a point, a line, a 2D circular surface, a 3D spherical or ellipsoidal volume. Experimental evidence indicates that the heat source from the welding arc is best represented by a 3D distribution, and the temperature gradient in front of the heat source is steeper than that at the trailing edge of the molten pool. To effectively model this heat flow pattern, an double ellipsoidal exponential power density distribution heat source was first proposed by Goldak et al [36] in 1984. The power density of a double ellipsoid is given by the following:

for the front quadrant:

$$
q_{f}(\xi, y, z, t)=\frac{6 \sqrt{3} f_{f} Q}{a_{1} b c \sqrt{\pi}} e^{-3[\xi+v(\tau-t)]^{2} / a_{1}^{2}} e^{-3 y^{2} / b^{2}} e^{-3 z^{2} / c^{2}}
$$


and for the rear quadrant:

$$
q_{r}(\xi, y, z, t)=\frac{6 \sqrt{3} f_{r} Q}{a_{2} b c \sqrt{\pi}} e^{-3\left[\xi+v_{1}(\tau-t)\right]^{2} / a_{2}^{2}} e^{-3 y^{2} / b^{2}} e^{-3 z^{2} / c^{2}}
$$

where,

$f_{f}$ and $f_{r}$ are the fractions of heat deposited in the front and rear quadrant respectively and have the relationship:

$$
f_{f}+f_{r}=2
$$

$\mathrm{Q}$ is the energy input rate (W), which is given by:

$$
Q=\eta V I
$$

where,

$\eta$ is the heat source efficiency,

$V$ is the welding voltage $(V)$,

$I$ is the welding current $(A)$,

$\tau$ is the welding time $(s)$,

$a_{1}, a_{2}, b$, and $c$ are heat source distribution parameters parallel to coordinate axes $\xi$, $y, z$, as shown in Figure 2.1, where $q$ denotes $q_{f}$ and $q_{r}$ depending on context, $t$ is a lag factor, $v_{1}$ is the welding speed $\left(m s^{-1}\right)$. 


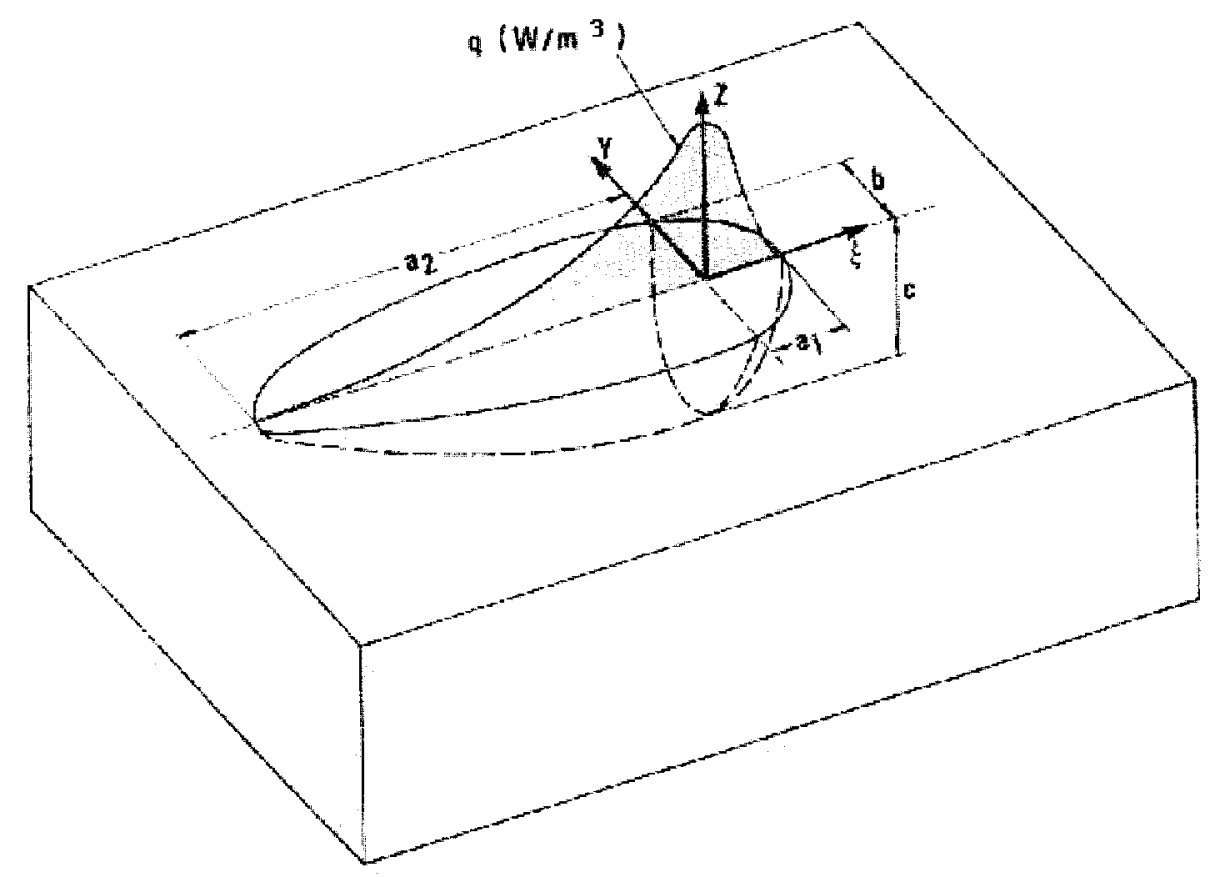

Figure 2.1: Double ellipsoid configuration [37].

From the above equations, one can see that four main variables govern the heat input to the workpiece:

- The magnitude of the rate of input energy;

- The arc efficiency;

- The distribution of heat input;

- The weld travel speed.

All of these variables depend on the welding process. For instance, Table (2.1) illustrates the arc efficiency for several conventional welding processes. 


\begin{tabular}{|c|c|}
\hline Welding Process & Arc Efficiency \\
\hline SMAW & $0.7-0.8$ \\
\hline GTAW & $0.22-0.48$ \\
\hline GMAW & $0.66-0.75$ \\
\hline SAW & $0.90-0.99$ \\
\hline
\end{tabular}

Table 2.1: Arc efficiency of various welding processes [11].

Currently, an accurate estimate of temperature in the weld pool is available. The maximum surface temperature of a steel weld pool is approximately $500 \mathrm{~K}$ below the boiling temperature [38]. Since the boiling point of iron is $3135 \mathrm{~K}$, the peak temperature of a steel weld can be assumed to be around $2200-2600 \mathrm{~K}$. As a result, it is more convenient and direct to model the heat source by prescribing the temperature to a double ellipsoid whose size and shape are equal to those of the weld pool [39].

To define a double ellipsoid in terms of prescribed-temperature, one first needs to define the center of the heat source $\left(x_{0}, y_{0}, z_{0}\right)$ and calculate the distance from the center. The distances in the front $\left(D_{f}\right)$ and rear portions $\left(D_{r}\right)$ are expressed as follows:

Distance in the front part:

$$
D_{f}=-1.0+\sqrt{\frac{\left(\xi-x_{0}\right)^{2}}{a_{1}^{2}}+\frac{\left(y-y_{0}\right)^{2}}{b^{2}}+\frac{\left(z-z_{0}\right)^{2}}{c^{2}}}
$$


Distance in the rear part:

$$
D_{r}=-1.0+\sqrt{\frac{\left(\xi-x_{0}\right)^{2}}{a_{2}^{2}}+\frac{\left(y-y_{0}\right)^{2}}{b^{2}}+\frac{\left(z-z_{0}\right)^{2}}{c^{2}}}
$$

For a specific node, if $D_{f}$ or $D_{r}$ is smaller than zero, the temperature at this node will be prescribed and the value is given by:

$$
T(\xi, y, z)=D^{2} \times\left(T_{\max }-T_{m e l t}\right)+T_{m e l t}
$$

where,

$D$ is either $D_{f}$ or $D_{r}$,

$T_{\max }$ is the peak temperature in the weld pool, the range of $T_{\max }$ is $2200-2600 \mathrm{~K}$ depending on the welding heat input,

$T_{\text {melt }}$ is the melting point of the steel.

Thus, when the size and shape of the weld pool, the maximum temperature and melting temperature are known, one can easily model the heat source using the prescribed-temperature double ellipsoid. During welding, the double ellipsoid moves along the welding direction and deposits heat as it passes along the joint. The heat then diffuses outward until the weld cools.

\subsubsection{Heat Transfer Governing Equations}

The heat transfer in the weldment is governed primarily by the conduction of heat, so a set of fundamental equations of heat conduction in a solid are employed in 
the following terms:

$$
\rho C \frac{\partial T(x, y, z, t)}{\partial t}=-\left(\frac{\partial R_{x}}{\partial x}+\frac{\partial R_{y}}{\partial y}+\frac{\partial R_{z}}{\partial z}\right)+Q(x, y, z, t)
$$

where,

$R_{x}, R_{y}, R_{z}$ are the heat fluxes $\left(W m^{-2}\right)$,

$T(x, y, z, t)$ is the transient temperature $(K)$,

$Q(x, y, z, t)$ is the rate of internal heat generation $\left(W m^{-3}\right)$,

$\rho$ is the density of the steel $\left(\mathrm{kgm}^{-3}\right)$,

$C$ is the specific heat of the steel $\left(J k^{-1} K^{-1}\right)$,

$t$ is the time $(s)$.

This model is completed by introducing the Fourier heat flow as:

$$
\begin{aligned}
& R_{x}=-k_{x} \frac{\partial T}{\partial x} \\
& R_{y}=-k_{y} \frac{\partial T}{\partial y} \\
& R_{z}=-k_{z} \frac{\partial T}{\partial z}
\end{aligned}
$$

where,

$k_{x}, k_{y}, k_{z}$ are the thermal conductivities in the $x, y$ and $z$ directions respectively.

\subsubsection{Boundary and Initial Conditions}

Boundary conditions are employed to account for surface heat losses and the heat flow in a weldment is essentially the solution of Eqn. (2.8) for given initial and 
boundary conditions.

The initial condition is expressed as:

$$
T(x, y, z, 0)=T_{0}(x, y, z)
$$

where,

$T(x, y, z, 0)$ is the temperature at time $\mathrm{t}=0$,

$T_{0}(x, y, z)$ is the given value.

In the thermal analysis of the welding process, there are four types of boundary conditions $(\mathrm{BC})$ commonly used:

- Prescribed surface temperature. This is a kind of Dirichlet BC (or essential $\mathrm{BC})$. For instance, melting temperature is prescribed at the boundary of a double ellipsoid.

- Prescribed heat flux. This is a kind of natural BC (or Neumann BC). Heat flux can be specified at the surface of a welding arc connected to the electrode or at the surface of workpiece underneath the welding arc. The heat flux is given by:

$$
q(x, y, z, t)=-\left.k \nabla T\right|_{\left(x_{1}, y_{1}, z_{1}\right)}
$$

where,

$\nabla$ is the gradient operator and is defined as follows:

$$
\nabla=i \frac{\partial}{\partial x}+j \frac{\partial}{\partial y}+k \frac{\partial}{\partial z}
$$


$\left(x_{1}, y_{1}, z_{1}\right)$ are the coordinates where the heat flux is prescribed.

- Convective BC. The convective boundary condition is given by:

$$
-(\nabla k T)=h\left(T-T_{\infty}\right)
$$

- Radiation BC. The radiation boundary condition is expressed as:

$$
-(\nabla k T)=k_{r}\left(T^{4}-T_{\infty}^{4}\right)
$$

where,

$T_{\infty}$ is the ambient temperature $(K)$,

$k$ is the thermal conductivity of the steel $\left(W m^{-1} K^{-1}\right)$,

$h$ is the convective coefficient,

$k_{r}$ is the radiative coefficient.

In this study, a combined convective and radiative heat transfer coefficient was adopted, as given by [40]:

$$
H=2.41 \times 10^{-3} \epsilon_{1} \sigma_{1}(T+273)^{1.61}
$$

where,

$\epsilon_{1}$ is the degree of blackness, $\epsilon_{1}<1.0$

$\sigma_{1}$ is the Stefan-Boltzmann's constant,

$T$ is the transient temperature of the previous time step $(K)$. 


\subsection{Finite Element Method (FEM) Procedure}

The FEM employs five steps to solve a specific problem [41]:

1. Discretize the domain, i.e., define elements.

2. Set up element equations. This requires the identification of: the force (or temperature), the relationship between the force (or temperature) and displacement (or heat flux), assumed trial functions for typical elements. Then an element stiffness matrix $\left[K^{e}\right]$ and an element force vectors $\left\{\mathbf{f}^{\mathrm{e}}\right\}$ are formed.

3. Assemble element stiffness matrices and derive the overall structure stiffness equations:

$$
[K]\{\mathbf{f}\}=\left\{\mathbf{R}_{\mathbf{f}}\right\}
$$

where

$[K]$ is the system stiffness matrix,

$\{\mathbf{f}\}$ is the vector of primary variables,

$\left\{\mathbf{R}_{\mathbf{f}}\right\}$ is the resultant vector of nodal thermal loads.

4. Solve set of equations (2.18) for primary and secondary variables by imposing the boundary conditions and initial condition. In thermal analysis, the set of algebraic equations are solved for the nodal temperatures and usually some form 
of Newton-Raphson iteration method together with a Gaussian elimination and back substitution would be involved in the process.

$$
\{\mathbf{f}\}=[\mathbf{K}]^{-\mathbf{1}}\left\{\mathbf{R}_{\mathbf{f}}\right\}
$$

5. Post processing to plot and evaluate the results.

During thermal analysis, the FEM imposes a piece-wise polynomial approximation of the temperature field within each reference element at each time step using the following equation [42]:

$$
T(x, y, z, t)=\sum_{i=1}^{\text {nodes }} N_{i}(x, y, z) T_{i}(t)
$$

where $N_{i}$ is the basis (or trial) function for node $i$. It depends only on the type of element and its size and shape. $T_{i}(t)$ are the nodal values of the temperature at time $t$. If the basis function are orthogonalized, $T_{i}(t)$ are generalized Fourier coefficients. The analyst specifies the basis functions $N_{i}$ by creating a mesh, which in turn determines the type and position of each element.

The temperature gradient at any point $(\mathrm{x}, \mathrm{y}, \mathrm{z}, \mathrm{t})$ can be obtained directly from Eqn. (2.20), such that:

$$
\left[\frac{\partial T}{\partial x}, \frac{\partial T}{\partial y}, \frac{\partial T}{\partial z}\right]=\left[\frac{\partial N_{i}}{\partial x} T_{i}, \frac{\partial N_{i}}{\partial y} T_{i}, \frac{\partial N_{i}}{\partial z} T_{i}\right]
$$

$N_{i}$ and $T_{i}$ are the abbreviations of $\sum N_{i}(x, y, z)$ and $T_{i}(t)$. 
In this study, Galerkin's FEM is employed in the energy solver to solve $T_{i}$. When Eqn. (2.20) is substituted into Eqn. (2.8), a residual must be introduced, and when Eqn. (2.20) is the exact solution, the residual is zero.

To determine the transient temperature field, an extrapolation method with a two-time interval was used as shown in the following equation:

$$
T(\tau)=T(t-\Delta t)+\frac{\tau}{\Delta t}[T(t-\Delta t)-T(t-2 \Delta t)]
$$

\subsection{Model Description}

\subsubsection{Model Consideration}

When a component is being welded, heat transfer is three dimensional and temperature gradients exist in $\mathrm{x}, \mathrm{y}$ and $\mathrm{z}$ directions, and the temperature varies with time. However, if the mesh of the problem is fixed in space (i.e., an Eulerian formulation), and the space has such a great extent in the $\mathrm{z}$ direction of the welding that no end effects exist, then the 3D transient problem becomes a 3D steady state problem, if the following assumptions are also accepted:

- The rate of heat input is constant.

- The welding speed is constant and straight forward along the workpiece.

- The cross section of the weld joint is also constant. 
- The material properties are isotropic or orthotropic.

When the above conditions are satisfied, the temperature distribution at any cross section is the same except for the response time lag, so this $3 \mathrm{D}$ problem can be simplified by using a $2 \mathrm{D}$ representation.

\subsubsection{Geometry of the Model}

The dimensions and mesh of the cross section involved in this model are shown in Figures 2.2 and 2.3. The width of the cross section is $282.5 \mathrm{~mm}$, out of which $2.5 \mathrm{~mm}$ is the gap between the two plates to be welded. The height, which is the thickness of the specimen, is $8 \mathrm{~mm}$. The weld is a single V-groove butt joint welded by three passes. The values of the double ellipsoid parameters, as shown in Table 2.2, have been specified based on the geometry of the weld joint. The distance in front of the heat source $\left(a_{1}\right)$ was taken to be roughly one-half the weld width and the distance behind the heat source $\left(a_{2}\right)$ was around twice the width. The $b$ value was set equal to the weld width and the $c$ value was set to slightly greater than the weld pass penetration. The welding speed for the root, fill and cap pass were $1.68,2.88$ and $2.08 \mathrm{~mm} / \mathrm{s}$, respectively. 


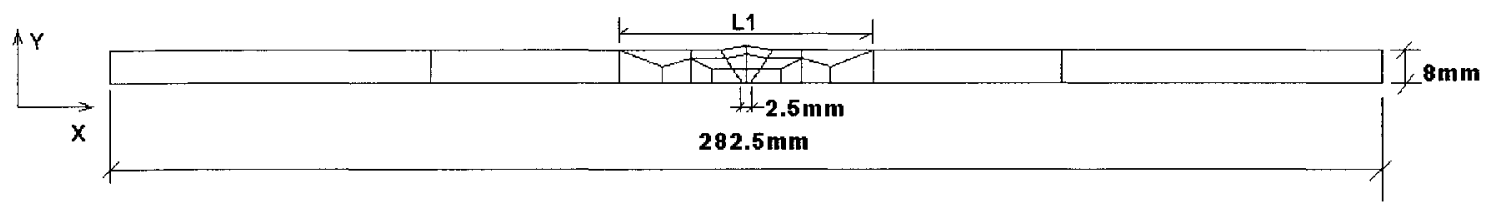

Figure 2.2: Geometry of the cross section.

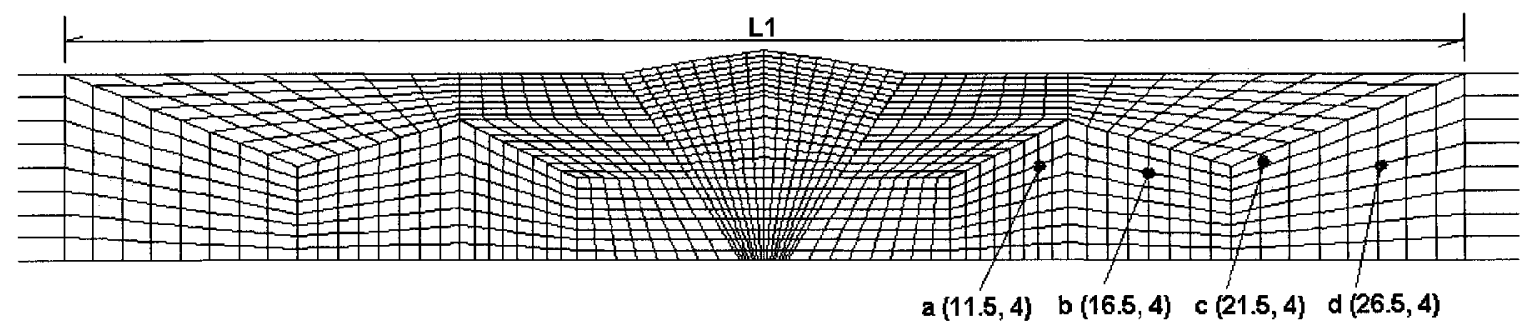

Figure 2.3: Mesh used in the calculation.

\subsubsection{Material Thermal Properties}

The material used in the analysis is a low carbon steel. The chemical composition is $0.17 \% \mathrm{C}, 1.46 \% \mathrm{Mn}$ and $0.34 \% \mathrm{Si}$ (wt\%). In solving the heat transfer equation, temperature dependent thermal conductivity, specific heat, enthalpy and density are employed. The thermal effects of the latent heat of phase transformation is modeled by the difference in enthalpy of various phases. The thermophysical properties used in the computation are plotted in Figures 2.4 to 2.6 , which are taken from reference $[43]$ and $[44]$. 


\begin{tabular}{|c|c|c|c|}
\hline Parameters & Root Pass & Fill Pass & Cap Pass \\
\hline$a_{1}(\mathrm{~mm})$ & 2.5 & 4 & 3.5 \\
\hline$a_{2}(\mathrm{~mm})$ & 8.5 & 19.5 & 20 \\
\hline $\mathrm{b}(\mathrm{mm})$ & 4 & 5.5 & 5.5 \\
\hline $\mathrm{c}(\mathrm{mm})$ & 4 & 6 & 6.5 \\
\hline$T_{\max }(\mathrm{K})$ & 2500 & 2500 & 2500 \\
\hline$T_{\operatorname{melt}}(\mathrm{K})$ & 1750 & 1750 & 1750 \\
\hline
\end{tabular}

Table 2.2: Double ellipsoid parameters

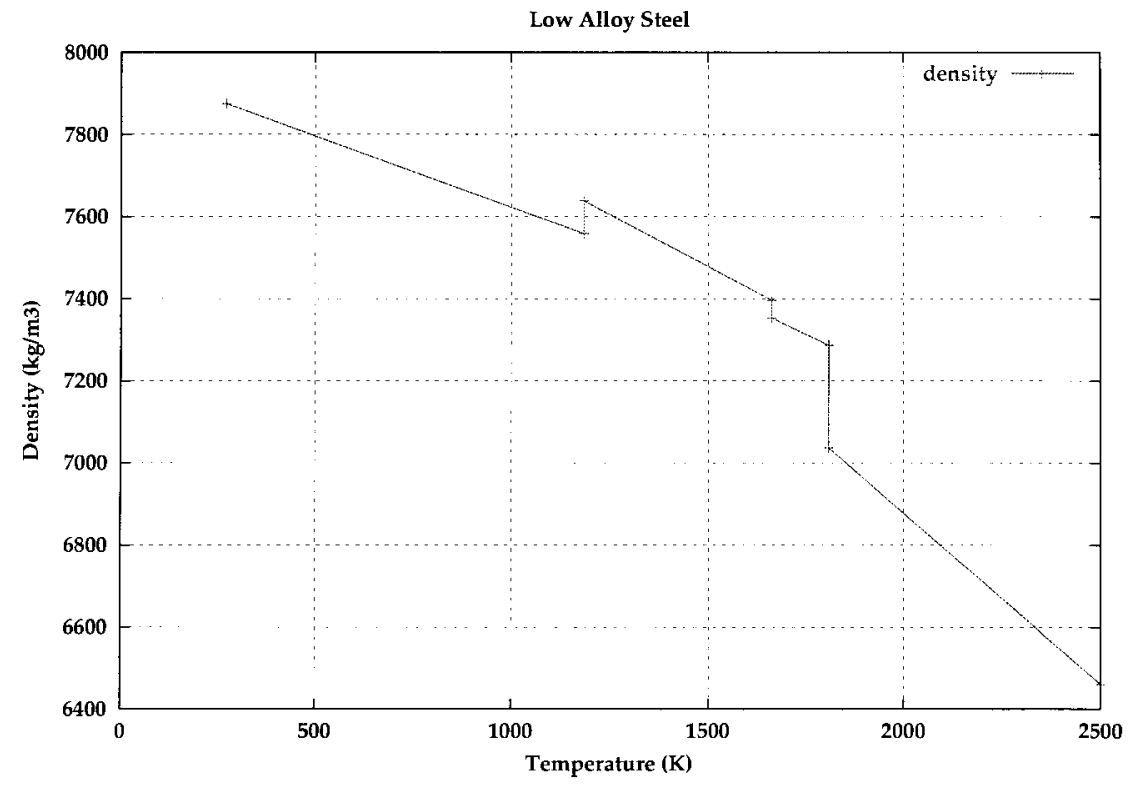

Figure 2.4: Temperature-dependent density [43]. 


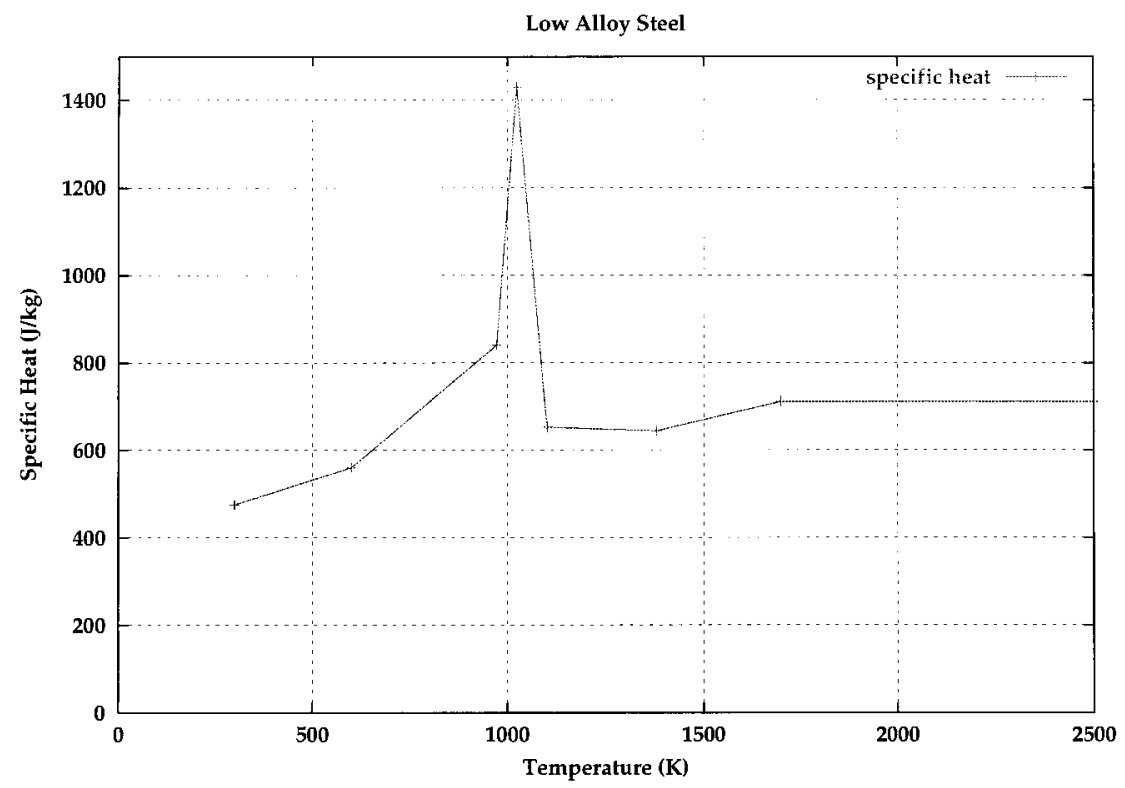

Figure 2.5: Temperature-dependent specific heat [44].

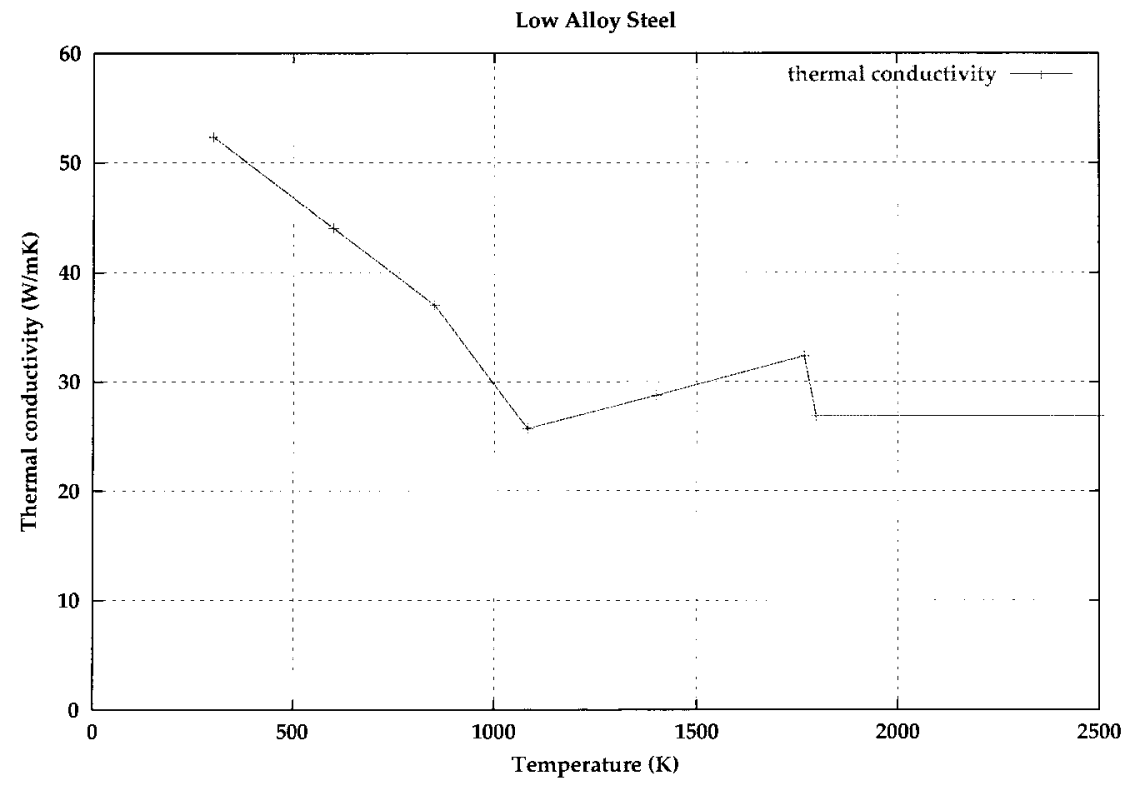

Figure 2.6: Temperature-dependent thermal conductivity [44]. 


\subsection{Testing Results and Validation}

\subsubsection{Mesh Optimization}

During the analysis, the meshing is optimized by refining the 4 node quad elements. The numbers of elements for mesh1, mesh2, mesh3 and mesh4 are 24, 384, 1536 and 6144 . The temperature variation with time of the four meshes at a node (8 $\mathrm{mm}$ away from the weld centerline and $3.5 \mathrm{~mm}$ of the thickness) is plotted in Figure 2.7. From Figure 2.7, one can see that the temperature difference is very minor for the last three meshes. The temperature results of mesh3 is therefore used to compare with the experimental values.

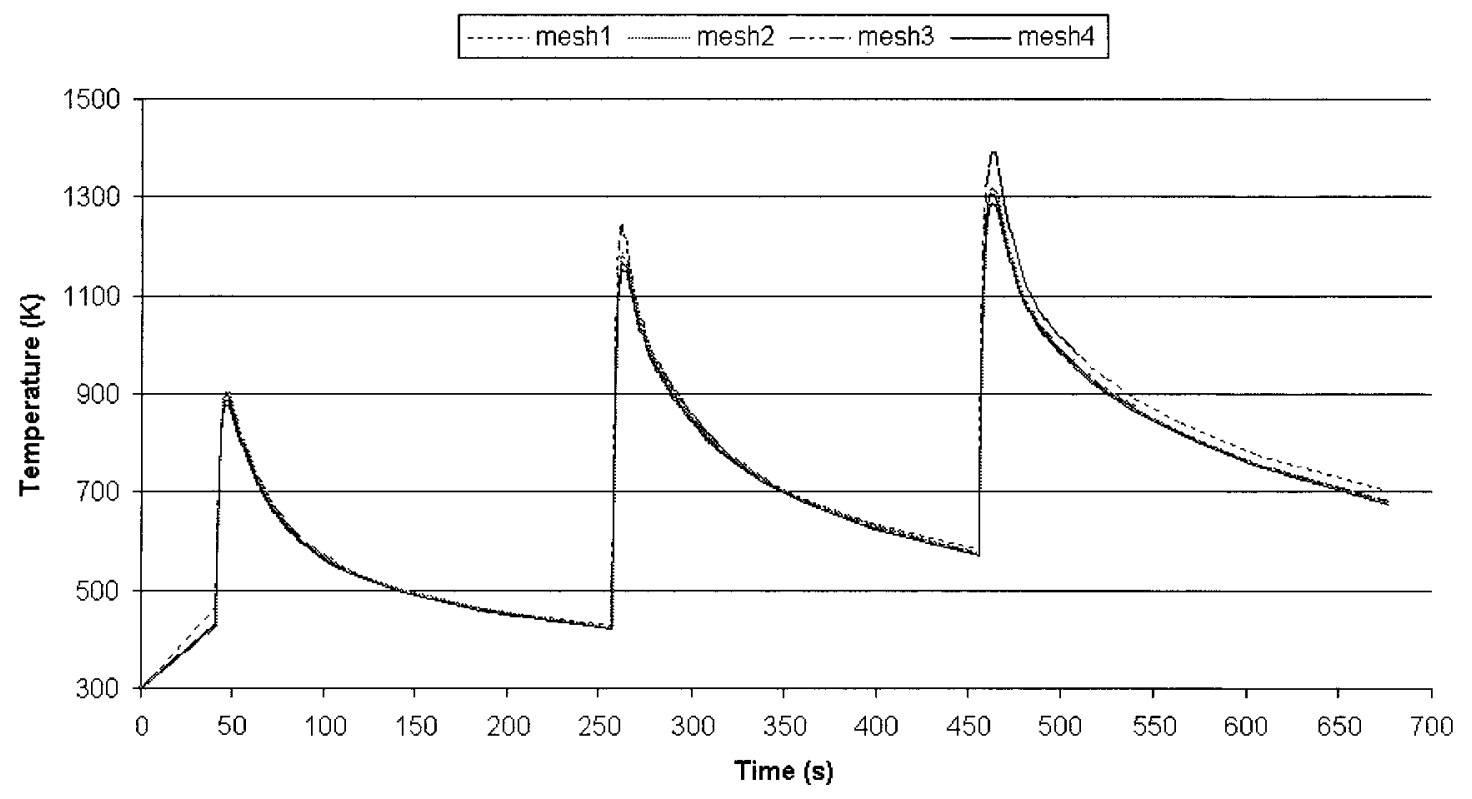

Figure 2.7: Temperature distribution in different meshes. 


\subsubsection{Model Validation}

The transient temperature was calculated for the domain and the resultant temperature distribution at time 465.4s (222th step) and is depicted in Figure 2.8 after all three weld passes were made. In addition, the temperature variation with time for four different points $\mathrm{a}, \mathrm{b}, \mathrm{c}$ and $\mathrm{d}$ at mid thickness of the plate, as shown in Figure 2.3 is illustrated in Figure 2.9. These temperature curves reveal that the temperature increases rapidly as heat is transfered from the heat source. The heating rate decreases as the distance from the weld centerline increases. After the temperature reaches a peak value, cooling begins and the cooling rate also varies with the distance from the centerline. Furthermore, the cooling rate decreases with time. It is evident that the thermal cycles vary from location to location in the weldment.

The calculated temperature field can be compared with the experimental data obtained by Murugan [46]. The welding parameters used in his experiment are listed in Table 2.3 and they are the same as those used in the present simulation. Figure 2.10 shows the comparison at point a (11.5 $\mathrm{mm}$ away from the weld centerline) and Figure 2.11 is the comparison at point $\mathrm{b}$ ( $16.5 \mathrm{~mm}$ away from the weld centerline). In both figures, the calculated temperatures show good agreement with the experimental values. 


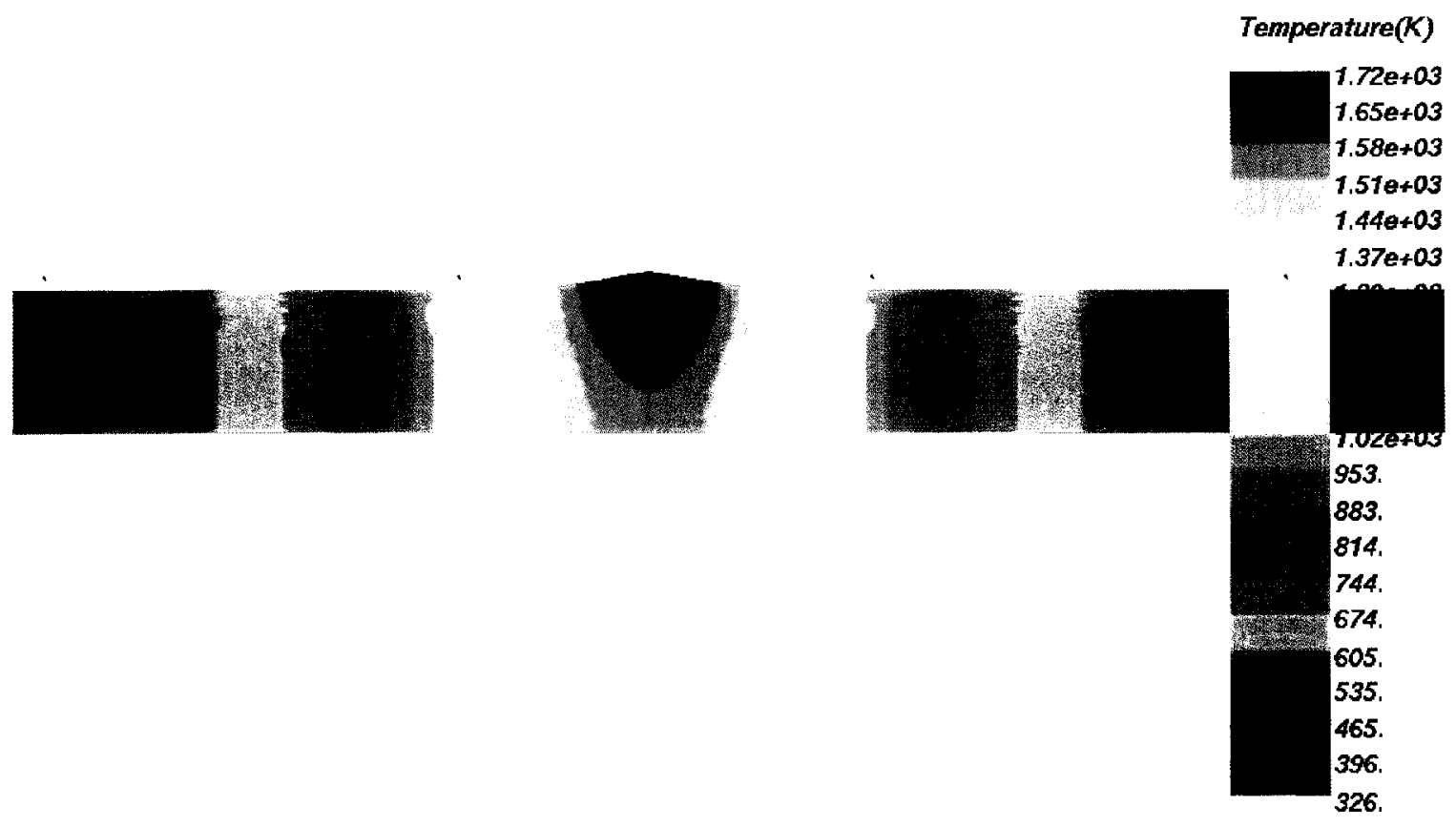

Figure 2.8: Temperature distribution at 222th step.

\begin{tabular}{|c|c|c|c|}
\hline Pass number & 1 & 2 & 3 \\
\hline Electrode diameter $(\mathrm{mm})$ & 2.5 & 4 & 4 \\
\hline Weld voltage $(\mathrm{V})$ & 21 & 24 & 22 \\
\hline Weld current $(\mathrm{A})$ & $65-75$ & $170-180$ & $175-185$ \\
\hline Weld speed $\left(\mathrm{mms}^{-1}\right)$ & 1.68 & 2.88 & 2.08 \\
\hline Heat input $\left(\mathrm{kJmm}^{-1}\right)$ & 0.656 & 1.094 & 1.427 \\
\hline
\end{tabular}

Table 2.3: Welding parameters for welding of $8 \mathrm{~mm}$ low carbon steel plates [46]. 


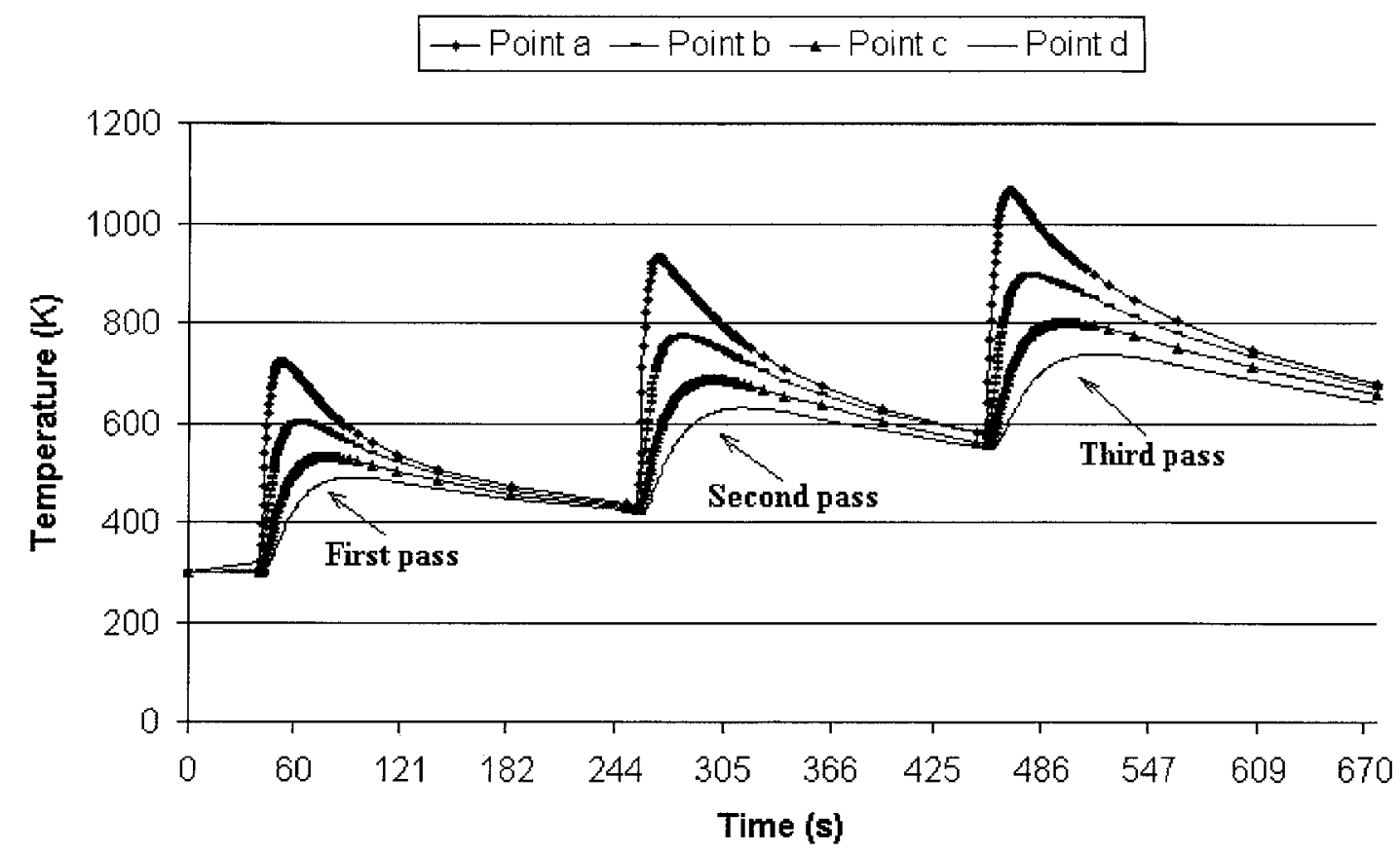

Figure 2.9: Transient temperature distribution.

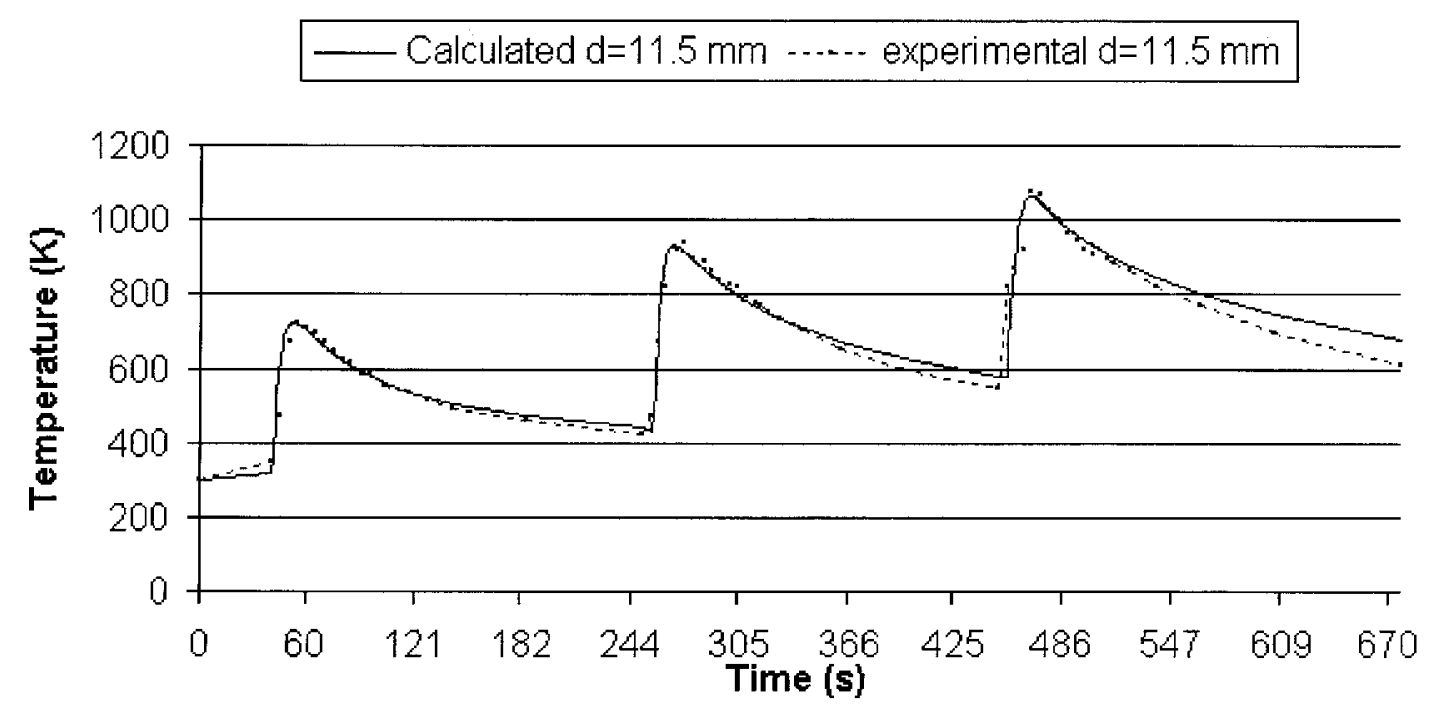

Figure 2.10: Comparison of temperature at point a. 


\section{Calculated $d=16.5 \mathrm{~mm} \cdots \cdots$ experimental $d=16.5 \mathrm{~mm}$}

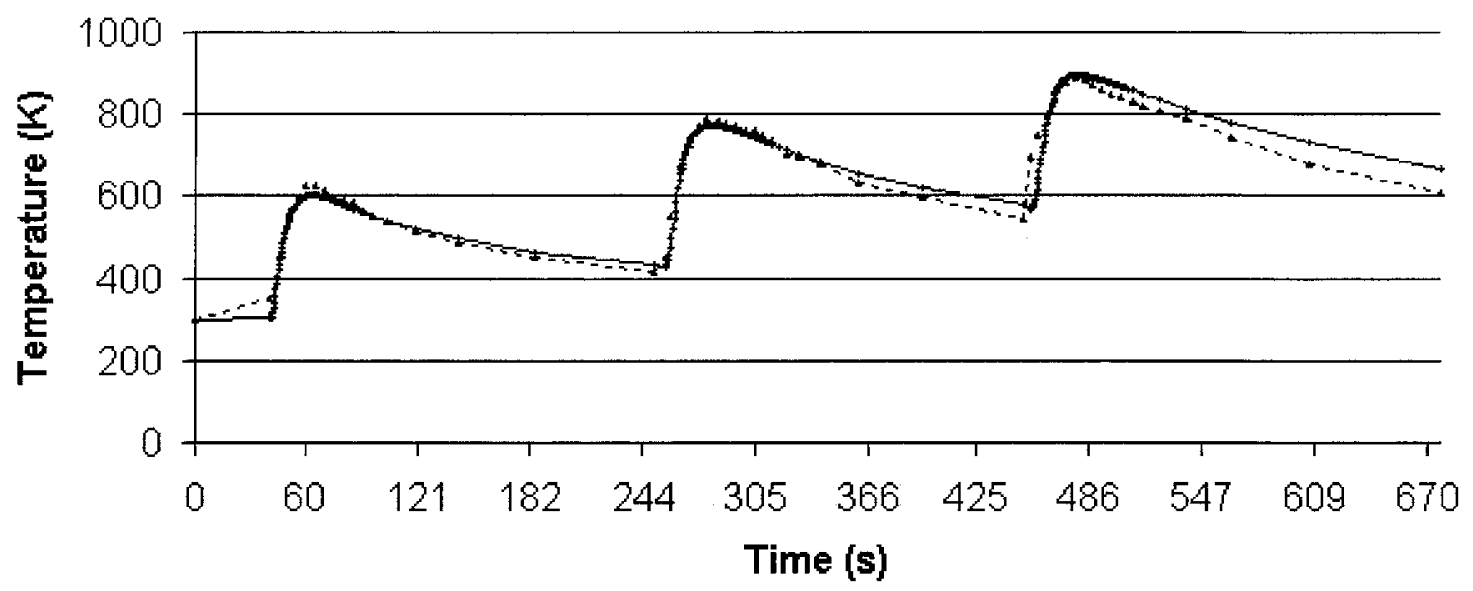

Figure 2.11: Comparison of temperature at point $b$.

\subsection{Sensitivity Study}

The solution obtained from the model is sensitive to the material thermophysical properties, especially the thermal conductivity. Since the thermal conductivities vary from about $15 \mathrm{Wm}^{-1} \mathrm{~K}^{-1}$ [47] for alloy steels to about $80 \mathrm{Wm}^{-1} \mathrm{~K}^{-1}$ [48] for low carbon steels, a set of four values of thermal conductivity $\left(16,25,40\right.$ and $\left.60 \mathrm{Wm}^{-1} \mathrm{~K}^{-1}\right)$ were used in the sensitivity study. Using different constant values, i.e., 16, 25, 40 and 60 respectively, for the thermal conductivities and keeping all the other material properties and welding parameters the same, the calculated temperature distribution at the top line of the domain at time step 222 is illustrated in Figure 2.12. 


$$
16 \mathrm{~W} /(\mathrm{mK}) \rightarrow-25 \mathrm{~W}(\mathrm{mK}) \rightarrow 40 \mathrm{~W} /(\mathrm{mK}) \rightarrow 60(\mathrm{~W} / \mathrm{mK})
$$

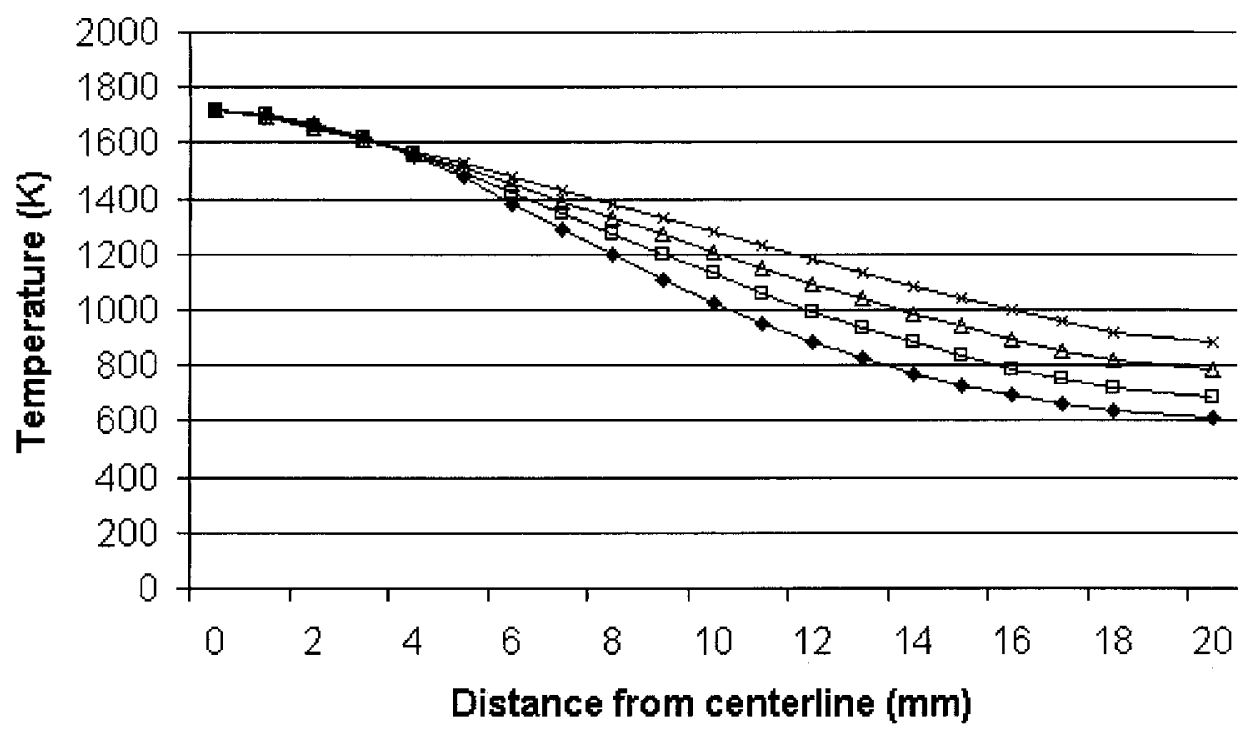

Figure 2.12: Effect of thermal conductivity on temperature field.

Although the temperature at the interface of the weld pool is set to the melting temperature, the HAZ temperature at a given time varies due to the thermal conductivity variation. The resultant temperature increases with the increase of thermal conductivity. 


\section{Chapter 3}

\section{Microstructure Evolution}

The mechanism of microstructure evolution in a weld joint is complicated by the various thermal processes involved before, during and after welding. The solid state phase transformation model described here was based on Khoral's model [7] for the HAZ and Bhadeshia's model [8] for the weld metal (WM). The HAZ may contain a mixture of ferrite, pearlite, bainite, martensite and/or retained austenite. Microstructural constituents of low alloy steel in the WM consist of ferrites, including allotriomorphic ferrite $\alpha$, Widmanstatten ferrite $\alpha_{w}$, and acicular ferrite $\alpha_{a}$, and microphase including small amounts of bainite, martensite, retained austenite or degenerate pearlite.

The interacting factors that influence the volume fraction of various austenite transformation products include: 
- Welding process parameters, such as welding current and welding voltage that determine the shape and size of the weld pool.

- The transformation kinetics of austenite to its ferritic products, which is controlled by the composition of the weld joint.

- Solidification features such as the solidification microstructure and the austenite grain size.

- Cooling rate in the temperature range of $1023-773 \mathrm{~K}\left(800-500^{\circ} \mathrm{C}\right)$.

- Non-metallic inclusion characteristics in the weld pool, such as concentration, composition, size and distribution.

\subsection{Literature Review}

\subsubsection{Characteristic Transformation Temperatures and Car- bon Content}

A pseudo-iron-carbon phase diagram was used to characterize the phase transform for low alloy steels, as shown in Figure 1.2. The phase diagram was determined by a set of algebraic equations in this study.

The liquidus and solidus temperatures were calculated as a formulation of carbon 
content, which were given by the following equations [7]:

$$
\begin{gathered}
T_{L}=1803.0-80.581 C \\
T_{S}=1800.0-181.356 C
\end{gathered}
$$

where,

$T_{L}$ and $T_{S}$ are liquidus and solidus temperatures, respectively $(K)$

$C$ is carbon content in weight percentage.

The upper and lower critical temperatures were expressed by $[48,49]$ :

$$
\begin{aligned}
A_{e 3}= & 1185-200 \sqrt{C}-15.2 N i+44.7 S i+104 \mathrm{~V}+315 \mathrm{Mo}+13.1 \mathrm{~W} \\
& -(30 \mathrm{Mn}+11 \mathrm{Cr}+20 \mathrm{Cu}-700 \mathrm{P}-400 \mathrm{Al}-120 \mathrm{As}-400 \mathrm{Ti}) \\
A_{e 1}= & 996-10.7 \mathrm{Mn}-16.9 \mathrm{Ni}+29 \mathrm{Si}+16.9 \mathrm{Cr}+290 \mathrm{As}+6.4 \mathrm{~W}
\end{aligned}
$$

where,

$A_{e 3}$ is the upper critical temperature $(K)$,

$A_{e 1}$ is the lower critical temperature $(K)$.

Concentrations of alloy elements are in weight percentage.

Other characteristic temperatures, which are not in the carbon-iron phase diagram, such as the precipitate dissolution temperature $(T S)$, the bainite start temperature $\left(B_{s}\right)$, and the martensite start temperature $\left(M_{s}\right)$, were given by the following formulations: 
The precipitate dissolution temperature, which determines the grain growth of austenite was given by [51]:

$$
T S=273+\frac{B^{*}}{A^{*}-\log \left[C_{m}^{a^{*}} C_{c}^{b^{*}}\right]}
$$

where,

$T S$ is the precipitate dissolution temperature $(K)$,

$A^{*}$ and $B^{*}$ are constants depending on the precipitate species,

$C_{m}$ and $C_{c}$ are concentrations of metal and non-metal in precipitate,

$a^{*}$ and $b^{*}$ are stoichiometry constants.

Some carbide and nitride precipitates used in steels and their constant values are listed in Table 3.1.

The bainite start temperature $B_{s}$ was calculated by [52]:

$$
B_{s}(K)=929-58 C-35 M n-75 S i-15 N i-34 C r-41 M o
$$

Similarly, the martensite start temperature $M_{s}$ was given by [50]:

$$
M_{s}(K)=834-474 C-35 M n-17 N i-17 C r-21 M o
$$

The carbon content of eutectoid alloys was calculated as following [49]:

$$
C_{e u t}=\frac{\left[\phi_{1}-\phi_{2}-A_{1}\right]^{2}}{203^{2}}
$$

where,

$$
\phi_{1}=910-15.2 N i+44.7 S i+104 V+315 M o+13.1 W
$$




\begin{tabular}{|c|c|c|c|c|}
\hline Compound & Metal & Non-metal & $A^{*}$ & $B^{*}$ \\
\hline $\mathrm{Cr}_{23} C_{6}$ & $\mathrm{Cr}$ & $\mathrm{C}$ & 5.90 & 7375 \\
\hline$V_{4} C_{3}$ & $\mathrm{~V}$ & $C_{0.75}$ & 5.36 & 8000 \\
\hline $\mathrm{TiC}$ & $\mathrm{Ti}$ & $\mathrm{C}$ & 2.75 & 7000 \\
\hline $\mathrm{NbC}$ & $\mathrm{Nb}$ & $C_{0.7}$ & 3.11 & 7520 \\
\hline $\mathrm{Nb}(\mathrm{C}, \mathrm{N})$ & $\mathrm{Nb}$ & $(\mathrm{CN})$ & 2.26 & 6770 \\
\hline $\mathrm{VN}$ & $\mathrm{V}$ & $\mathrm{N}$ & 2.27 & 7070 \\
\hline $\mathrm{AlN}$ & $\mathrm{Al}$ & $\mathrm{N}$ & 1.80 & 7750 \\
\hline $\mathrm{NbN}$ & $\mathrm{Nb}$ & $\mathrm{N}$ & 4.04 & 10230 \\
\hline $\mathrm{TiN}$ & $\mathrm{Ti}$ & $\mathrm{N}$ & 0.32 & 8000 \\
\hline
\end{tabular}

Table 3.1: Solubility products for carbides and nitrides in steels [51].

$$
\phi_{2}=30 M n+11 C r+20 C u-700 P-400 A l-120 A s-400 T i
$$

The allotriomorphic ferrite start temperature $\left(A_{s}\right)$ and the Widmanstatten start temperature $\left(W_{s}\right)$ were calculated from the time temperature transformation (TTT) diagram. This procedure made direct use of the experimental cooling curve data, and the $W_{s}$ was taken to be the temperature at which the shear and diffusional $\mathrm{C}$ curves cross [22]. An example of TTT curves for welds of a low carbon steel $(0.094 \%$ C, $0.21 \% \mathrm{Si}$ and $0.71 \% \mathrm{Mn}$ ) using four different filler metals are given in Figure 3.1. 


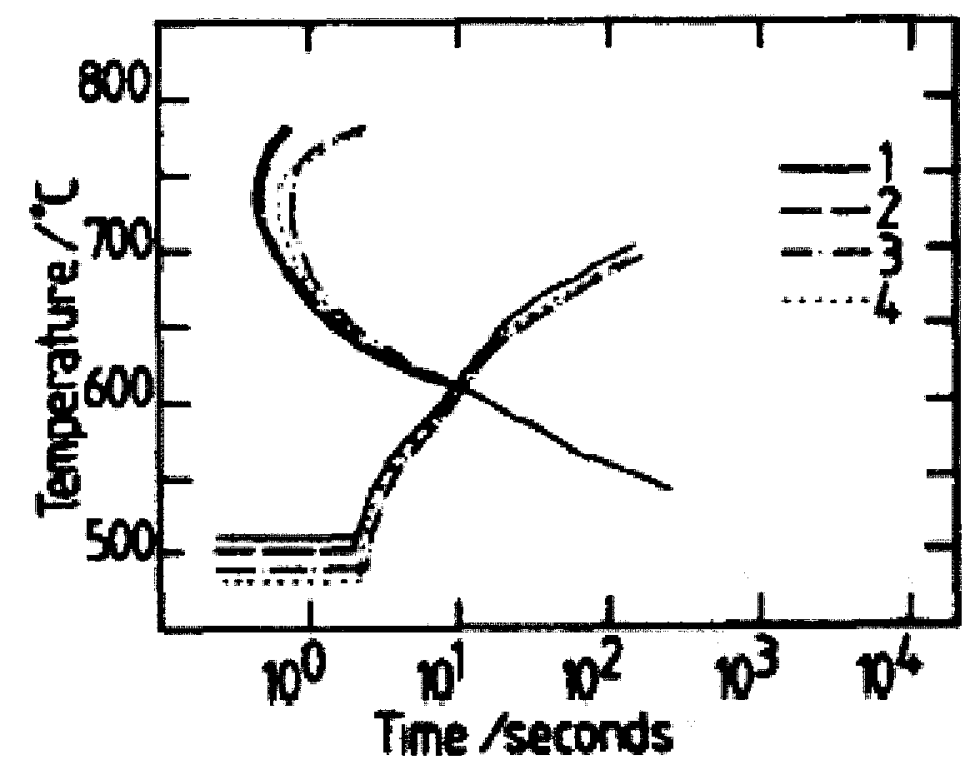

Figure 3.1: TTT diagram for weld deposits [22].

\subsubsection{Austenite Grain Size}

1. Austenite Grain Size in Weld Metal (WM)

The austenite grain size in the WM can be calculated using an empirical correlation based on the heat input $Q\left(K \mathrm{Jmm}^{-1}\right)$ and the composition of $C, S i$ and $M n(w t \%)$. The mean linear intercept, $\bar{L}_{t n}(\mu \mathrm{m})$, on a transverse section in an orientation normal to the major axes of the columnar grains (as shown in Figure 3.2) was given by [53]:

$$
\bar{L}_{t n}=64.5-445.8 C+138.6 S i-7.581 M n+16 Q
$$




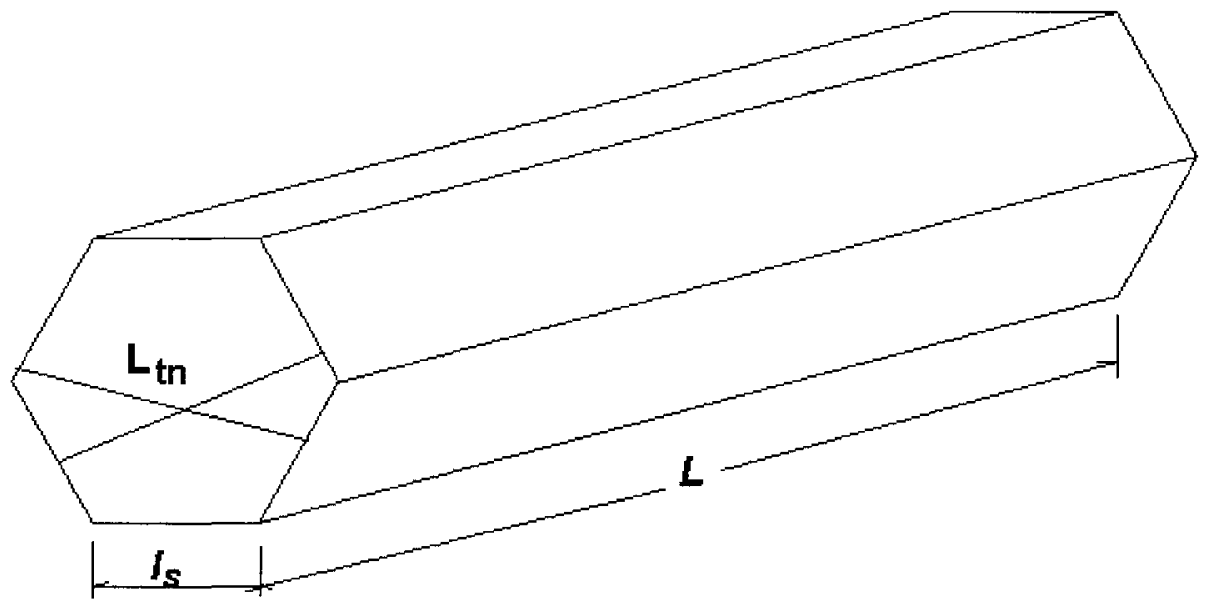

Figure 3.2: Schematic diagram of a columnar austenite grain.

Then the side length of the hexagonal $\operatorname{prism} l_{s}$ was calculated by the following relationship using the stereology theory [54]:

$$
\bar{L}_{t n}=\pi l_{s} \cos \left\{30^{\circ}\right\} / 2
$$

2. Austenite Grain Size in Heat Affected Zone (HAZ)

The grain growth in the HAZ was assumed to be diffusion controlled, driven by surface energy and not to require nucleation. The rate of growth at a fixed temperature $\mathrm{T}$ was given by [55]:

$$
\frac{d g}{d t}=\frac{k_{1}}{2 g} \exp \left(-\frac{Q_{a}}{R T}\right)
$$

The grain size $g$ after time $t$ was given by:

$$
g^{2}-g_{0}^{2}=k_{1} t \exp \left(-\frac{Q_{a}}{R T}\right)
$$


where,

$g_{0}$ is the initial grain size,

$k_{1}$ is a kinetic constant,

$Q_{a}$ is an activation energy,

$R$ is the gas constant.

\subsubsection{Solidification}

When a weld joint temperature falls below the $T_{L}$ temperature, solidification begins. The solidification microstructure is dominated by the temperature gradient $\left(G^{\prime}\right)$ and the growth rate $\left(R_{g}\right)$. The ratio $G^{\prime} / R_{g}$ determines the mode of solidification while the product $G^{\prime} R_{g}$ governs the length scale of the solidification structure [9].

Depending on the solidification condition and the material system involved, the solidification mode changes from planar to cellular, then to columnar dendritic, and finally to equiaxed dendritic when the degree of constitutional supercooling continues to increase from the liquid-solid interface to the centerline, as shown in Figure 3.3.

Non-metallic elements such as oxygen and nitrogen in the steel induce formation of inclusions in the weld metal. These inclusions promote the intragranular nucleation of non-martensitic transformation products, for instance, acicular ferrite [56]. In addition inclusions on the grain boundary enhance grain boundary ferrite nucleation. 


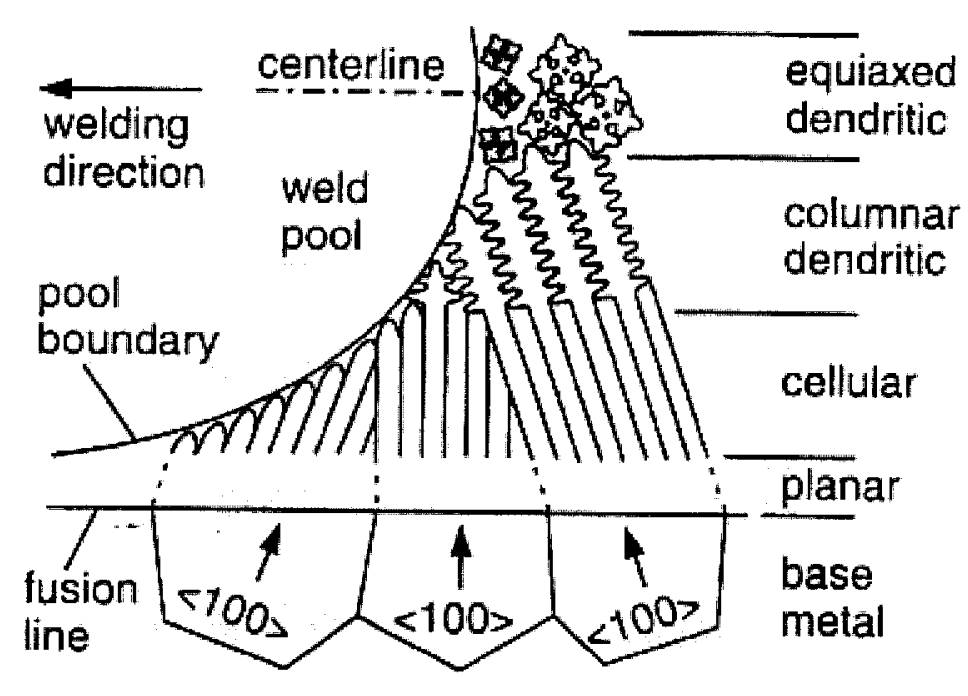

Figure 3.3: Solidification mode in steels [9].

Moreover, some alloy elements such as vanadium in weld metal are known to promote $\mathrm{GBF}$ and $\mathrm{AF}$ and these seem to be at the expense of Widmanstatten ferrite [8].

The $\delta$-ferrite grains are the first phase to form from the grain structure of the parent plate. They are columnar in shape due to the steep temperature gradient, and the major axes of the grains is roughly along the maximum temperature gradient direction. After further cooling, austenite grains nucleate at the $\delta$-ferrite grain boundaries.

As the temperature continues to decrease, austenite to ferrite transformation starts at the grain boundaries, allotriomorphic ferrite ( $\alpha$ or grain boundary ferrite, GBF) 
being the first to form along the austenite grain boundaries, Widmanstatten ferrite ( $\alpha_{w}$ or side plate ferrite) then developing from austenite grain boundaries or from the existing GBF grain boundaries. Carbide layers grow between individual side plates. When the temperature continues to fall, intragranular nucleation of acicular ferrite commences. As ferrite forms, carbon is rejected from ferrite and this leads to carbonrich austenite that will transform to microphases such as martensite, bainite and pearlite depending on the cooling rate and local alloy composition [9][56][57]. The microstructure evolution in weld metal can be illustrated on a continuous cooling transformation (CCT) diagram, as shown in Figure 3.4.

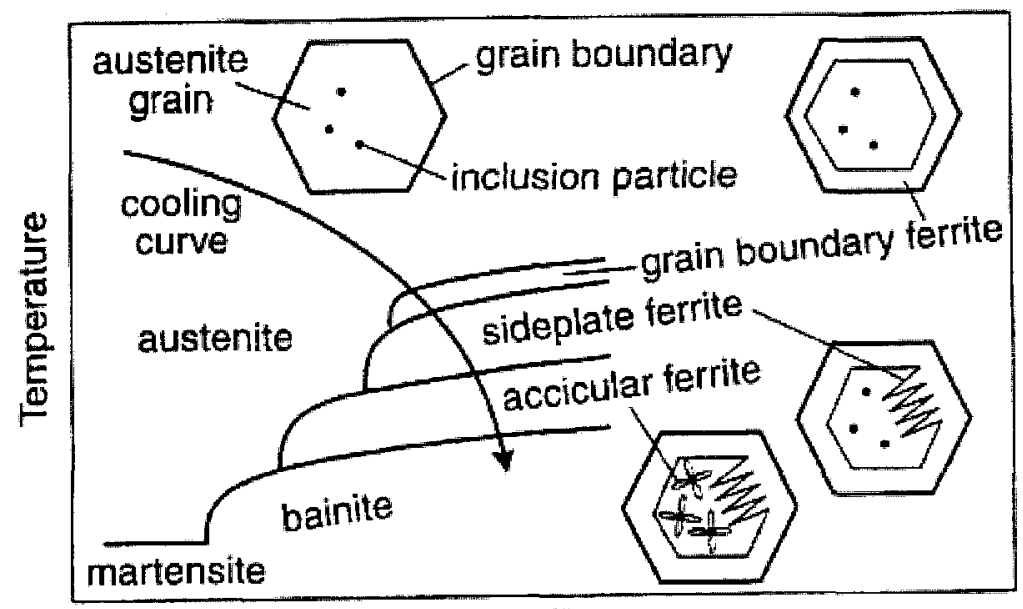

$\log$ Time

Figure 3.4: CCT diagram for weld metal of low-carbon steel [9]. 


\subsubsection{Solid State Phase Transformation in Weld Metal (WM) - Bhadeshia's Model}

The classification of various austenite to ferrite transformation products in steel WM was based on the transformation mechanisms.

1. Evolution of Allotriomorphic Ferrite

Allotriomorphic ferrite is the first phase to nucleate at the austenite grain boundaries when cooling below the $A_{e 3}$ temperature. It grows by a reconstructive mechanism [53], which involves a change in crystal structure and with possible redistribution of solute contents between parent and product phases. In low alloy steel welds, the austenite grain boundaries rapidly become decorated with virtually continuous layers of ferrite, as shown in Figure 3.5 where the illustrated half-thickness is $H_{t}$. As a result, the ferrite grain growth is a thickening process and can be modeled in terms of the normal migration of planar $\alpha / \gamma$ interfaces. The half-thickness was given by [58]:

$$
H_{t}=\alpha_{1} t^{1 / 2}
$$

where,

$H_{t}$ is the half-thickness, 

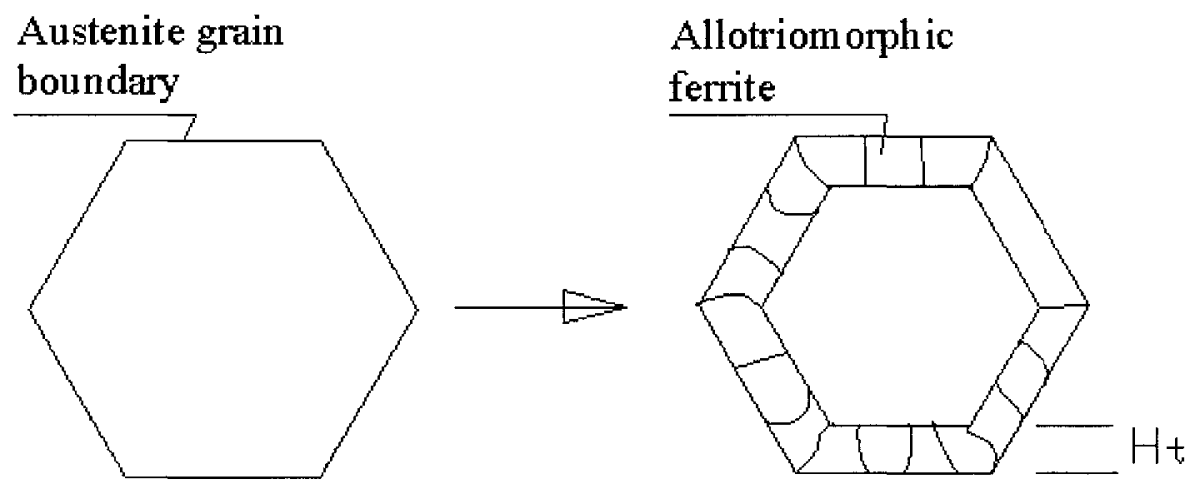

Figure 3.5: Schematic diagram of allotriomorphic ferrite formation.

$t$ is the time (s).

$\alpha_{1}$ is the $1 \mathrm{D}$ parabolic thickening rate constant and was obtained by solving the following equation [22]:

$$
\frac{2\left(C^{\gamma \alpha}-\bar{C}\right)}{C^{\gamma \alpha}-C^{\alpha \gamma}}\left(\frac{\bar{D}}{\pi}\right)^{\frac{1}{2}}=\alpha_{1} \exp \left(\frac{\alpha_{1}^{2}}{4 \bar{D}^{*}}\right)\left[1-\operatorname{erf}\left(\frac{\alpha_{1}}{2 \bar{D}^{\frac{1}{2}}}\right)\right]
$$

where,

$C^{\gamma \alpha}$ is the paraequilibrium carbon content in $\gamma$,

$C^{\alpha \gamma}$ is the corresponding paraequilibrium carbon content in $\alpha$,

$\bar{C}$ is the average carbon content in the steel,

$\bar{D}^{*}$ is a weighted average diffusivity of carbon in $\gamma$, given by [58]:

$$
\bar{D}^{*}=\int_{C^{\gamma \alpha}}^{\bar{C}} \frac{D^{*}}{\bar{C}-C^{\gamma \alpha}} d C
$$

where, 
$D^{*}$ is the diffusivity of carbon in $\gamma$, a function of the amount of carbon in austenite and of the substitutional alloying concentration.

The half-thickness $H_{t}$ was then obtained by integrating the thickening of the layers over the temperature range $A_{3}$ to $W_{s}$ under diffusion-controlled growth condition and was given by [8]:

$$
H_{t}=\int_{t=0}^{t_{1}} 0.5 \alpha_{1} t^{-0.5} d t
$$

where,

$t=0$ is at temperature $A_{3}$ and $t=t_{1}$ is at temperature $W_{s}$, at which $\alpha$ phase growth is assumed to cease.

The volume fraction of GBF was then given by [8]:

$$
X_{\alpha}=\frac{2 H_{t} \tan \left(30^{\circ}\right)\left(2 l_{s}-2 H_{t} \tan 30^{\circ}\right)}{l_{s}^{2}}
$$

\section{Evolution of Widmanstatten Ferrite}

Widmanstatten ferrite $\left(\alpha_{w}\right)$ grows by a displacive mechanism [53], in which the atoms move less than an interatomic distance and retain their relative relationships with their neighbors and no iron or substitutional alloying element diffusion takes place. The $\alpha_{w}$ has a characteristic thin-wedge morphology shown in Fig 3.6. The volume fraction $X_{w}$ of $\alpha_{w}$ was calculated by considering $\alpha_{w}$ to 


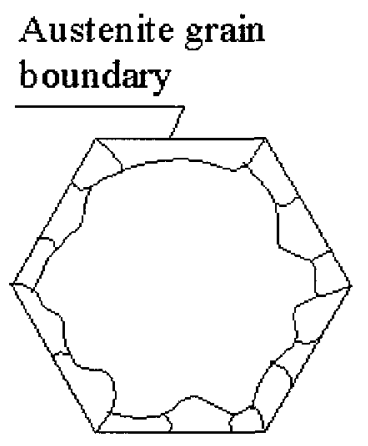

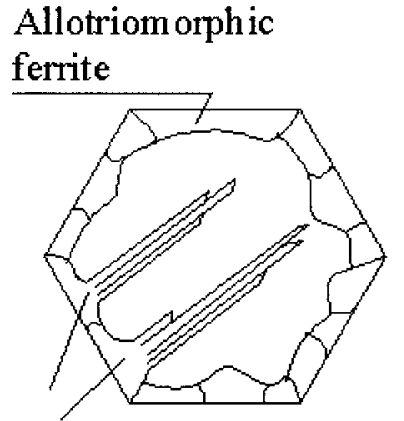

Displacive formation of Widmanstatten ferrite

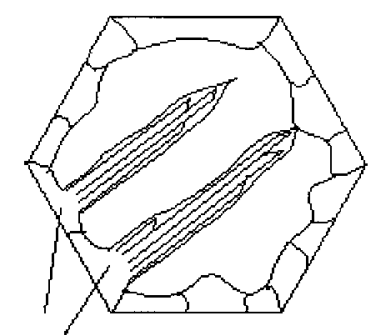

Final form of Widmanstatten ferrite

Figure 3.6: Schematic diagram of Widmanstatten ferrite formation.

nucleate at the $\alpha / \gamma$ boundaries and grow into the interior of the columnar austenite grains, which was given by [8]:

$$
X_{w}=\frac{C_{4} G_{l}\left(2 l_{s}-4 H_{t} \tan \left(30^{\circ}\right)\right) t_{2}^{2}}{\left(2 l_{s}\right)^{2}}
$$

where,

$C_{4}$ is a constant independent of alloy composition,

$t_{2}$ is the time available for the formation of $\alpha_{w}$. It can be calculated by $\left(2 l_{s} \sin \left(60^{\circ}\right)-2 H_{t}\right) / G_{l}$ or be the time between the cessation of $\alpha$ and the onset of $\alpha_{a}$.

$G_{l}$ is the lengthening rate, which was calculated by solving the equation [22]:

$$
\Omega_{0}=(\pi p)^{0.5} \exp (p) \operatorname{erf}(p)^{0.5}\left[1+\left(r_{c} / r\right) \Omega_{0} S_{2}\right]
$$


$\Omega_{0}$ was given by:

$$
\Omega_{0}=\frac{\bar{C}-C^{\gamma \alpha}}{C^{\alpha \gamma}-C^{\gamma \alpha}}
$$

$p$ is Peclet number and was given by:

$$
p=\frac{G_{l} r}{2 \bar{D}}
$$

$r$ and $r_{c}$ are the plate tip radius and the critical plate tip radius. The ratio $r / r_{0}$ is assumed to give the maximum growth rate.

$S_{2}$ is a function of $p$ presented by Trivedi [59].

\section{Evolution of Microphase}

The microphase in the weld metal includes bainite, martensite, degenerated pearlite and retained austenite and their total volume fraction can be equated to the amount of retained austenite at the $M_{s}$ temperature. The retained austenite is calculated by assuming that the ferritic products form to the maximum extent specified by the lever rule as applied to the $A_{e 1}$ and $A_{e 3}$ lines at the $M_{s}$ temperature, as illustrated in Figure 3.7. The volume fraction of ferritic products is given by the lever rule:

$$
X_{F \prime}=\frac{\bar{C}-C^{\gamma}}{C^{\alpha \gamma}-C^{\gamma}}
$$




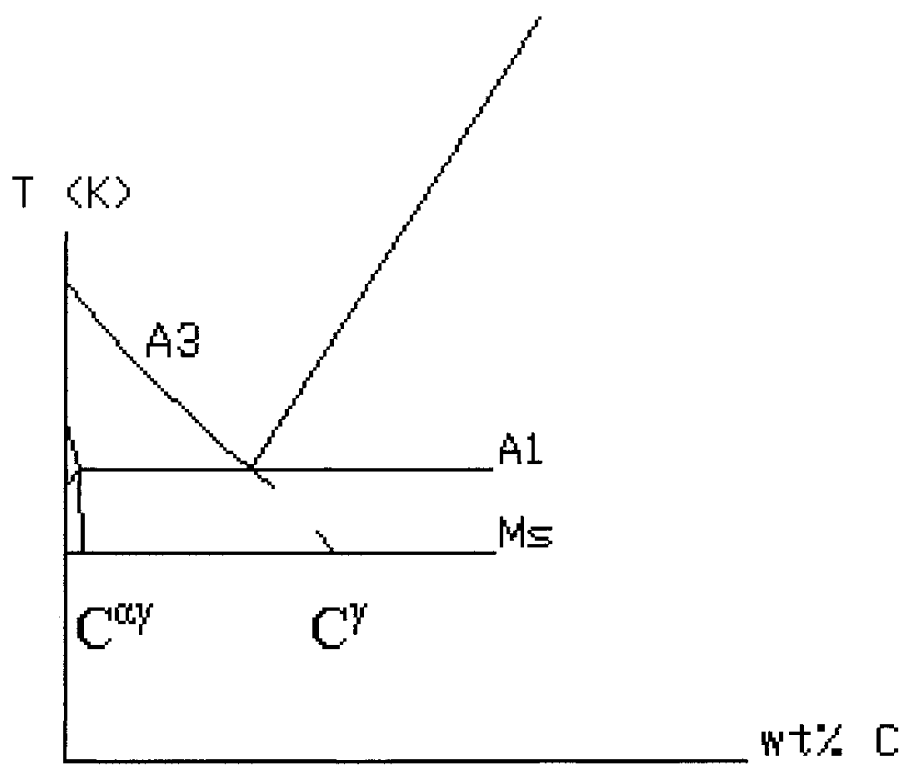

Figure 3.7: Schematic diagram of microphase calculation.

And then the volume fraction of microphase is:

$$
X_{m}=1-X_{F \prime}
$$

4. Evolution of Acicular Ferrite

Acicular ferrite forms at a temperature lower than $A_{s}$ and grows by a displacive mechanism. After determining the volume fraction of allotriomorphic ferrite, Widmanstatten ferrite and the microphase, the acicular ferrite volume fraction can be calculated by:

$$
X_{a}=1-X_{\alpha}-X_{w}-X_{m}
$$




\subsubsection{Microstructure Evolution in Heat Affected Zone - Kho- ral's Model}

The volume fraction of microstructural constituents in the HAZ of low alloy steels can be quantitated by using algebraic equations for thermodynamics and ordinary differential equations (ODEs) for kinetics.

1. Initialization of the Base Metal Microstructure

In the temperature range from room temperature to lower critical temperature $\left(A_{1}\right)$, the volume fraction of ferrite and pearlite is given by the lever rule:

For ferrite, volume fraction $X_{F}$ is:

$$
X_{F}=\frac{C-C_{e u t}}{C_{\alpha}-C_{e u t}}
$$

Then the pearlite volume fraction is:

$$
X_{P}=1-X_{F}
$$

where,

$C_{\alpha}$ is the carbon content of ferrite at temperatures lower than $A_{1}$, which is given by assuming a linear decrease from the eutectoid value to a value of zero at room temperature [60]:

$$
C_{\alpha}=\frac{T-20.0}{A_{1}-20.0}\left(0.105-115.3 \times 10^{-6} \times A_{1}\right)
$$




\section{Austenitization}

Similar to the fraction of ferrite and pearlite at a temperature lower than $A_{1}$, the volume fraction of ferrite and austenite at temperatures higher than $A_{1}$ under equilibrium condition is determined by:

$$
X_{F}=\frac{C-C_{\gamma}}{C_{\alpha}-C_{\gamma}}
$$

where,

$C_{\alpha}$ now is the carbon content of ferrite at temperatures higher than $A_{1}$, which is given by:

$$
C_{\alpha}=0.105-115.3 \times 10^{-6} \times T
$$

The carbon content of austenite, $C_{\gamma}$ is calculated as follows:

$$
C_{\gamma}=\frac{\left[\phi_{1}-\phi_{2}-T\right]^{2}}{203^{2}}
$$

Then the austenite volume fraction is:

$$
X_{A}=1-X_{F}
$$

The austenite grains in the HAZ grow in the temperature range from a temperature higher than TS, to the maximum temperature reached, to cooling down to upper critical temperature. The rate of growth is given by Eqn. (3.13). The austenite grain size is obtained by Eqn. (3.14) 
3. Solid State Transformation on Cooling

The kinetics of austenite decomposition into ferritic products were calculated as a function of undercooling below the $A_{3}$ line and the austenite grain size, using ordinary differential equations (ODEs) of the form [61]:

$$
\frac{d X}{d t}=B_{r}(G, T) X^{m}(1-X)^{n}
$$

where,

$X$ is the volume fraction of the ferritic products,

$B_{r}$ is an effective rate coefficient,

$G$ is the austenite grain size index number,

$T$ is the temperature,

$m$ and $n$ are the semi-empirical coefficients set to be less than one to assure convergence.

In details, the volume fractions of the austenite to ferritic products transformation were given by following equations:

- Austenite to ferrite transformation was calculated as [52]:

$$
\frac{d X}{d t}=\frac{2^{\frac{G-1}{2}}(\Delta T)^{3} \exp \left(-\frac{23500}{R T}\right)}{59.6 M n+1.45 N i+67.7 C r+24.4 M o} X^{\frac{2(1-X)}{3}}(1-X)^{\frac{2 X}{3}}
$$

where, 
$G$ is the ASTM grain size index number, calculated by:

$$
G=1+1.44 \times\left\{\ln \left[\left(\frac{25.4}{g}\right)^{2} \times 100\right]\right\}
$$

$g$ is the grain size $(\mu m)$.

$\Delta T$ is the undercooling, given as:

$$
\Delta T=A_{e 3}-T
$$

$X$ was given by the following equation:

$$
X=\frac{X_{F}}{X_{F E}}
$$

where,

$X_{F}$ is the fraction of ferrite formed,

$X_{F E}$ is the equilibrium amount of ferrite and is updated at each time step as temperature is cooling down.

- Austenite transforms to pearlite was calculated by [52]:

$$
\frac{d X}{d t}=\frac{2^{\frac{G-1}{2}}(\Delta T)^{3} D}{1.79+5.42(C r+M o+4 N i)} X^{\frac{2(1-X)}{3}}(1-X)^{\frac{2 X}{3}}
$$

where,

$\Delta T$ is the undercooling, given as:

$$
\Delta T=A_{e 1}-T
$$


$D$ is a diffusion parameter and it is given by:

$$
\frac{1}{D}=\frac{1}{\exp \left(-\frac{27500}{R T}\right)}+\frac{0.01 C r+0.52 M o}{\exp \left(-\frac{37000}{R T}\right)}
$$

$X$ is given by the following equation:

$$
X=\frac{X_{P}}{X_{P E}}
$$

where,

$X_{P}$ is the fraction of pearlite formed,

$X_{P E}$ is the equilibrium amount of pearlite and is updated at each time step as the temperature cools down.

- Austenite transforms to bainite was given by [52]:

$$
\frac{d X}{d t}=\frac{2^{\frac{G-1}{2}}(\Delta T)^{3} \exp \left(-\frac{27500}{R T}\right)}{10^{-4}(2.34+10.1 C+3.8 C r+19 M o) Z} X^{\frac{2(1-X)}{3}}(1-X)^{\frac{2 X}{3}}
$$

where,

$\Delta T$ is the undercooling, given as:

$$
\Delta T=B_{s}-T
$$

$Z$ was given by the following equation:

$$
Z=\exp \left[X^{2}(1.9 C+2.5 M n+9 N i+1.7 C r+4 M o-2.6)\right]
$$

If $(1.9 \mathrm{C}+2.5 \mathrm{Mn}+9 \mathrm{Ni}+1.7 \mathrm{Cr}+4 \mathrm{Mo}-2.6)<0$, then $\mathrm{Z}=1.0$

$X$ is the amount of bainite formed. 
- Austenite transforms to martensite was calculated by [62]:

$$
X_{M}=1-\exp \left[-k_{2}\left(M_{s}-T\right)\right]
$$

where,

$X_{M}$ is the volume fraction of martensite,

$k_{2}$ is a constant and the value is $0.011^{\circ} \mathrm{C}^{-1}$ for most steels.

\subsection{Implementation of Khoral's Model}

The procedure of computing the volume fractions of room temperature microstructural constituents in a weld joint utilizing Khoral's model involves the following steps:

1. Set up the calculation domain, create the mesh, specify the time step, and select material thermal properties.

2. Input the values of chemical composition for both base metal and filler metal.

3. Determine the characteristic temperatures based on the chemical composition. The liquidus temperature $T_{L}$, solidus temperatures $T_{S}$, upper critical temperature $A_{3}$, lower critical temperature $A_{1}$, precipitate dissolution temperature $T S$, bainite start temperature $B_{s}$ and martensite temperature $M_{s}$ involved in the 
microstructure volume fraction calculation were determined using Eqns. (3.1) through (3.7).

4. Determine the transient temperature field of the weld joint at each time step by employing the thermal model described in Chapter 2 .

5. Compute the initial ferrite and pearlite volume fractions using Eqns. (3.27) through (3.29).

6. When the temperature goes above $A_{1}$, compute the austenite volume fraction using Eqns. (3.30) through (3.33) and compute the austenite grain size using Eqns. (3.13) and (3.14).

7. During the cooling stage, the solidification microstructure of weld metal is assumed to be $100 \%$ austenite, then the volume fraction of transformation products is computed based on the transient temperature and the cooling rate using Eqns. (3.35) through (3.46).

8. The computation of ferrite volume fraction begins when the weld cools below $A_{3}$ using Eqn. (3.35). The formation of ferrite stops when its fraction reaches the equilibrium value or the temperature reaches $B_{s}$.

9. If the cooling rate is slow enough for the formation of pearlite, the pearlite forms when the temperature cools below $A_{1}$ and its volume fraction is computed 
using Eqn. (3.39). The formation of pearlite stops when its fraction reaches the equilibrium value or the temperature reaches $B_{s}$.

10. The bainite volume fraction is computed using Eqn. (3.43) if both of the following conditions are satisfied: if the temperature cools below $B_{s}$ and if there is austenite remaining after the formation of ferrite and pearlite. Bainite formation will stop when the austenite is consumed or $M_{s}$ is reached.

11. The martensite volume fraction is computed using Eqn. (3.46) when temperature cools below $M_{s}$ and this transformation will stop at room temperature or when the austenite is consumed.

\subsection{Simulation and Results}

\subsubsection{Geometry and Chemical Composition of the Weld Joint}

The geometry of the weld joint considered in this study is shown in Figures 3.8 and 3.9. The plate thickness is $8 \mathrm{~mm}$, the same as that used in the thermal model, and the width of the base metal analyzed is $46 \mathrm{~mm}$. The weld is made by three passes, the root pass is $3.5 \mathrm{~mm}$ thick, the second pass is $2.5 \mathrm{~mm}$ thick and the third pass is $2 \mathrm{~mm}$ thick. As shown in Figure 3.8 point $\mathrm{A}$ is a point in the HAZ, whereas point $\mathrm{B}$, C, and D in Figure 3.9 are points of root pass WM, second pass WM and third pass 
WM, respectively. The base metal is high strength low alloy structural steel, and the chemical composition of the filler metal and base metal are given in Table 3.2. Based on the chemical composition, the characteristic temperatures for the base metal and weld metal are shown in Table 3.3.

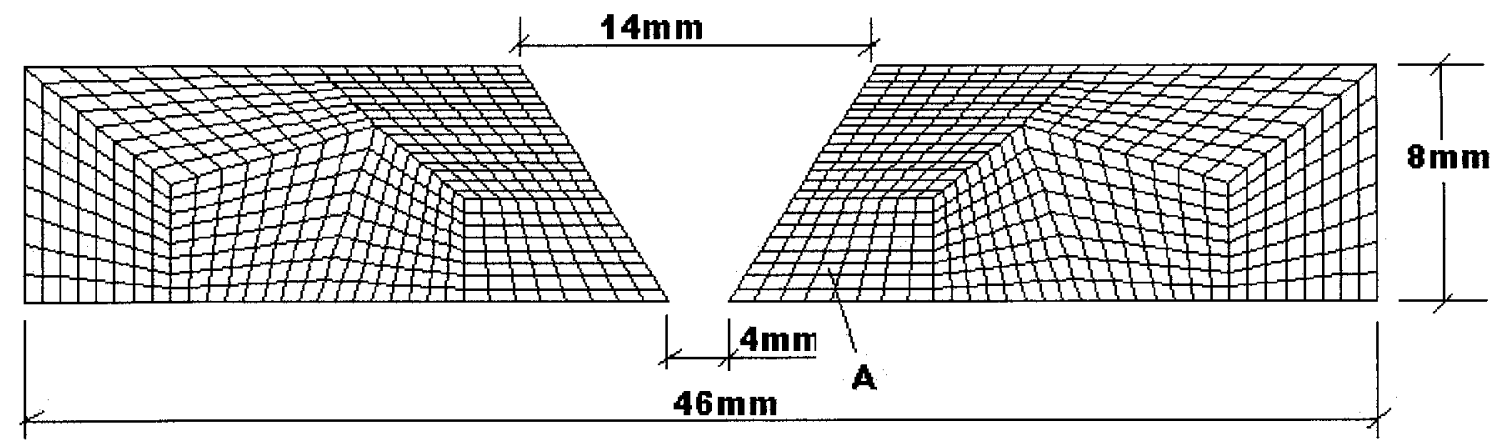

Figure 3.8: Mesh of the base metal.

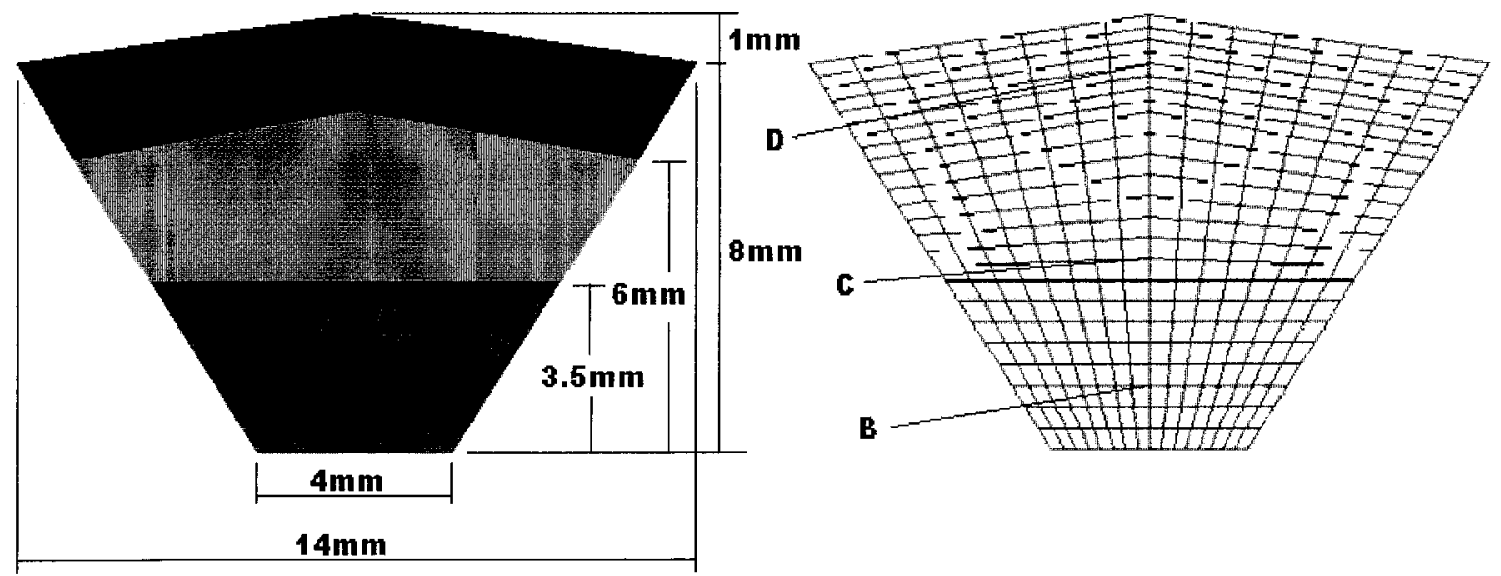

Figure 3.9: Geometry and mesh of the filler metal. 


\begin{tabular}{|c|c|c|c|c|c|c|c|c|c|c|}
\hline Parts & $\mathrm{C}$ & $\mathrm{Si}$ & $\mathrm{Mn}$ & $\mathrm{Cu}$ & $\mathrm{Nb}$ & $\mathrm{N}$ & $\mathrm{Al}$ & $\mathrm{Mo}$ & $\mathrm{P}$ & $\mathrm{S}$ \\
\hline Base metal & 0.12 & 0.16 & 0.91 & 0.12 & 0.021 & 0.011 & 0.04 & 0.0 & 0.002 & 0.005 \\
\hline Filler metal & 0.10 & 0.6 & 0.95 & 0.0 & 0.0 & 0.0 & 0.0 & 0.5 & 0.0 & 0.0 \\
\hline
\end{tabular}

Table 3.2: Chemical composition of the base metal and the filler metal (wt\%).

\begin{tabular}{|c|c|c|c|c|c|c|}
\hline Parts & $T_{s}(K)$ & $T S(K)$ & $A_{e 3}(K)$ & $A_{e 1}(K)$ & $B_{s}(K)$ & $M_{s}(K)$ \\
\hline Base metal & 1778 & 1657 & 1110.6 & 990.9 & 878.2 & 745.3 \\
\hline filler metal & 1781 & N/A & 1277.6 & 1003.2 & 824.5 & 742.9 \\
\hline
\end{tabular}

Table 3.3: Characteristic temperatures of the base metal and the filler metal.

\subsubsection{Thermal History}

The temperature variation with time at points $\mathrm{A}, \mathrm{B}, \mathrm{C}$ and $\mathrm{D}$ is shown in Figure 3.10. As can be seen in Figure 3.10, for this three-pass weld, the HAZ temperature (point A) increases whenever the arc goes through, but the peak temperature is less than the melting point, i.e., $1778 \mathrm{~K}$. Point B is located in the fusion zone of the first pass and the temperature increases to a peak value around $2500 \mathrm{~K}$ when the arc first passes. Then the temperature increases again when the subsequent passes are made.

The temperature at point $\mathrm{C}$ and $\mathrm{D}$ represent temperature variation of filler metal at the second and last passes. To achieve higher accuracy, the time step was set to 0.25 second when the temperature is higher than $500 \mathrm{~K}$. Additionally, in order to 
reduce the computing time, an exponentially increasing time step length was used when temperature was lower than $500 \mathrm{~K}$. The total computation involved 680 time steps. The maximum temperature difference for one step is depicted in Table 3.4. In the temperature between $1073 \mathrm{~K}$ and $773 \mathrm{~K}$, which is critical for the austenite to ferritic products transformation, the maximum temperature difference for one step is just $21 \mathrm{~K}$, so the time step is adaptive for the microstructure computation.

The initial temperature $T_{0}$ was set to $300 \mathrm{~K}$, and the interpass temperatures were $364.5 \mathrm{~K}$ for the second pass and $453.2 \mathrm{~K}$ for the last pass.

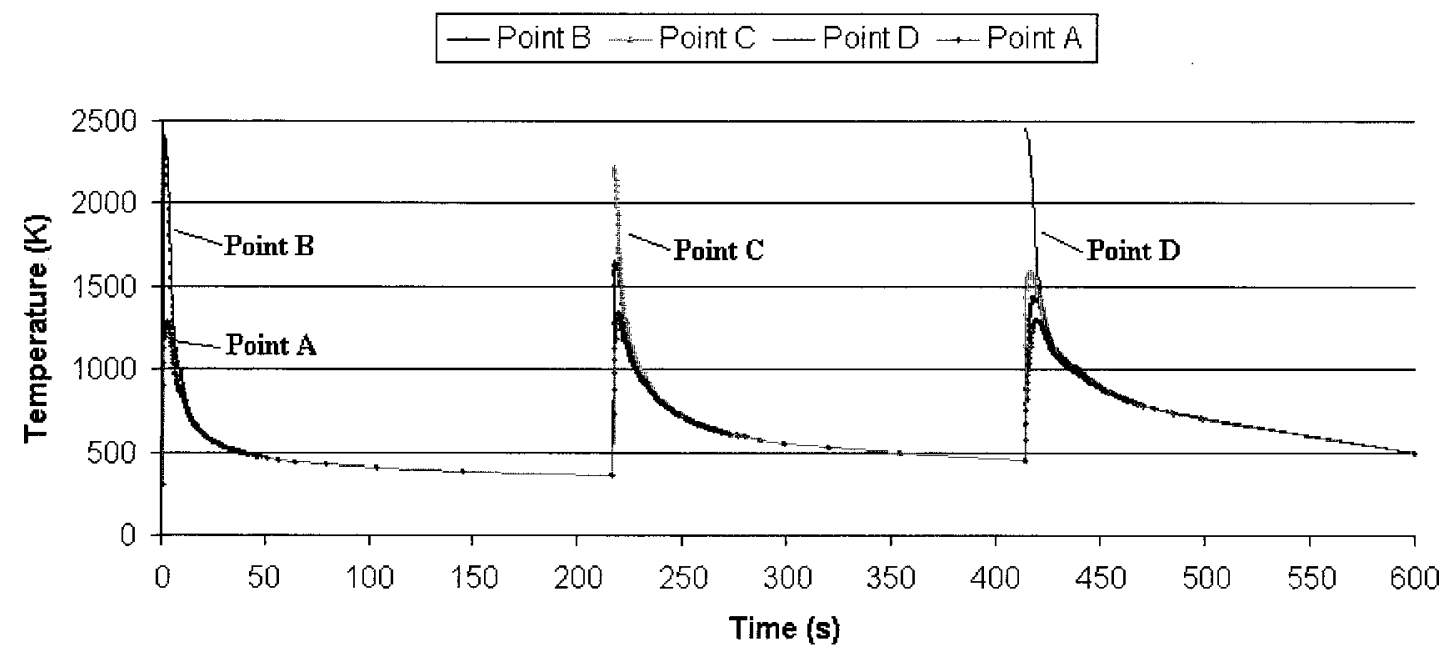

Figure 3.10: Temperature variation at different points. 


\begin{tabular}{|c|c|c|c|c|c|c|}
\hline Pass & At & Max. $\Delta T$ & At & Max. $\Delta T$ & FZ $t_{8 / 5}$ \\
No. & Time steps & $(K)$ & Time steps & $*(K)$ & HAZ $t_{8 / 5}$ \\
\hline First & 17 to 18 & 140 & 29 to 30 & 21 & 6.54 & 7.55 \\
\hline Second & 206 to 207 & 90 & 242 to 243 & 5.1 & 20.29 & 22.7 \\
\hline Third & 495 to 496 & 79 & 543 to 544 & 2.9 & 46.28 & 49.88 \\
\hline
\end{tabular}

Table 3.4: Temperature difference at one time step and cooling time $t_{8 / 5}$. * is the temperature difference for temperature range $1073-773 \mathrm{~K}$.

\subsubsection{Microstructure Development}

The final volume fractions of microstructural constituents of the whole weld joint cross section are illustrated in Figures 3.11 through 3.14 and the microstructure evolution at points A, B, C and D are shown in Figures 3.15, 3.17, 3.19 and 3.20. 


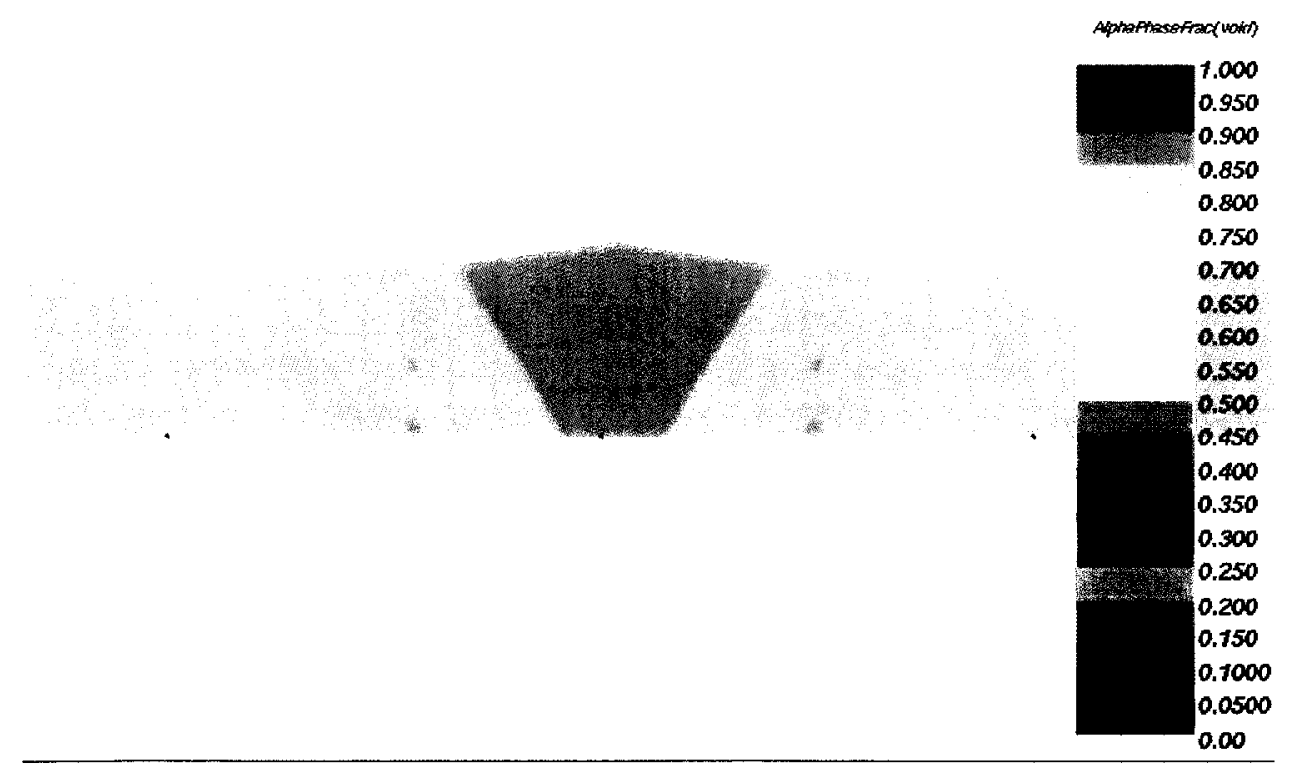

Figure 3.11: Volume fraction of ferrite.

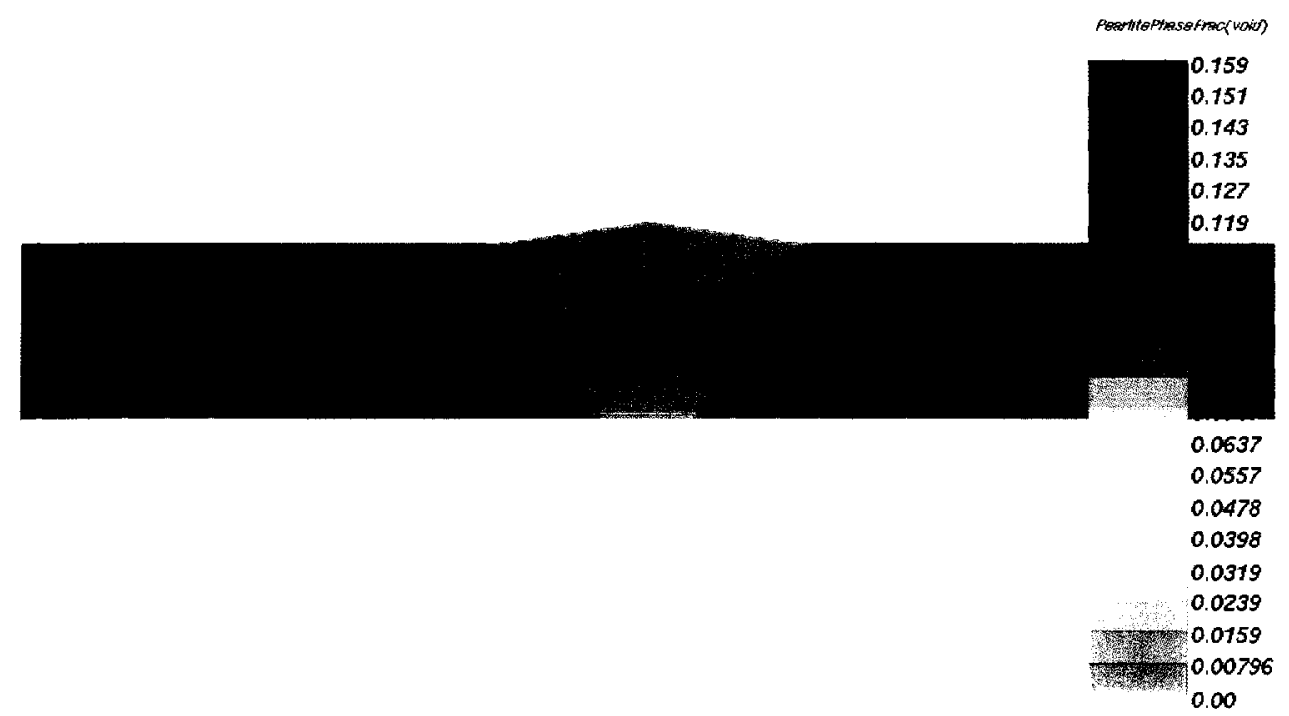

Figure 3.12: Volume fraction of pearlite. 


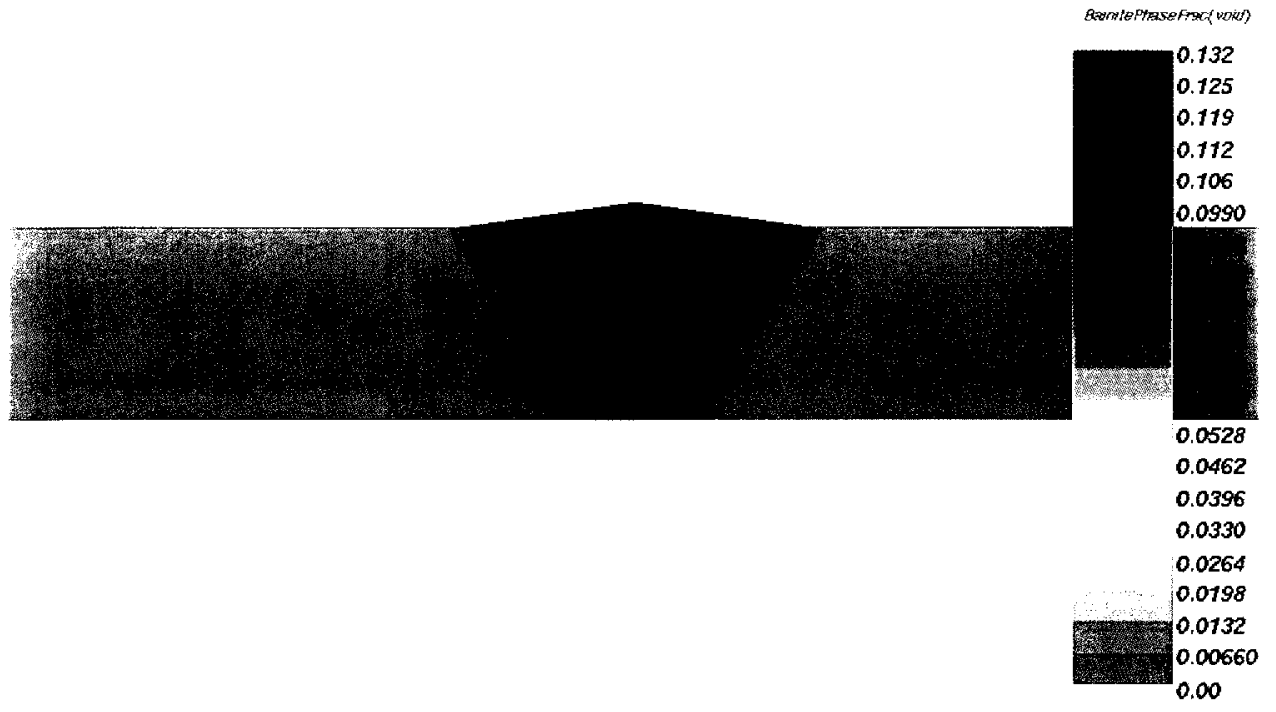

Figure 3.13: Volume fraction of bainite.

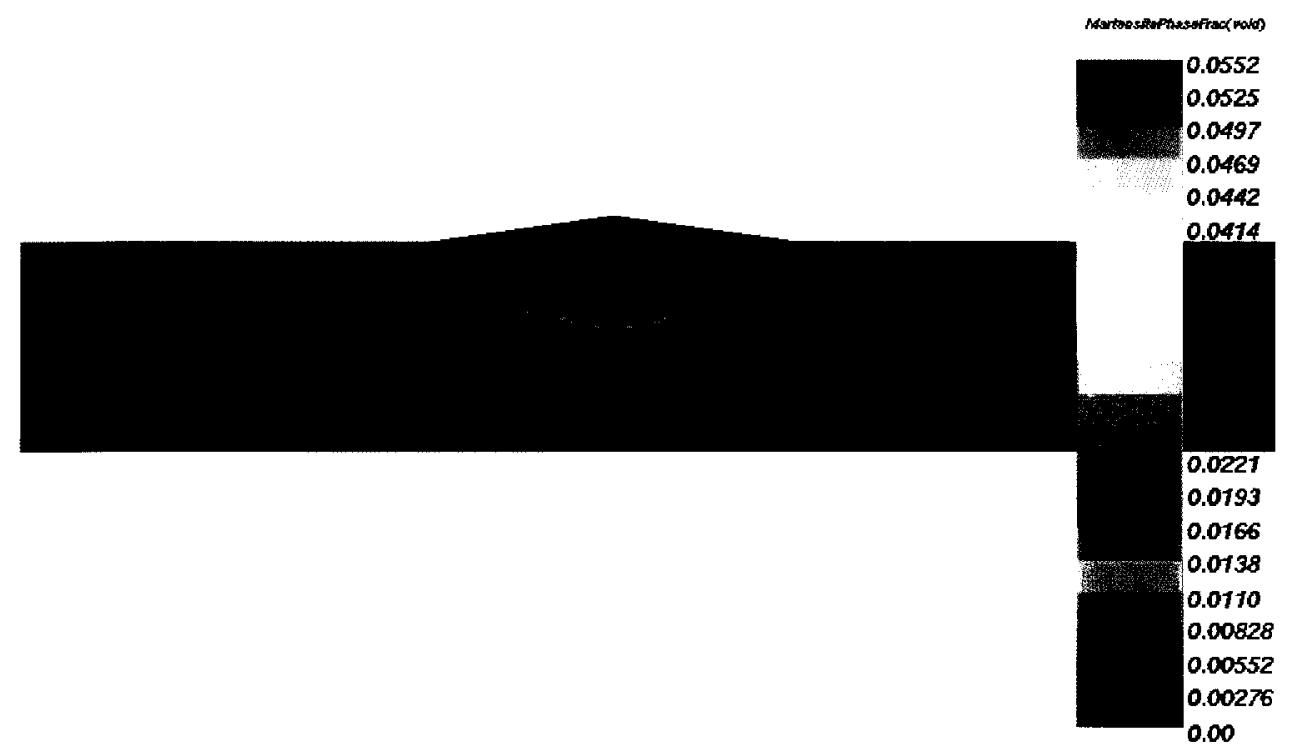

Figure 3.14: Volume fraction of martensite. 
At point $A$, the highest temperature experienced is lower than $T_{s}$ but higher than $A_{3}$, so the microstructure fully austenitizes whenever the heat source passes by. On subsequent cooling ferrite forms when temperature decreases from $A_{3}$, and the pearlite forms when the temperature continues to decrease below $A_{1}$. There is no bainite or martensite formed at point A based on the calculation, while the final volume fractions for ferrite and pearlite are $84.1 \%$ and $15.9 \%$, respectively.
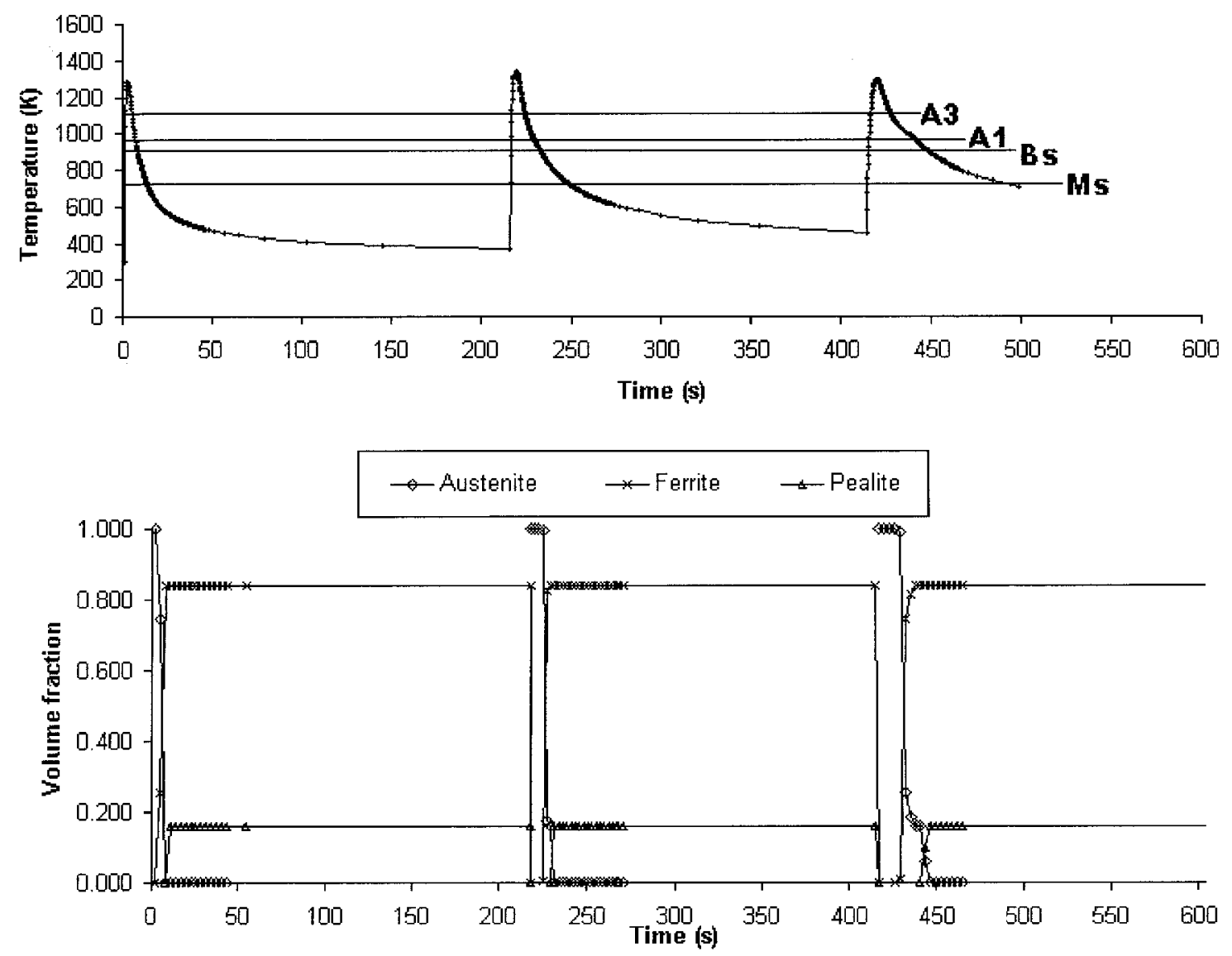

Figure 3.15: Temperature and microstructure development at point A. 
At point B, filler metal is deposited when the first weld pass is made, and the peak temperature of the weld pool can be as high as $2500 K$. Solidification takes place and $\delta$ phase forms as temperature decreases below $T_{L}$. On further cooling, $\delta$ phase is completely transformed to $100 \% \gamma$ phase. Ferrite, bainite and martensite form subsequently when the temperature reaches $A_{e 3}, B_{s}$ and $M_{s}$. Due to the high cooling rate and the presence of alloy element Mo, no pearlite appears and the maximum volume fraction of martensite reaches $12.1 \%$ at point $B$. As the second weld pass is deposited, point $\mathrm{B}$ is in the HAZ of the second pass and the area is reheated, thus the microstructure undergoes reaustenitization and retransformation and the martensite fraction is reduced to $4.3 \%$. When the third pass is deposited, a similar transformation takes place and the martensite disappears from the final microstructural constituents. The final phases at point $\mathrm{B}$ are $86.8 \%$ ferrite and $13.2 \%$ bainite. Figure 3.18 gives an example CCT diagram explaining the effect of cooling rate on microstructure development of steel. As one can see from Figure 3.18, when the cooling rate is between the Z-cooling curve and the P-cooling curve, the microstructural constituents will be ferrite, bainite and martensite. 


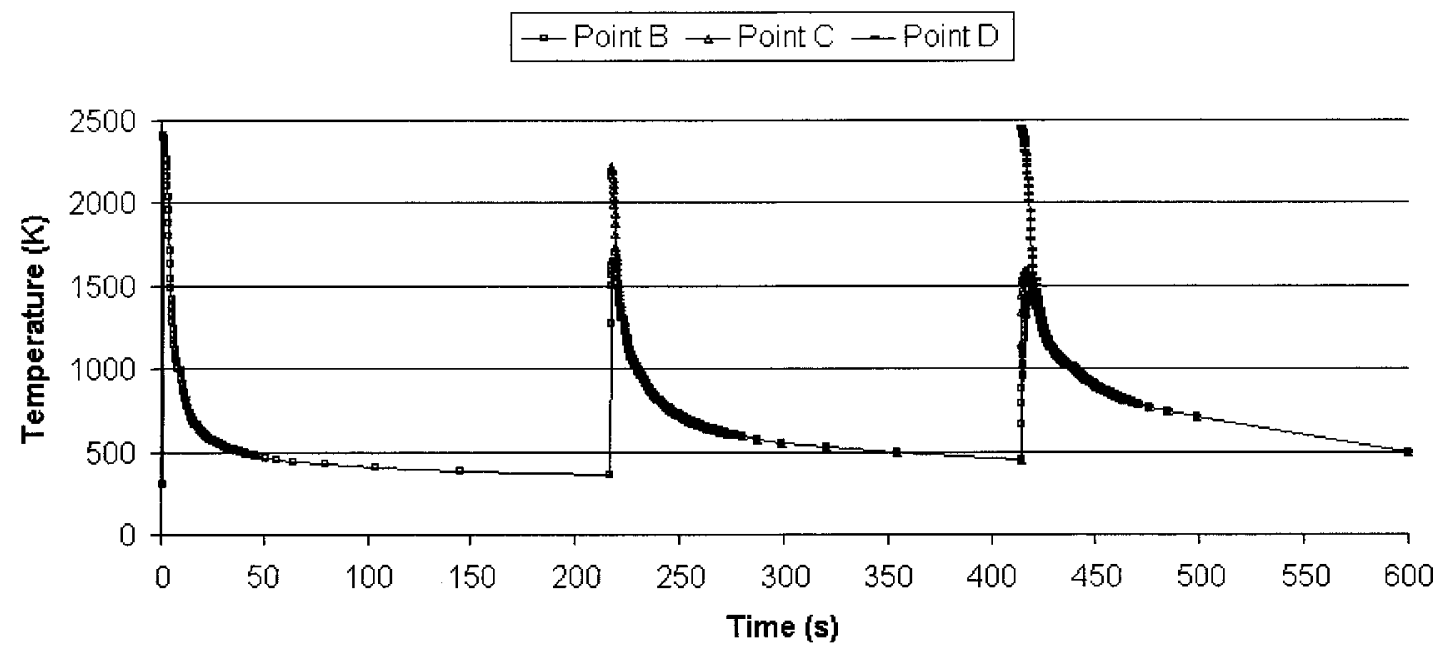

Figure 3.16: Temperature development at point B, C and D.

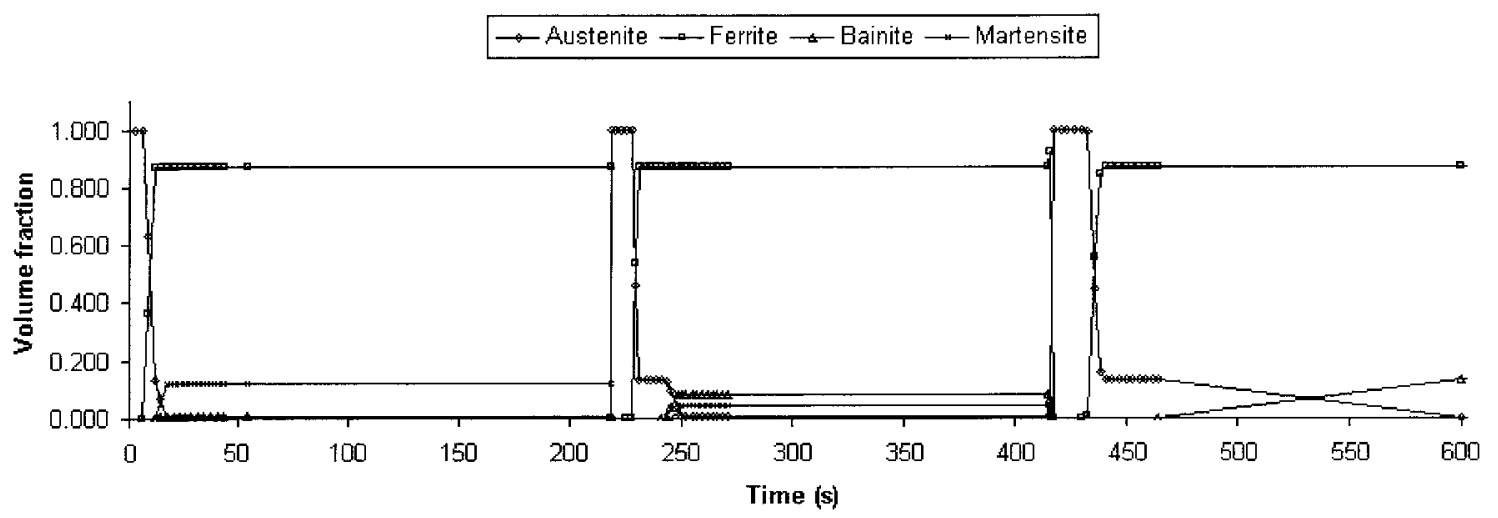

Figure 3.17: Microstructure development at point B. 


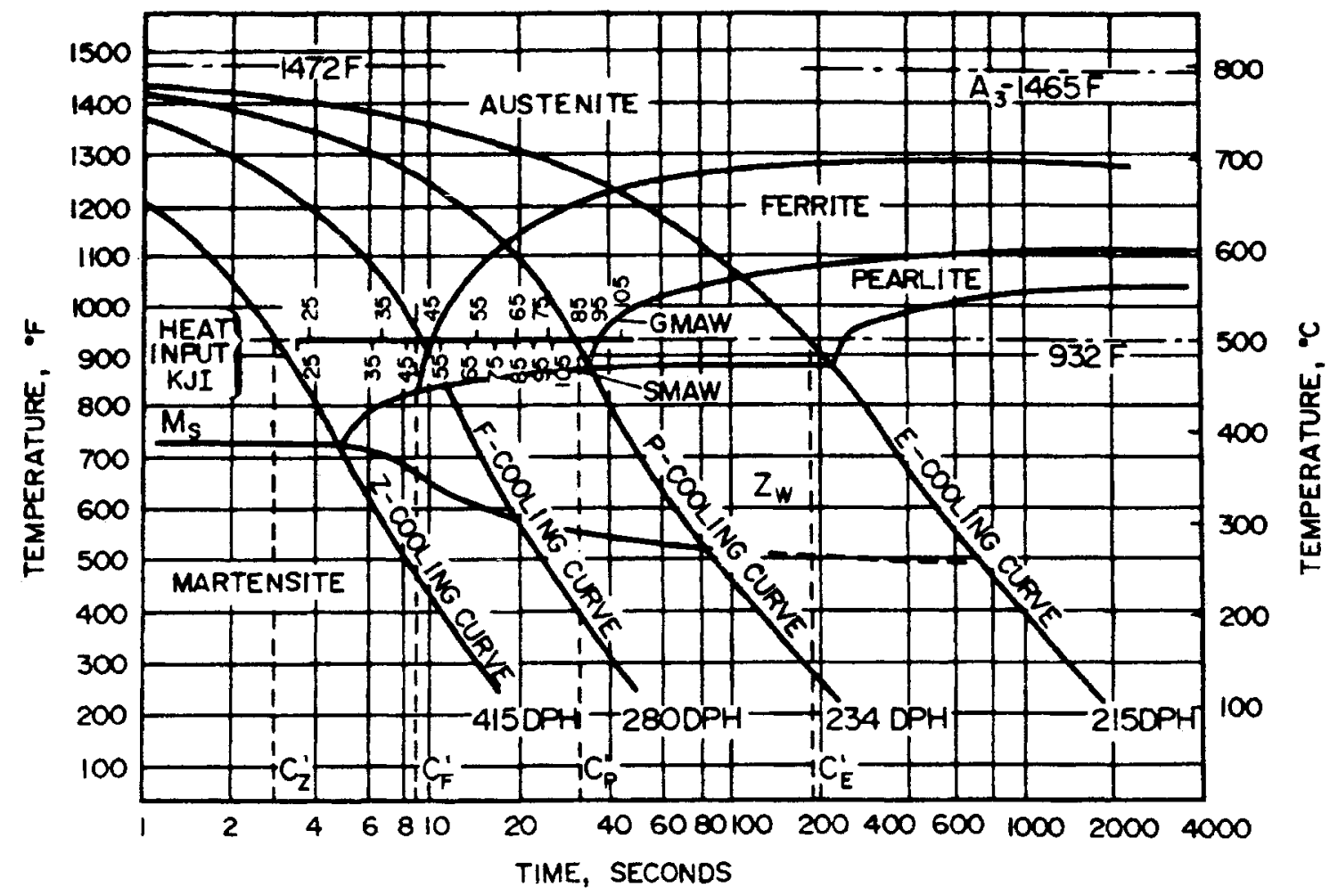

Figure 3.18: CCT diagram of $0.17 \mathrm{C}$ wt\% carbon steel [20].

At points $\mathrm{C}$ and $\mathrm{D}$, the final constituents are ferrite and bainite. The volume fractions of ferrite and bainite at both points are $86.8 \%$ and $13.2 \%$, respectively. 


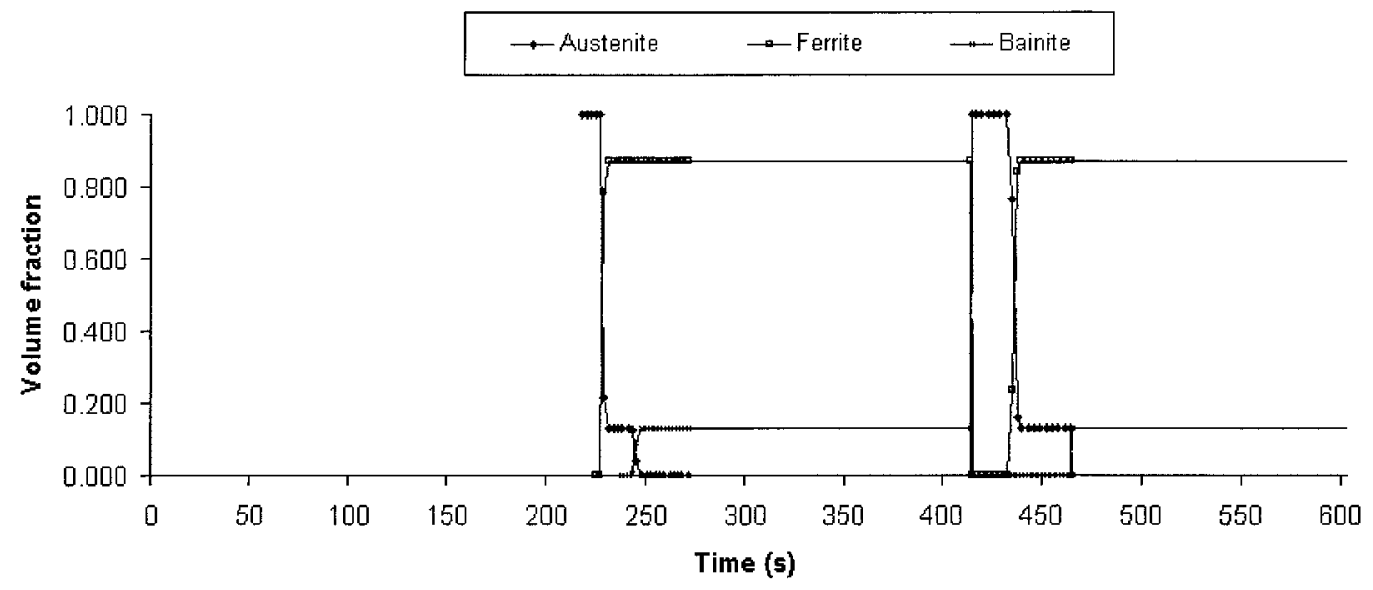

Figure 3.19: Microstructure development at point C.

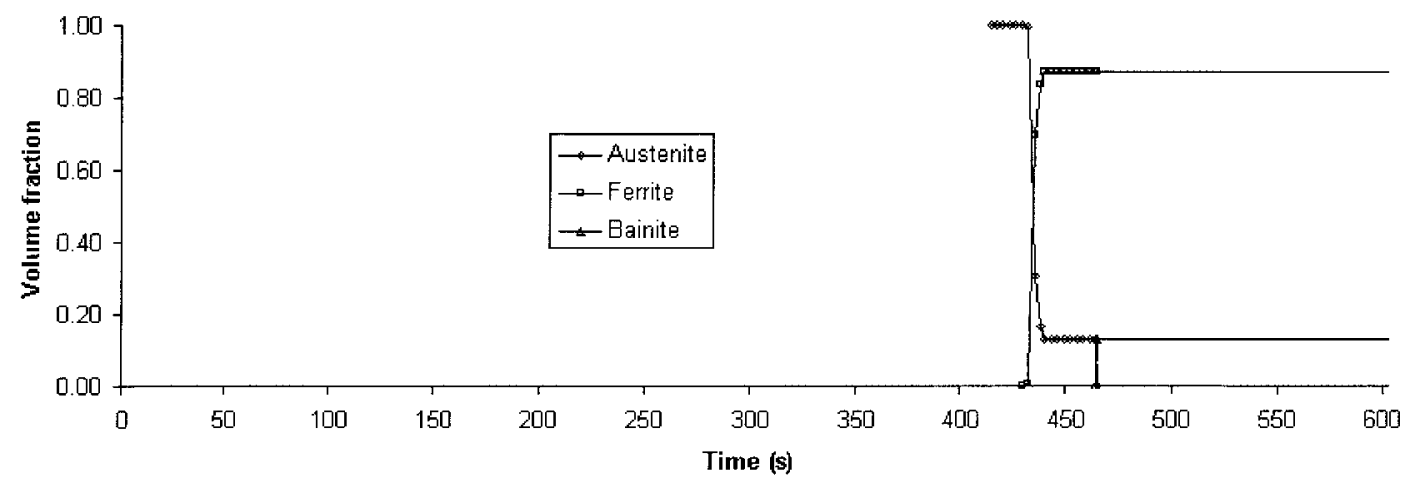

Figure 3.20: Microstructure development at point D. 


\section{Chapter 4}

\section{Residual Stress Analysis}

\subsection{Fundamental Concepts}

Residual stresses are stresses that remain after all external loads are removed. Welding-induced residual stresses are the consequence of the inhomogeneous temperature distribution occuring during the welding processes, i.e., the localized heat source used to create a fusion zone during welding leads to a non-uniform temperature distribution, associated thermal strains and localized plastic deformation. The origin of welding residual stresses includes impeded shrinkage processes, quenching processes and phase transformations [63]. The impeded shrinking processes are dominant, and can be calculated according to the coefficient of thermal expansion and the existing temperature difference. The residual stresses due to the other two processes often 
develop together with residual stresses due to shrinking processes.

The residual state of a weldment is determined by the severity of induced temperature gradients and the degree of restraint the joint imposes on the thermal deformation, and it is characterized by a combination of internally balanced residual stresses and weld distortion.

In accordance with the definition of residual stress, the equilibrium condition of residual stresses on a cut-plane can be expressed as:

$$
\int \sigma d A=0
$$

on any plane section, and

$$
\int d M=0
$$

where,

$\sigma$ is the Cauchy stress separated by:

$$
\{\sigma\}^{T}=\left\{\begin{array}{llllll}
\sigma_{x x} & \sigma_{y y} & \sigma_{z z} & \sigma_{x y} & \sigma_{y z} & \sigma_{x z}
\end{array}\right\}^{T}
$$

$\sigma_{x x}, \sigma_{y y}$ and $\sigma_{z z}$ are the stress components normal to the $\mathrm{x}, \mathrm{y}$ and $\mathrm{z}$ plane, $\sigma_{x y}, \sigma_{y z}$ and $\sigma_{x z}$ are the shear stress components,

$A$ is the area,

$M$ is the moment of residual stress.

Due to limited computational capacity, most computer models of residual stress were conducted using $2 \mathrm{D}$ models in the 1980s. In these $2 \mathrm{D}$ models, only the stress 
perpendicular to the welding direction was calculated and out-of-plane behavior was considered to be plane stress (assuming zero out-of-plane stress), plane strain (assuming zero out-of-plane strain), or generalized plane strain (assuming constant strain normal to the model plane). However, $2 \mathrm{D}$ representation is inadequate to quantify the weld-induced residual stress accurately since the temperature gradient in the welding direction is significant in a weld joint, so more and more researchers have employed 3D models after year 2000 .

\subsection{Theoretical Considerations}

\subsubsection{Governing Equations}

Heat transfer and thermal stress analyses were performed in two uncoupled consecutive steps. The transient heat transfer, i.e., the energy equation Eqn. (2.8) in Chapter 2 was solved for the temperature field in the first stage. In the second stage, the saved nodal temperatures specified the thermal loading to produce the residual stress field.

The basic equations for stress analysis include the rate of change balanced by applied forces and rate of change of moment of momentum balanced by applied torque, the conservation of mass, the constitutive relation between stress and strain, and the compatibility relations between strain and displacement. 
- The conservation of momentum equation neglecting inertial forces is:

$$
\nabla \sigma+\mathbf{b}=0
$$

where,

b is the body force vector,

$\sigma$ is the Cauchy stress.

- The conservation of mass is:

$$
\dot{\rho}+\rho \nabla \cdot v_{1}=0
$$

where,

$\rho$ is density,

$\dot{\rho}$ is the rate of change of density of a material point,

$v_{1}$ is the velocity.

- The constitutive relation between stress and strain is expressed by the generalized Hooke's law:

$$
\{\sigma\}=D\{\epsilon\}
$$

or

$$
\{\epsilon\}=D^{-1}\{\sigma\}
$$

where, 
$\epsilon$ is the infinitesimal strain

$D$ is the material property matrix. For an isotropic elastic material, it can be expressed as:

$$
D=\frac{E}{(1+\nu)(1-2 \nu)}\left[\begin{array}{cccccc}
1-\nu & \nu & \nu & 0 & 0 & 0 \\
\nu & 1-\nu & \nu & 0 & 0 & 0 \\
\nu & \nu & 1-\nu & 0 & 0 & 0 \\
0 & 0 & 0 & \frac{(1+\nu)}{2} & 0 & 0 \\
0 & 0 & 0 & 0 & \frac{(1+\nu)}{2} & 0 \\
0 & 0 & 0 & 0 & 0 & \frac{(1+\nu)}{2}
\end{array}\right]
$$

$E$ is Young's modulus,

$\nu$ is Poisson's ratio.

For a thermo-elasto-plastic material model, stress-strain relations can be further written in terms of differential forms [64]:

$$
[d \sigma]=\left[D^{e p}\right] d \epsilon-\left[D^{t h}\right] d T
$$

with

$$
\left[D^{e p}\right]=\left[D^{e}\right]+\left[D^{p}\right]
$$

where,

$\left[D^{e}\right]$ is the elastic stiffness matrix, 
$\left[D^{p}\right]$ is the plastic stiffness matrix,

$\left[D^{t h}\right]$ is the thermal stiffness matrix,

$d \sigma$ is the stress increment,

$d \epsilon$ is the strain increment,

$d T$ is the temperature increment.

The total strain increment can be divided into elastic, thermal, plastic, and transformation plasticity increment as follows:

$$
d \epsilon^{\text {Tot }}=d \epsilon^{\text {Elas }}+d \epsilon^{\text {Therm }}+d \epsilon^{\text {plas }}+d \epsilon^{\text {TransPlas }}
$$

Depending on the temperature, different material models can be applied during the residual stresses analysis. At temperatures below 50\% melting temperature, a rate-independent plasticity model may be adopted. At temperature between $50 \%$ to $80 \%$ melting temperature, a rate-dependent visco-plastic model can be employed. And at temperature above $80 \%$ melting temperature, a linear viscous model can be used. This enables a stress analysis of a weldment to be conducted near the weld pool.

- The strain - displacement compatibility is given by [65]:

$$
\epsilon=\frac{1}{2}\left(\nabla u+\nabla u^{T}\right)
$$

In matrix form, it is expressed as: 


$$
\{\epsilon\}=\left\{\begin{array}{c}
\epsilon_{x x} \\
\epsilon_{y y} \\
\epsilon_{z z} \\
\epsilon_{x y} \\
\epsilon_{y z} \\
\epsilon_{x z}
\end{array}\right\}=\left\{\begin{array}{c}
\frac{\partial u}{\partial x} \\
\frac{\partial v}{\partial y} \\
\frac{\partial w}{\partial z} \\
\frac{\partial u}{\partial y}+\frac{\partial v}{\partial x} \\
\frac{\partial v}{\partial z}+\frac{\partial w}{\partial y} \\
\frac{\partial w}{\partial x}+\frac{\partial u}{\partial z}
\end{array}\right\}=\left[\begin{array}{ccc}
\frac{\partial}{\partial x} & 0 & 0 \\
0 & \frac{\partial}{\partial y} & 0 \\
0 & 0 & \frac{\partial}{\partial z} \\
\frac{\partial}{\partial y} & \frac{\partial}{\partial x} & 0 \\
0 & \frac{\partial}{\partial z} & \frac{\partial}{\partial y} \\
\frac{\partial}{\partial z} & 0 & \frac{\partial}{\partial x}
\end{array}\right]\left\{\begin{array}{c}
u \\
v \\
w
\end{array}\right\}
$$

where,

$\epsilon_{x x}, \epsilon_{y y}$ and $\epsilon_{z z}$ are normal strain components,

$\epsilon_{x y}, \epsilon_{y z}$ and $\epsilon_{x z}$ are shear strain components,

$u, v$ and $w$ are the displacement components of a point along $\mathrm{x}, \mathrm{y}$ and $\mathrm{z}$ axes, respectively.

By combining Eqns. (4.6) and (4.12), one can obtain:

$$
\sigma=D \epsilon=D B\left\{\begin{array}{c}
u \\
v \\
w
\end{array}\right\}
$$

where,

$B$ is the strain-to-displacement mapping matrix.

For FEM formulation, the principle of virtual work is employed to find the displacement field [66]. This principle states that for any compatible, small virtual 
displacements imposed on a body in equilibrium, the internal virtual work equals the external virtual work, and it is expressed as:

$$
\int_{\Omega} \epsilon^{* T} \sigma d \Omega-\int_{\Omega} u^{* T} \mathbf{b} d \Omega-\int_{\Gamma} u^{* T} \mathbf{f} d \Gamma=0
$$

where,

$\epsilon^{*}$ is the virtual strain,

$u^{*}$ is the virtual displacement,

$\mathbf{b}$ is the body force vector,

f is the surface traction vector.

The first term of Eqn. (4.15) is internal virtual work, which is equal to the inner product of the actual stress $\sigma$ and the virtual strain $\epsilon^{*}$ corresponding to the virtual displacement $u^{*}$. The external work of the actual external forces with the virtual displacement $u^{*}$ is given by the last two terms of the equation.

If the trial function is given by:

$$
u^{* T}=u_{i}^{* T} N_{i}^{T}(x, y, z)
$$

One can obtain from Eqn. (4.15):

$$
u^{* T}\left[\int_{\Omega} B^{T} D B u_{i} d \Omega-\int_{\Omega} N_{i}^{T} \mathbf{b} d \Omega-\int_{\Gamma} N_{i}^{T} \mathbf{f} d \Gamma\right]=0
$$

Because the choice of $u^{* T}$ is arbitrary, Eqn. (4.17) is valid for any values of $u^{* T}$, and thus:

$$
\int_{\Omega} B^{T} D B u_{i} d \Omega-\int_{\Omega} N_{i}^{T} \mathbf{b} d \Omega-\int_{\Gamma} N_{i}^{T} \mathbf{f} d \Gamma=0
$$


Eqn. (4.18) can be further written as the standard FEM formulation in terms of:

$$
[K]\{\mathbf{u}\}=\left\{\mathbf{b}_{\mathbf{f}}\right\}
$$

where,

$K=\Pi K^{e}$, where $K^{e}$ is the element stiffness matrix and $\Pi$ is the operator that assembles element stiffness into global stiffness:

$$
K^{e}=\int_{\Omega} B^{T} D B d \Omega
$$

$\mathbf{u}$ is the nodal displacement vector,

$\mathbf{b}_{\mathbf{f}}$ is the force vector written as the sum of the body force vector and the boundary traction vector:

$$
\mathbf{b}_{\mathbf{f}}=\int_{\Omega} N_{i}^{T} \mathbf{b} d \Omega+\int_{\Gamma} N_{i}^{T} \mathbf{f} d \Gamma
$$

\subsubsection{Computation Procedure}

Thermal analysis was performed by solving the energy equation using 8-node brick elements for nodal temperature at each time step in a Lagrangian formulation.

Then the 3D transient nonlinear thermal stress analysis was conducted. Temperaturedependent Young's modulus, Poisson's ratio, yield strength, hardening modulus and viscosity were selected based on the element temperature and strain rate determined from the previous time step. The transient temperature field of the thermal analysis specified the thermal load. 
For each time step, the solver first computes a trial displacement in an updated Lagrangian formulation. From this trial displacement, the stress at each Gauss point is calculated by using the constitutive equation. Then the residual at each Gauss point is computed from this stress and the external loads. Using this residual a new displacement field is computed.

The iterative procedure was done by using the Newton-Raphson method and the residual (R) for the iteration was computed by the following equation [67]:

$$
\mathbf{R}=\mathbf{P}-\Pi \int B^{T} \sigma_{2}
$$

where,

$B$ is the FEM matrix that maps nodal displacements to the strain at a point,

$\mathbf{P}$ is the nodal vector of external loads,

$\sigma_{2}$ is the second Piola-Kirchoff stress and is given by:

$$
d \sigma_{2}=\mathbf{D} d \epsilon_{e l}
$$

$\mathbf{D}$ is the elasticity tensor represented as a $6 \times 6$ matrix,

$d \epsilon_{e l}$ is the elastic strain increment.

Each Newton-Raphson iteration computes a correction $(d u)$ to the current trial displacement by solving the following equation:

$$
K d u=-\mathbf{R}
$$


where,

$K$ is the global stiffness matrix.

In this study, the linear equation (4.24) was solved to a set tolerance of $10^{-7}$ in the energy norm for each Newton-Raphson iteration. When the 1-norm of the residual $R$ was less than $10^{-4}$, this time step was considered to be converged.

The final residual stresses were calculated from the accumulation of the thermal strains and stress, and the latter was obtained from the correlation between the thermal strain and the temperature increment. Thermal strains and stresses were calculated at each time step, and the residual stresses were updated as time steps increased.

\subsubsection{Error Estimation}

An error bound was used to monitor the error of the FEM solution in the stress analysis. This technique involves a statically admissible stress (SAS) field $\sigma_{s}$ and a kinematically admissible stress (KAS) field $\sigma_{k}$ to compute an error bound in the FEM solution. The error bound is defined as follows [68].

A strain energy norm of the stress vector is defined by the following inner product:

$$
S E=\int_{\Omega} \sigma^{T} D^{-1} \sigma d \Omega
$$

From Eqn (4.25), strain energy of both kinematically admissible stress and statically admissible stress field in the whole domain $\Omega$ are respectively expressed as 
follows:

$$
\begin{aligned}
& S E_{k}=\int_{\Omega} \sigma_{k}^{T} D^{-1} \sigma_{k} d \Omega \\
& S E_{s}=\int_{\Omega} \sigma_{s}^{T} D^{-1} \sigma_{s} d \Omega
\end{aligned}
$$

The error bound and relative error for an individual element are defined as:

$$
\begin{gathered}
\Delta S E_{i}=\int_{e_{i}}\left(\sigma_{s}-\sigma_{k}\right)^{T} D^{-1}\left(\sigma_{s}-\sigma_{k}\right) \operatorname{det} J \\
E_{i}=\frac{\Delta S E_{i}}{0.5 \times\left(S E_{k}+S E_{s}\right)}
\end{gathered}
$$

The total error bound and total relative error in the whole domain are defined as:

$$
\begin{gathered}
\Delta S E=\int_{\Omega}\left(\sigma_{s}-\sigma_{k}\right)^{T} D^{-1}\left(\sigma_{s}-\sigma_{k}\right) d \Omega \\
E_{t o t}=\frac{\Delta S E}{0.5 \times\left(S E_{k}+S E_{s}\right)}
\end{gathered}
$$

It has been proved by Mashaie [69] that the homogeneous kinematically (zero displacement boundary condition) and homogeneous statically admissible stress (zero traction boundary condition and zero body force) spaces, $\Sigma_{0}$ and $\Pi_{0}$, are mutually orthogonal with respect to the inner product

$$
\int_{\Omega} \sigma_{k}^{T} D^{-1} \sigma_{s} d \Omega=0
$$


Thus, the exact solution is the intersection of an inhomogeneous KAS field and an inhomogeneous SAS field of problem and this solution $\left(u_{\text {exact }}, \sigma_{\text {exact }}\right)$ is unique.

The difference between a KAS field and a SAS field associated with the problem in norm (4.25) is an upper bound for the difference between the calculated stress fields and the exact solution of the problem.

In mathematical form:

$$
\begin{aligned}
& \left\|\sigma_{k}-\sigma_{\text {exact }}\right\|^{2} \leq\left\|\sigma_{k}-\sigma_{s}\right\|^{2} \\
& \left\|\sigma_{s}-\sigma_{\text {exact }}\right\|^{2} \leq\left\|\sigma_{k}-\sigma_{s}\right\|^{2}
\end{aligned}
$$

where,

$\sigma_{\text {exact }}$ is the exact stress solution,

$\sigma_{k}$ is a kinematically admissible solution of the problem,

$\sigma_{s}$ is a statically admissible solution of the problem.

This relationship can also be expressed as: the hypotenuse of a right-angled triangle is bigger than either of its two legs (Figure 4.1).

When the contribution of an individual element to the global error is greater than the average value of the total domain, this element can be refined. Conversely, if the error of this element is less than the average value, it can be coarsened. If each element makes exactly the same contribution to the total error, $E_{t o t}$, then one can say that this mesh is optimal. 


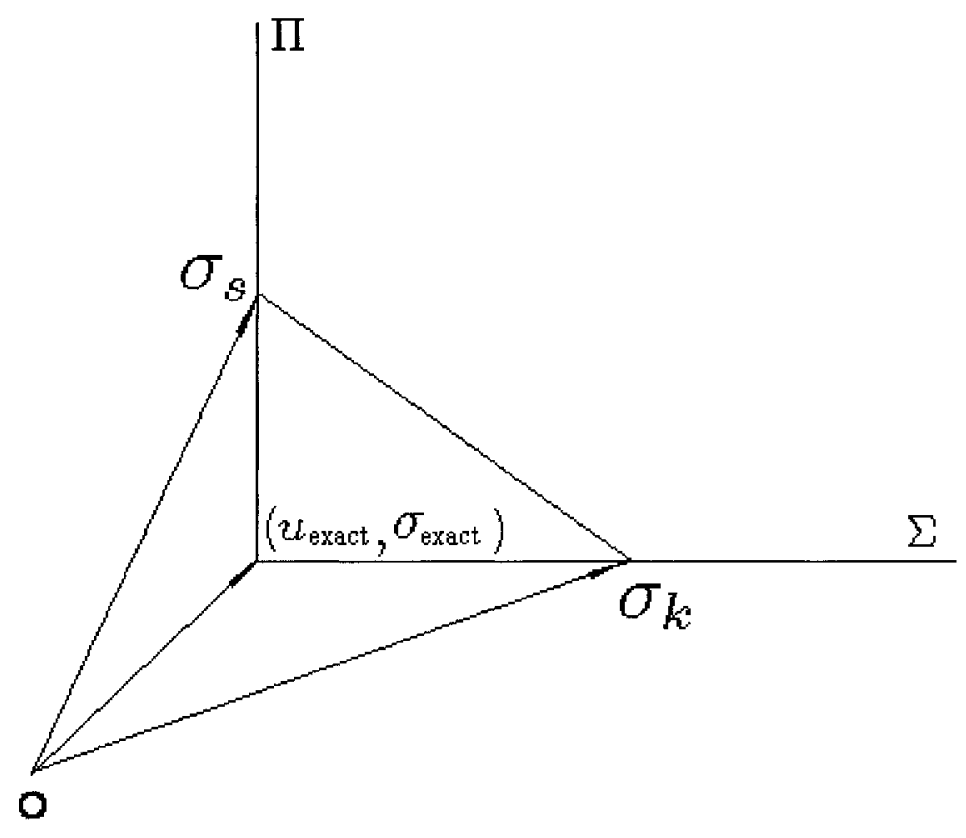

Figure 4.1: Stress field and exact solution [68].

\subsection{Implementation of Residual Stress Analysis}

\subsubsection{Model Construction}

Two different configurations, namely, a multipass butt-welded plate and a singlepass T-joint were investigated in this study. The geometries of the test specimens are displayed in Figures 4.2 and 4.3, the dimensions chosen are based on the commonly used specimens in industrial practice. A graded mesh technique was employed to reduce the computational time in butt weld tests, i.e., a fine mesh was used near the weld and a coarse mesh was used far from the weld. There were 1400 eight-node 3D 
brick elements in the butt weld plate domain and 1600 eight-node 3D brick elements in the T-joint domain.

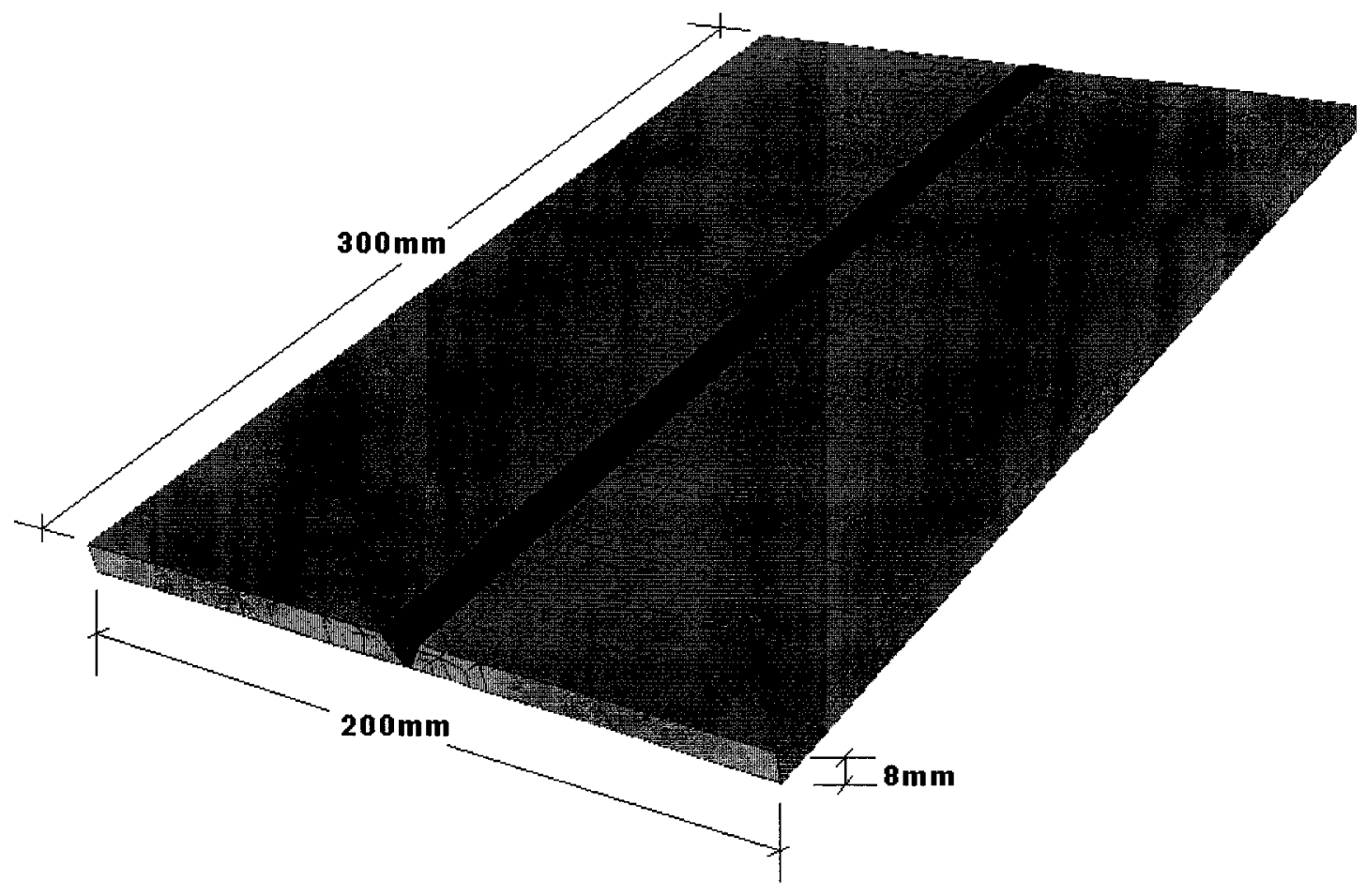

Figure 4.2: Geometry of the plate butt weld.

Simulation of weld filler metal variation with time in the weld joint was done using a dynamic domain. The added metal was included in the original mesh and the elements of filler metal (weld deposit) were turned on as they were added.

Both the butt joint and $\mathrm{T}$-joint were constrained by fixing the displacement of eight boundary nodes in all $\mathrm{x}, \mathrm{y}$ and $\mathrm{z}$ directions at the top and bottom surfaces when welding. The fixity was released after welding was completed. 


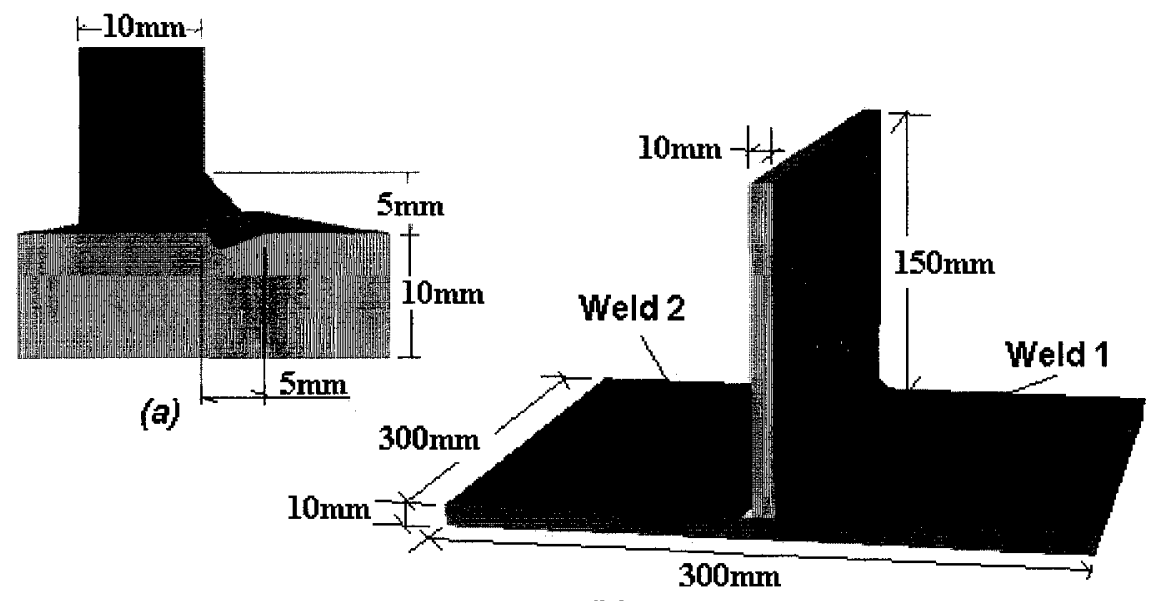

(b)

Figure 4.3: Geometry of the T-joint.

Welding parameters were the same as those in the thermal model described in Chapter 2 but they were applied to a $3 \mathrm{D}$ instead of a $2 \mathrm{D}$ domain. Temperature was the only load for all residual stress analyses.

The displacement, strain and stress were computed for 205 time steps for the butt weld and 55 time steps for the T-joint.

\subsubsection{Material Properties}

The thermal properties used were the same as those of Chapter 2 ; the mechanical properties used in stress computation were from reference [45]. Both thermal and mechanical properties involved are temperature dependent and they are illustrated in Appendix A. In general, when temperature increases from room temperature, Young's modulus, yield stress and thermal conductivity decrease, while the thermal expansion 
coefficient and specific heat increase.

\subsubsection{Results and Discussion}

Transient stresses in the butt weld at two points A (HAZ) and B (WM) are illustrated in Figure 4.4. It can be seen from Figures 4.4(b) and (d) that the HAZ, e.g., at point $A$, is stress free before welding. As the heat source passes through, this point is compressed as temperature increases and then is in tension as temperature cools down. Furthermore, it is compressed and then in tension again when the subsequent heat source passes through. In weld metal, e.g., point B, the transient stress is compressive when the filler metal of this pass or the subsequent passes is deposited, and it changes to tensile as the weld cools down, as shown in Figures 4.4(a) and (c).

In addition, one can also see that multipass welding reduces the magnitude of tensile stress in HAZ (point A) from Figure 4.4(b) and (d). The first weld pass induces the highest tensile stress and then it is released by the subsequent passes. 


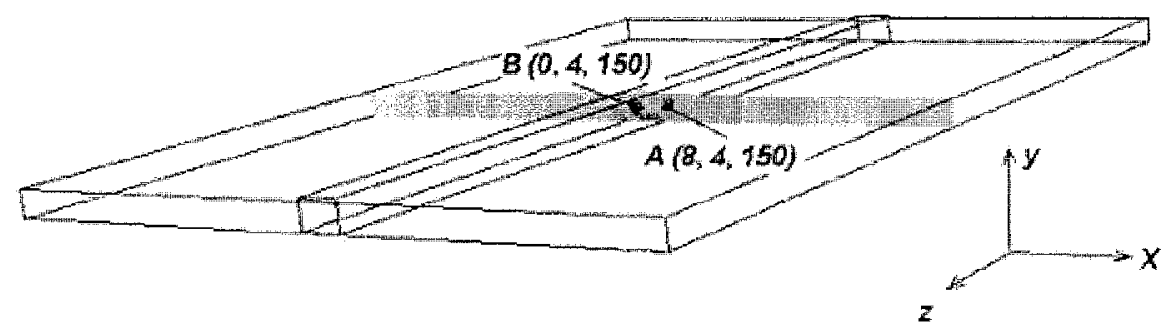

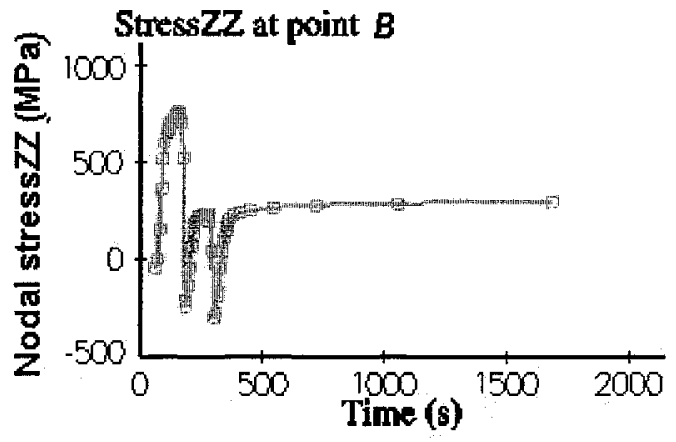

(a)

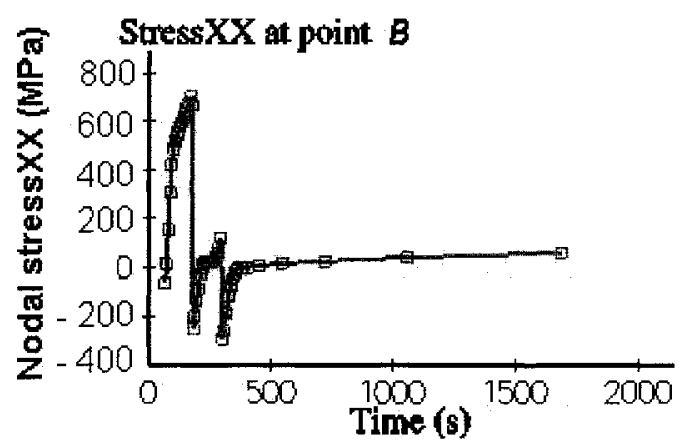

(c)

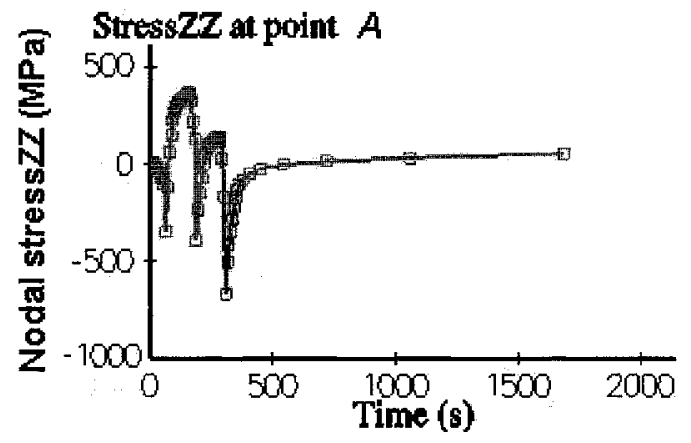

(b)

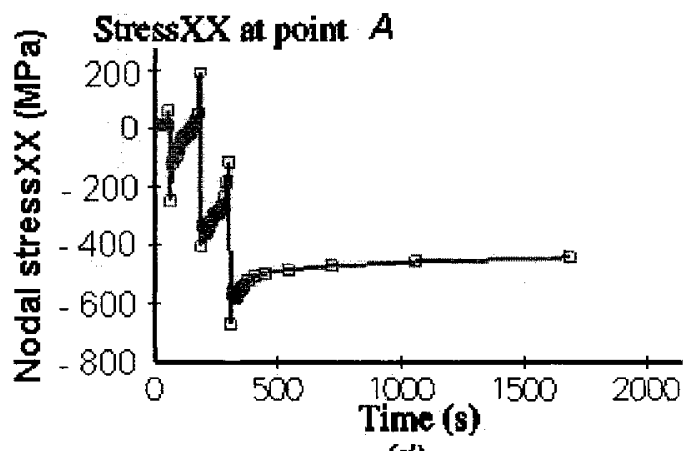

(d)

Figure 4.4: Transient stress in weld metal and HAZ.

Residual stresses in the butt weld are depicted in Figures 4.5 through 4.7. Figure 4.5 illustrates the normal stresses along $\mathrm{X}$ (transverse to the weld) and $\mathrm{Z}$ (parallel to the weld) directions in the mid plane.

As shown in Figures 4.5(a) and (b), for longitudinal stresses (Stress ZZ), i.e., 

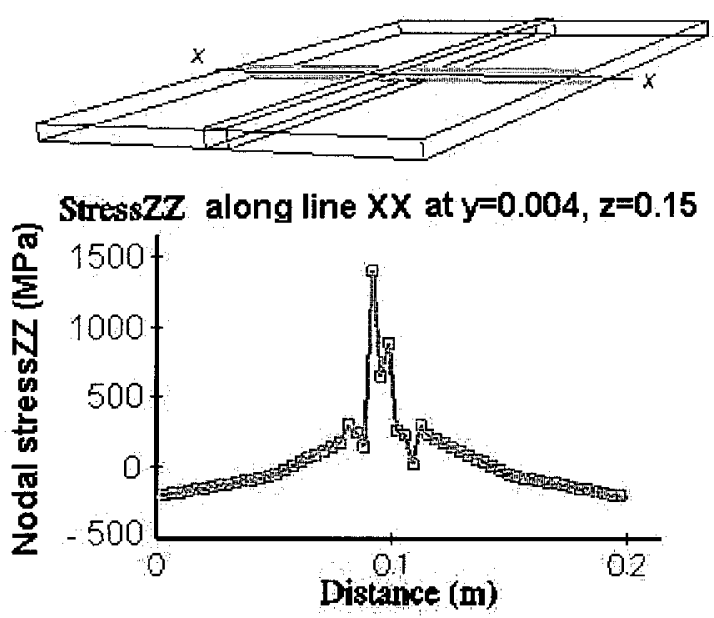

(a)

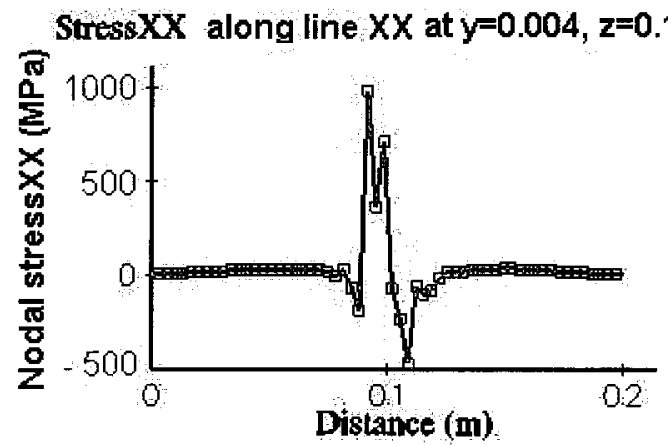

(c)

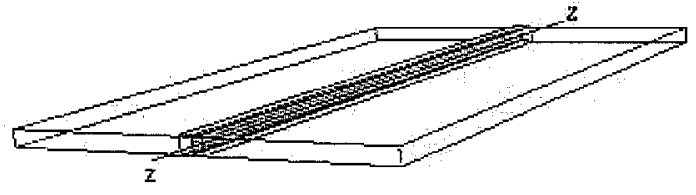

Stress $Z Z$ along line $Z Z$ at $x=0, y=0.004$

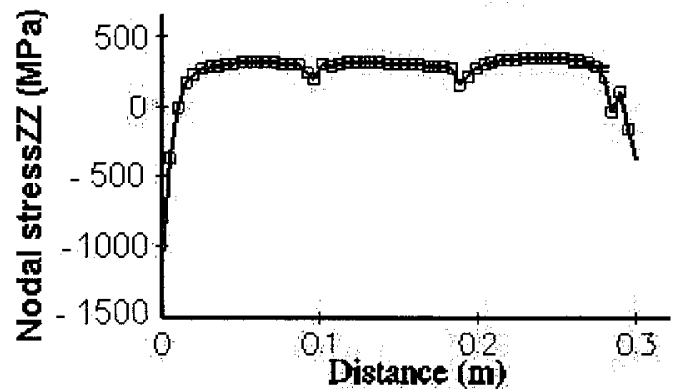

(b)

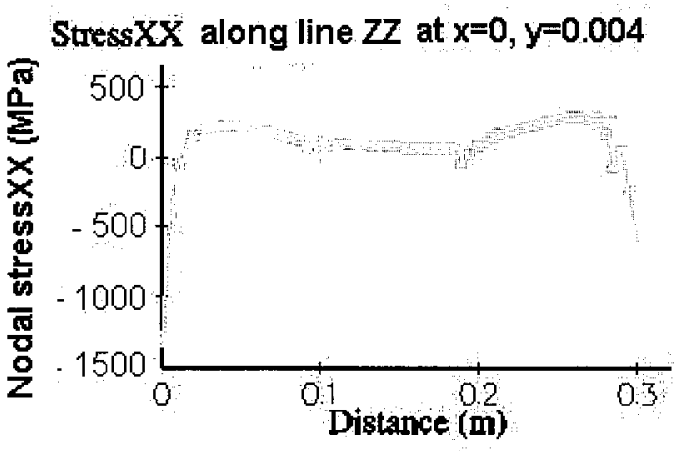

(d)

Figure 4.5: Normal stress in the butt weld.

stresses acting parallel to the direction of the weld, high tensile stresses occur near the weld due to the resistance to contraction of the components as it cools to room temperature. Along a transverse line passing through the weld at mid thickness (line XX), the tensile stress present in a small region in the middle of the plate, and the compressive stress present at the two edges. Along the weld centerline at mid 
thickness (line ZZ), compressive stress exists at both ends of the weld and tensile stress exists in the middle of the weld. In addition, due to the strain hardening effect, the magnitude of both tensile and compressive stresses exceeds the initial yield stress.

For transverse stresses (Stress XX), i.e., stresses acting normal to the direction of the weld, both high tensile and compressive stresses occur near the weld as shown in Figure 4.5(c) and (d). Along the line XX away from the weld, the transverse stress varies from tensile to compressive, then finally vanish at the edges of the plate.

The magnitude of the longitudinal stresses is much higher than that of the transverse stresses due to the moving heat source in this direction.

The effective stress, which describes the general stress state in the weld joint, is displayed in Figure 4.6. It can be seen that the distribution of effective stress is similar to that of the normal stresses. A high tensile stress is also formed in the central region of the weld, as shown in Figure 4.6(a).

During the welding process, thermal strains are always accompanied by plastic deformation of the metal. When the weld joint cools to room temperature, a large proportion of the plastic strain is retained in the weld joint. The effective plastic strain in the butt weld is illustrated in Figure 4.7. Along the X direction (line X1X1, $\mathrm{X} 2 \mathrm{X} 2$ and $\mathrm{X} 3 \mathrm{X} 3$ ), high effective plastic strain is present in the middle cross section near the weld. The peak value reaches 0.1, as shown in Figures 4.7(a), (b) and (c). The plastic strain present at both edges, as shown in Figures 4.7(a) and (b), is caused 

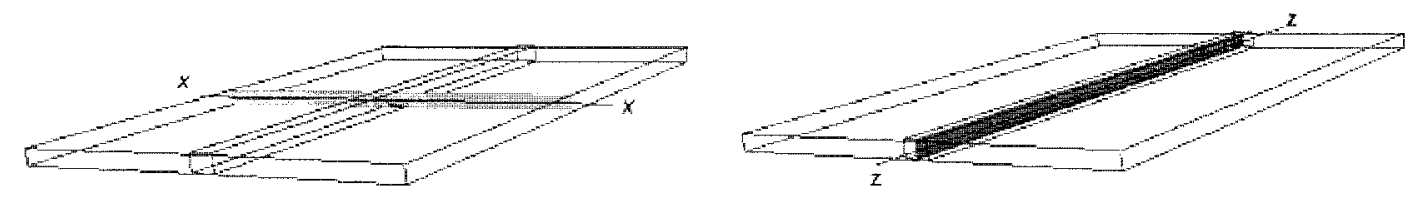

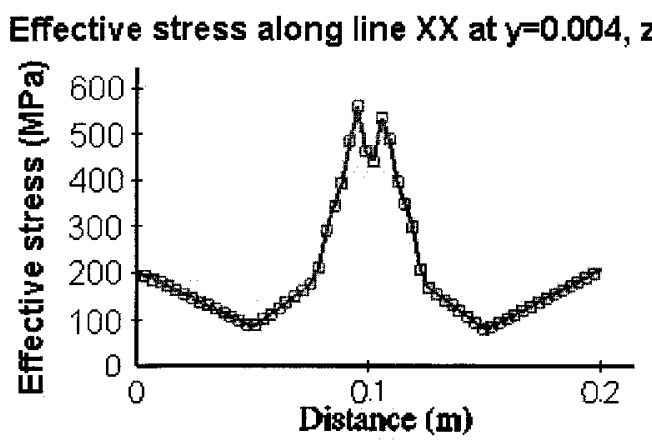

(a)

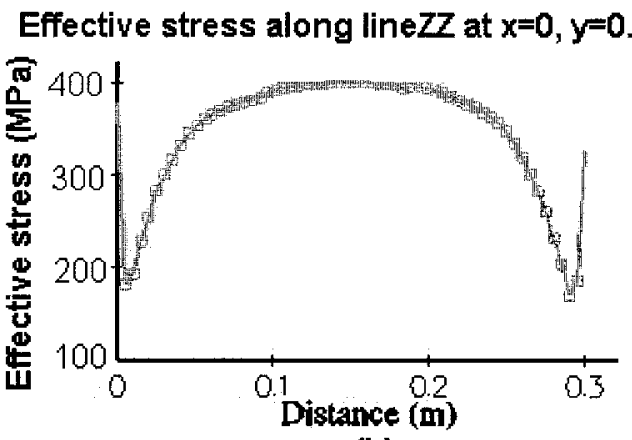

(b)

Figure 4.6: Effective stress in the butt weld.

by the nodal constraints. Along the $\mathrm{Z}$ direction (lines Z1Z1 and Z2Z2), the highest plastic strain is present in the middle part in the bottom surface (line Z2Z2) and the maximum value is as high as 0.12 , see Figure $4.7(\mathrm{e})$. As the hardening modulus was specified to be temperature-dependent but not strain-dependent in this study, a high plastic strain induces high residual stresses, which are much higher than the initial yield stress. If the hardening modulus is set to zero after the plastic strain exceeds 0.04 , the final residual stresses will be much lower than the values presented.

The residual deformation in the butt weld is depicted in Figure 4.8. The largest displacement is in the central region of the weld and both shrinkage and bending contribute to the final deformation. It is evident that these deformations lead to a 

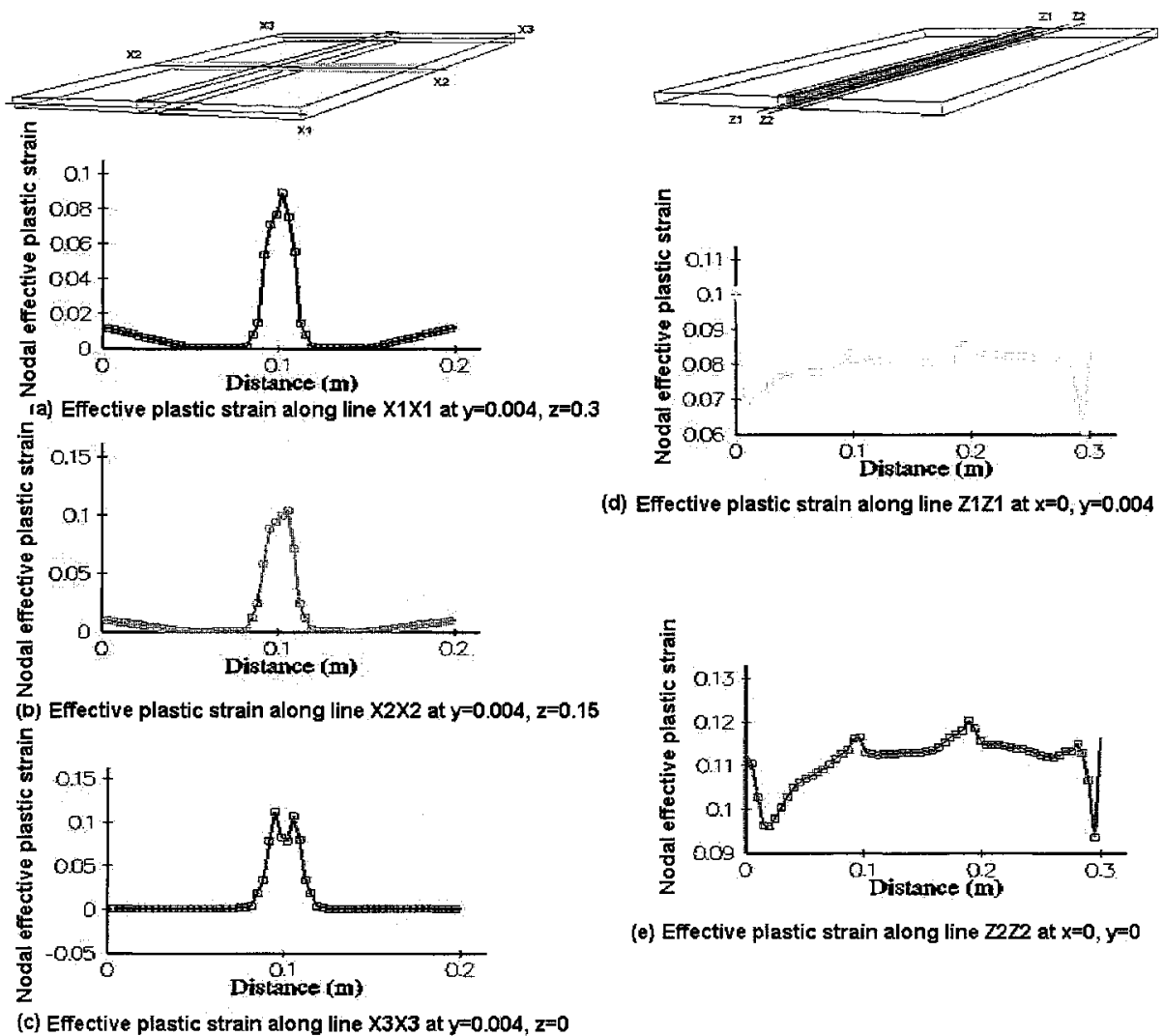

(d) Effective plastic strain along line $Z 1 Z 1$ at $x=0, y=0.004$

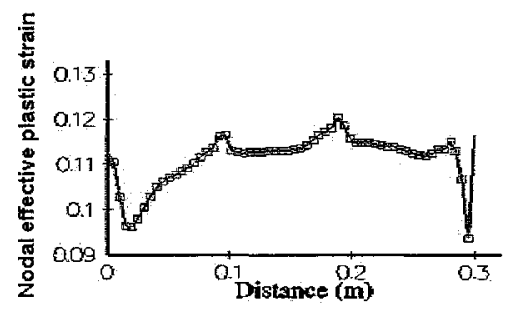

(e) Effective plastic strain along line $Z 2 Z 2$ at $x=0, y=0$

Figure 4.7: Effective plastic strain in the butt weld.

distorted shape or uncorrected dimensions of welded structures, so deformation of the weld joint must be controlled by optimal weld joint design or proper welding process control.

The longitudinal and transverse residual stresses in the T-joint made by weld 1 (see Figure 4.3) are illustrated in Figures 4.9(a) through 4.9(d). It can be seen from 


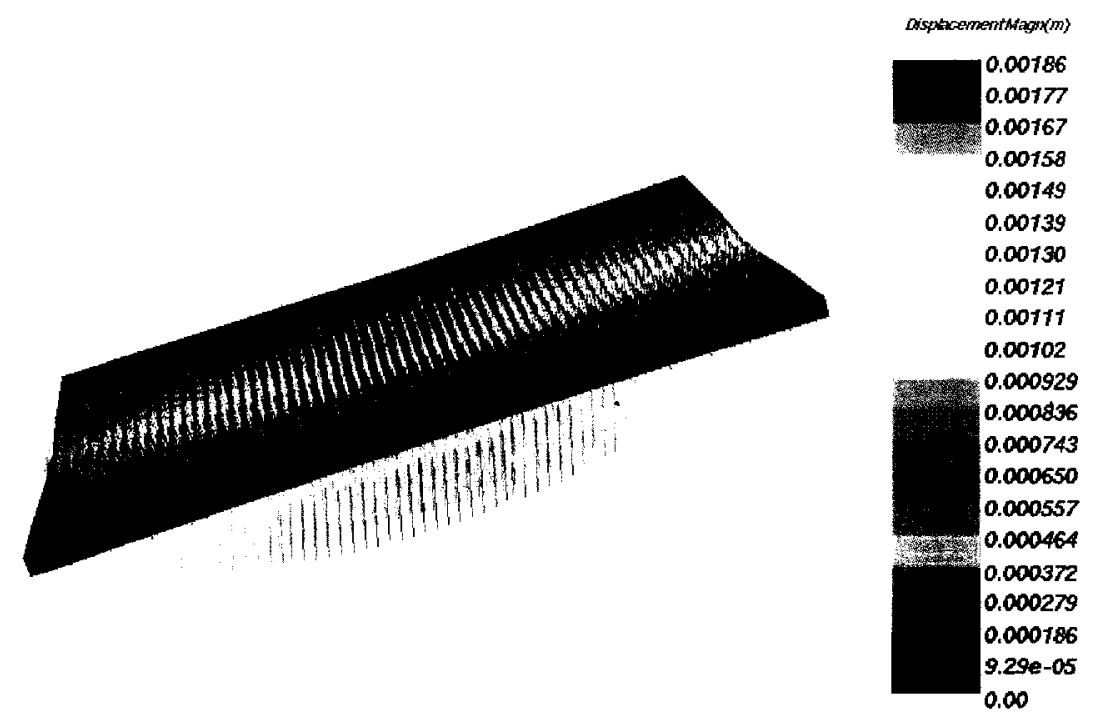

Figure 4.8: Displacement in the weld joint.

Figures 4.9(a) and (b) that along line XX, the highest tensile stress exists in right hand side of the HAZ. Due to the absence of weld 2, the value of tensile stress on the left hand side is smaller than that on the right hand side. The distribution of residual stresses along line ZZ is similar to that in the butt weld, however the magnitude of these residual stresses is much lower than in the butt weld due to the smaller weld size for the T-joint. 

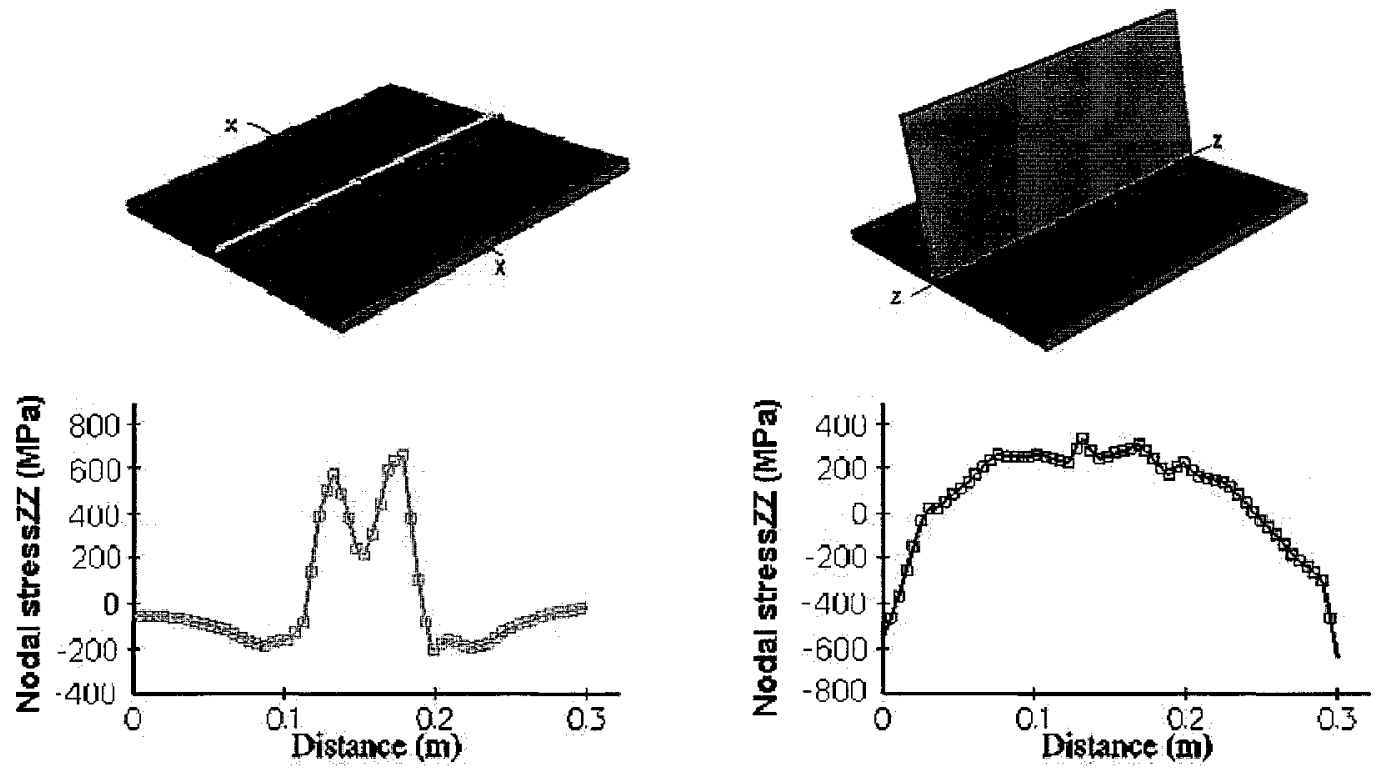

(a) StressZZ along line $X X$ at $y=0.005, z=0.15$

(c) Stress ZZ along line $Z 7$ at $x=0.005, y=0.01$
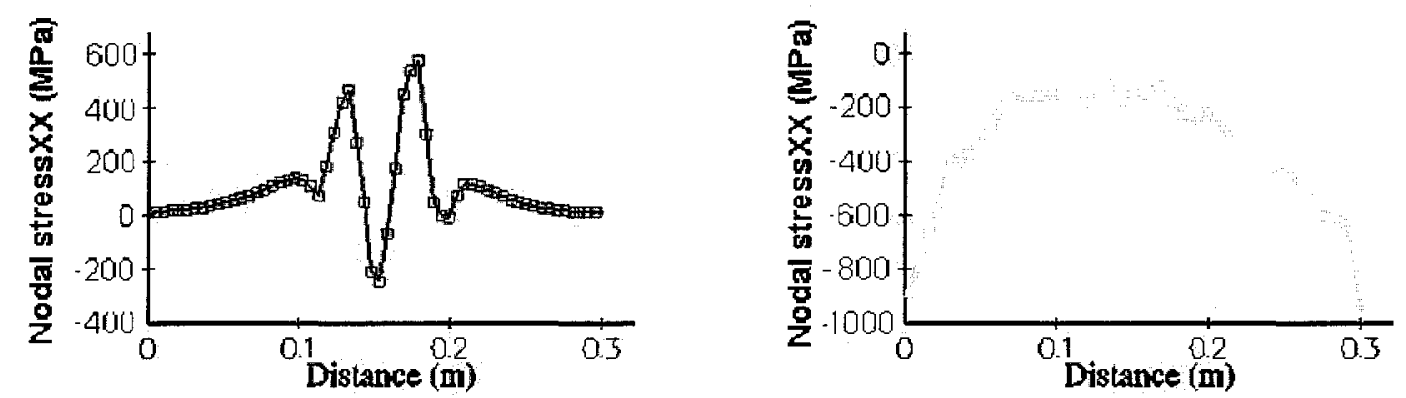

(b) Stress $X X$ along line $X X$ at $y=0.005, z=0.15$

(d) StressXX along line $Z Z$ at $x=0.005, y=0.01$

Figure 4.9: Stress distribution in the T-joint. 


\subsubsection{Parametric Study}

Welding conditions strongly affect the residual stresses, so in order to reduce the residual stress, it is necessary to characterize the effects of certain welding conditions on the residual stresses. The effects of weld length, constraints and welding sequence are investigated in the study.

\section{Effects of Weld Length}

The effects of weld length on the residual stress were tested by using four specimens with individual lengths of $150 \mathrm{~mm}, 300 \mathrm{~mm}, 450 \mathrm{~mm}$ and $600 \mathrm{~mm}$. The results are shown in Figures 4.10 and 4.11. These figures indicate that the high tensile longitudinal and transverse stresses in the central region decrease with the increasing length of the specimens. On the other hand, the magnitude of the compressive transverse stresses in the central region increases as the weld length increase. 


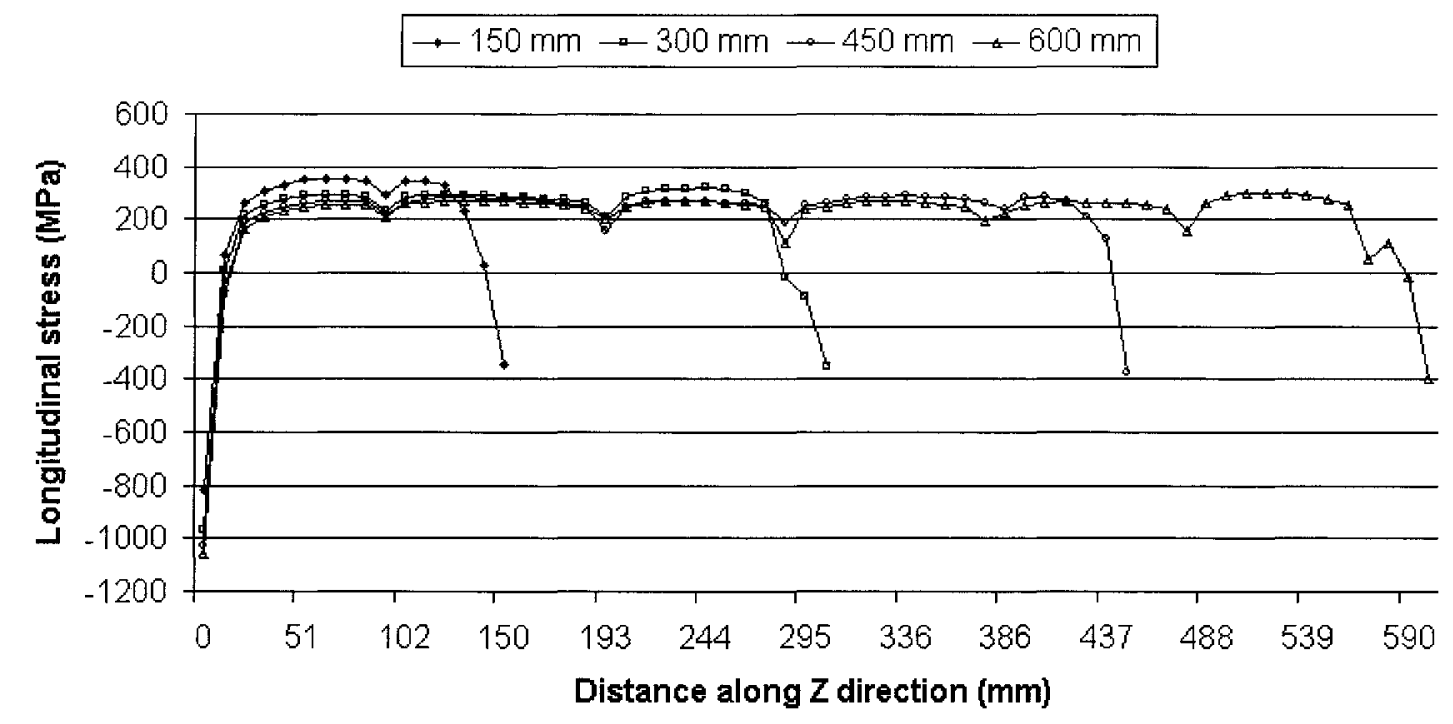

Figure 4.10: Comparison of longitudinal stress along $\mathrm{Z}$ direction.

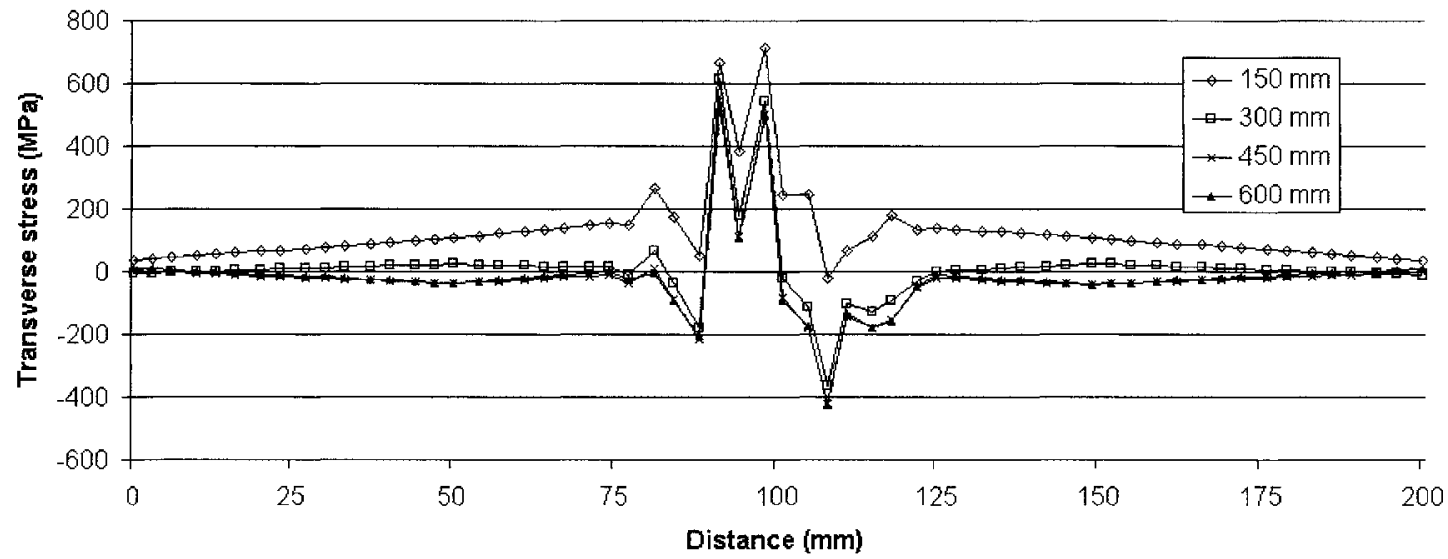

Figure 4.11: Comparison of transverse stress along X direction. 


\section{Effects of External Constraints}

Three types of external constraint are employed in this study. The first, fixes eight nodes at both edges parallel to the weld and the two plates to be welded are connected by tack welds at the root, as shown in Figure 4.12(a). The second one fixes four nodes at one edge, as displayed in Figure 4.12(b). The third one fixes eight nodes but the joint is prepared by prewelding instead of tack welding as shown in Figure 4.12(c). The longitudinal and transverse stresses are displayed in Figures 4.13 and 4.14. It can be seen that the residual stresses are similar for the constraints 1 and 2 conditions. However, the residual stress of the preweld joint is much lower than the others although it is fixed at eight nodes.

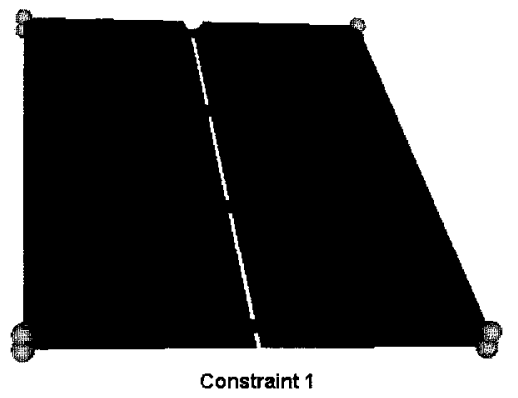

(a)

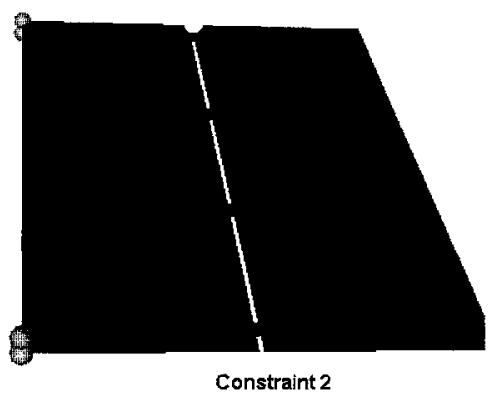

(b)

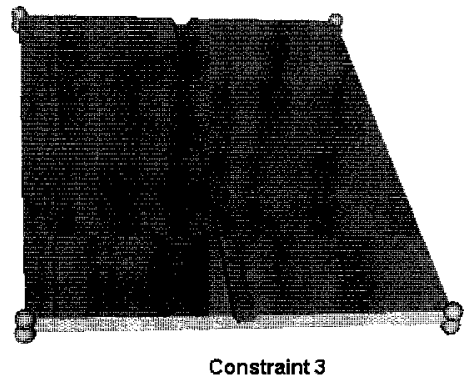

(c)

Figure 4.12: Nodal fixity of the model. 


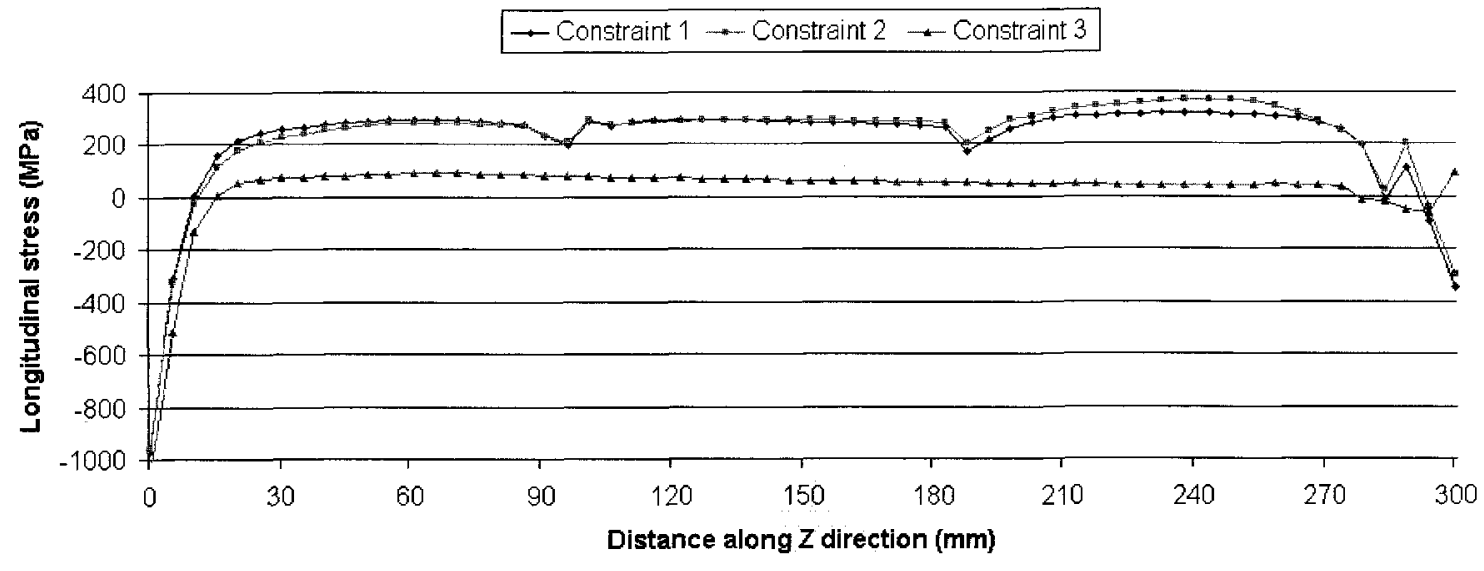

Figure 4.13: Longitudinal stress distribution for different constraints.

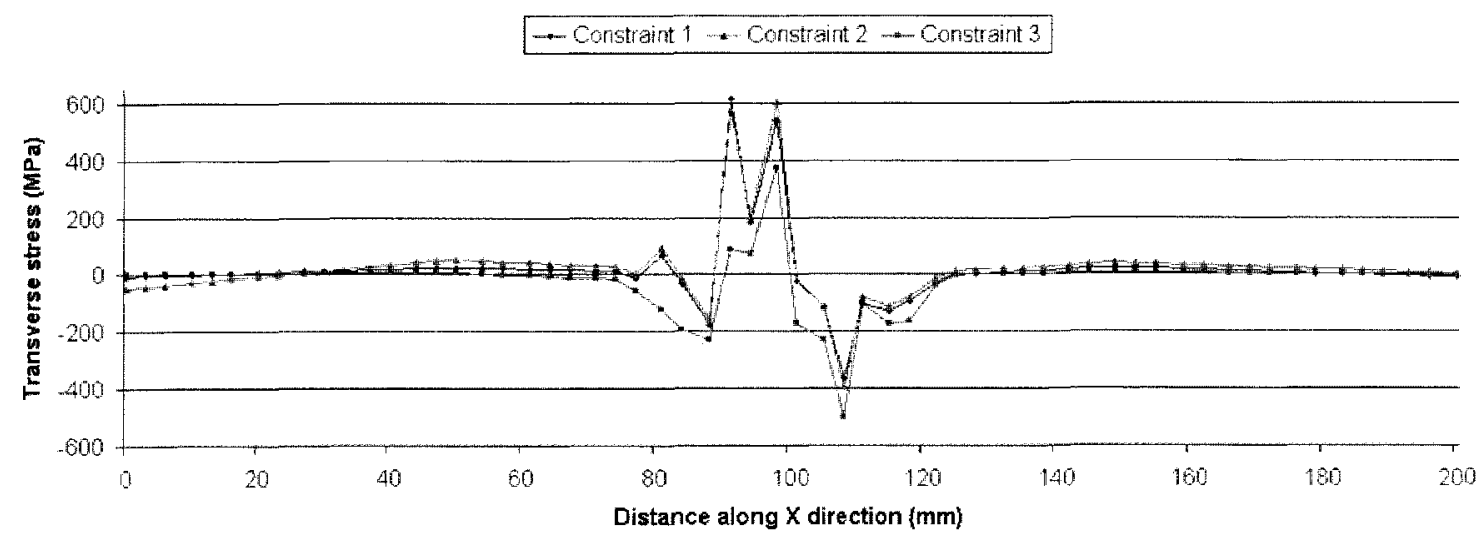

Figure 4.14: Transverse stress distribution for different constraints. 


\section{Effects of Welding Sequence}

Three different welding sequences were tested for the T-joint. The first specimen consists of only weld 1 , and weld 2 is replaced by tack weld at both ends. The second one consists of weld 1 and weld 2 and they are made by a double-torch at the same time along the same direction. The third one also consists of weld 1 and weld 2 but they are made sequentially. The longitudinal stresses along line $\mathrm{ZZ}$ and transverse stresses along line $\mathrm{XX}$ of these three welds are displayed in Figures 4.15 and 4.16. (The location of line $\mathrm{ZZ}$ and $\mathrm{XX}$ is displayed in Figure

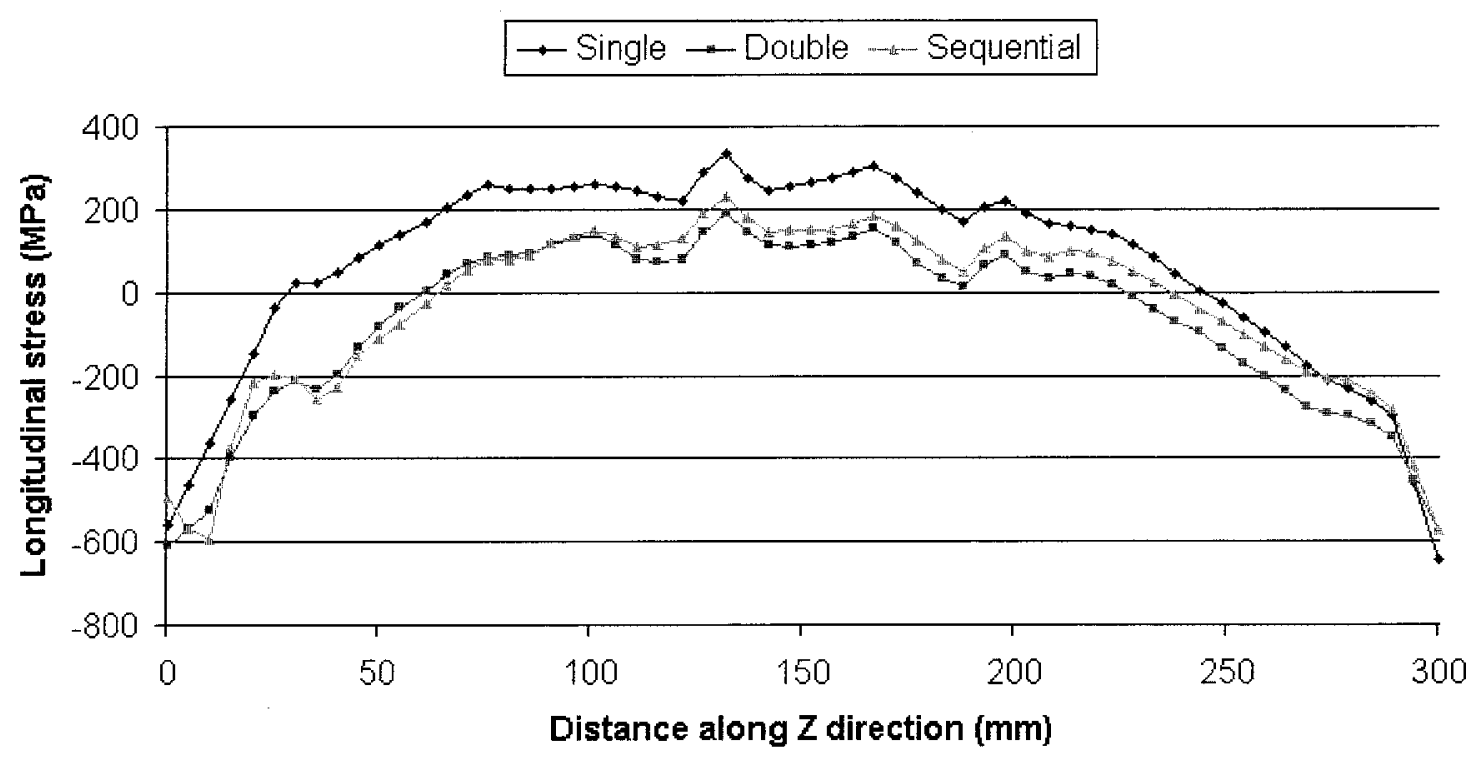

Figure 4.15: Comparison of T-joint longitudinal stress along $\mathrm{Z}$ direction. 
From Figure 4.15, one can see that the magnitude of longitudinal stress is high for the single condition compared to the double-torch and sequential conditions, and this indicates that the synchronous welding process might reduce the residual stress.

It can be seen from Figure 4.16 that when weld 1 and weld 2 are made sequentially, the magnitude of the transverse stresses in the region near weld 2 is lower than that in the region near weld 1. Figure 4.16 also indicates that double torches welding induces symmetric transverse stress distribution along line XX.

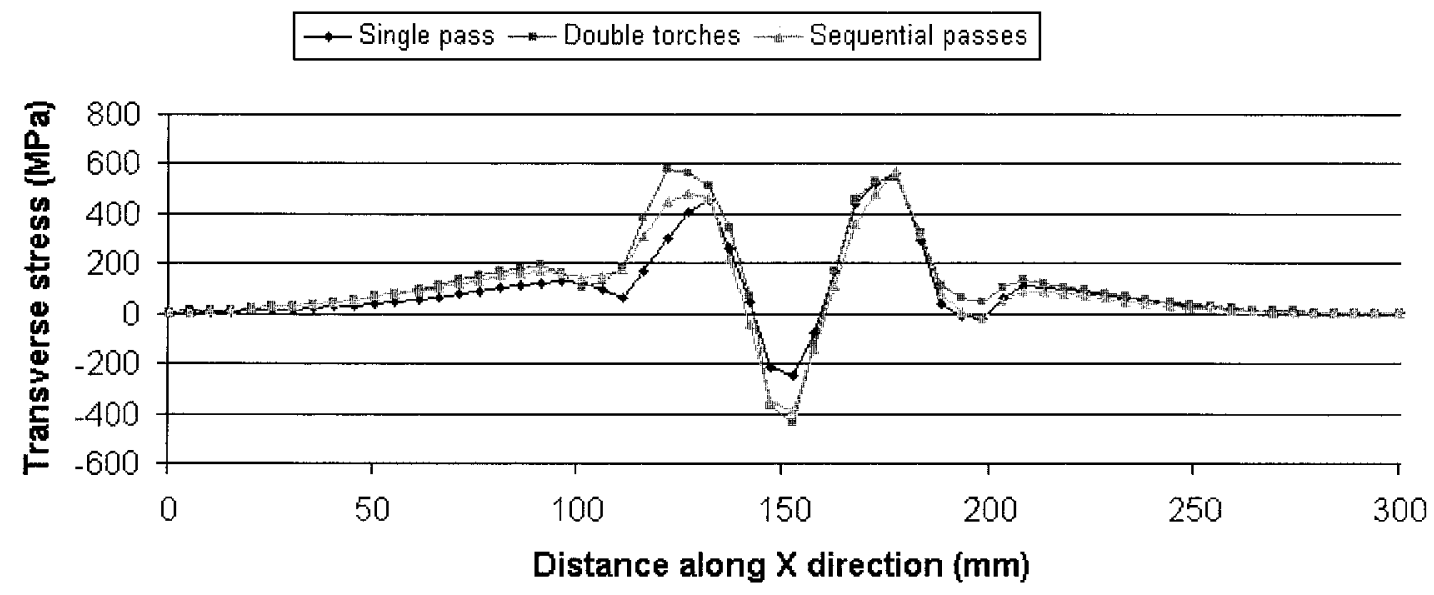

Figure 4.16: Comparison of $\mathrm{T}$-joint transverse stress along $\mathrm{X}$ direction. 


\section{Chapter 5}

\section{Conclusions and Future Work}

\subsection{Conclusions}

Thermal, microstructural and mechanical analyses were systematically performed in this study. Based on the discussion and simulations presented in the previous chapters, the following conclusions can be drawn:

1. Temperature, microstructure and residual stresses in weld joints can be modeled with useful accuracy with utilizing FEM code SimManTech.

2. Temperature Field

The thermal history of a weld joint determines the microstructure and residual stress development and can be calculated by using a prescribed-temperature, 
moving double ellipsoid heat source. The temperature field in a 2D cross section agrees well with the published experimental data.

\section{Microstructure Evolution}

The microstructure solver used for the HAZ microstructure computation has been extended to compute the microstructure of both the HAZ and the deposited filler metal. Due to the thermal cycle, original austenite grain size and chemical composition difference, the volume fractions of ferritic products vary between the HAZ and the weld metal. In the HAZ, the microstructural constituents of the steel under investigation are ferrite and pearlite. By contrast, microstructure in the weld metal consists mainly of ferrite with some bainite and no pearlite under the welding condition applied.

\section{Residual Stresses Estimation}

High tensile residual stresses exist in the central region of the weld joints. Along the weld centerline ( $\mathrm{Z}$ direction), compressive residual stresses are present at the start and end sections, and tensile residual stresses are present in the central region. Along the transverse line passing across the weld, high tensile longitudinal residual stresses are present in a small area near the weld and they become compressive towards the two edges. On the other hand, high tensile transverse residual stresses exist in the central area, then decrease and become 
compressive as the distance from the weld increases, and finally become zero at both edges.

The maximum value of both tensile and compressive residual stresses are higher than the initial yield stress due to the strain hardening effect.

Residual stresses are also affected by the welding conditions.

\subsection{Future Work}

Future work might focus on the following aspects:

1. Further classification of the evolution of ferrite in the weld metal to allotriomorphic, Widmanstatten and acicular ferrite.

2. The experimental validation of the microstructure and residual stress models.

3. The microstructure effects on the residual stress evaluation. 


\section{Appendix A}

\section{Material properties}

Thermal and mechanical properties used in the residual stress analysis

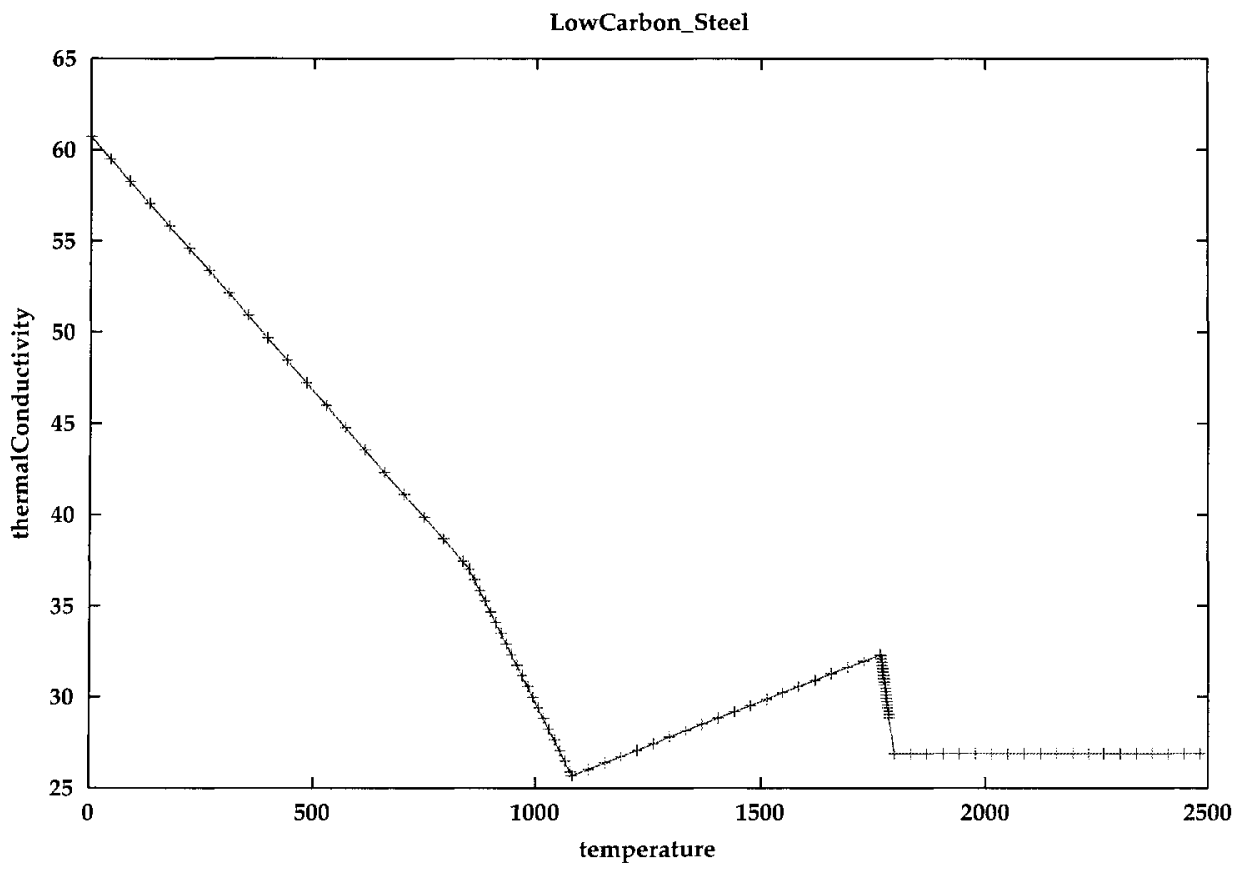

Figure A.1: Temperature-dependent thermal conductivity [44]. 


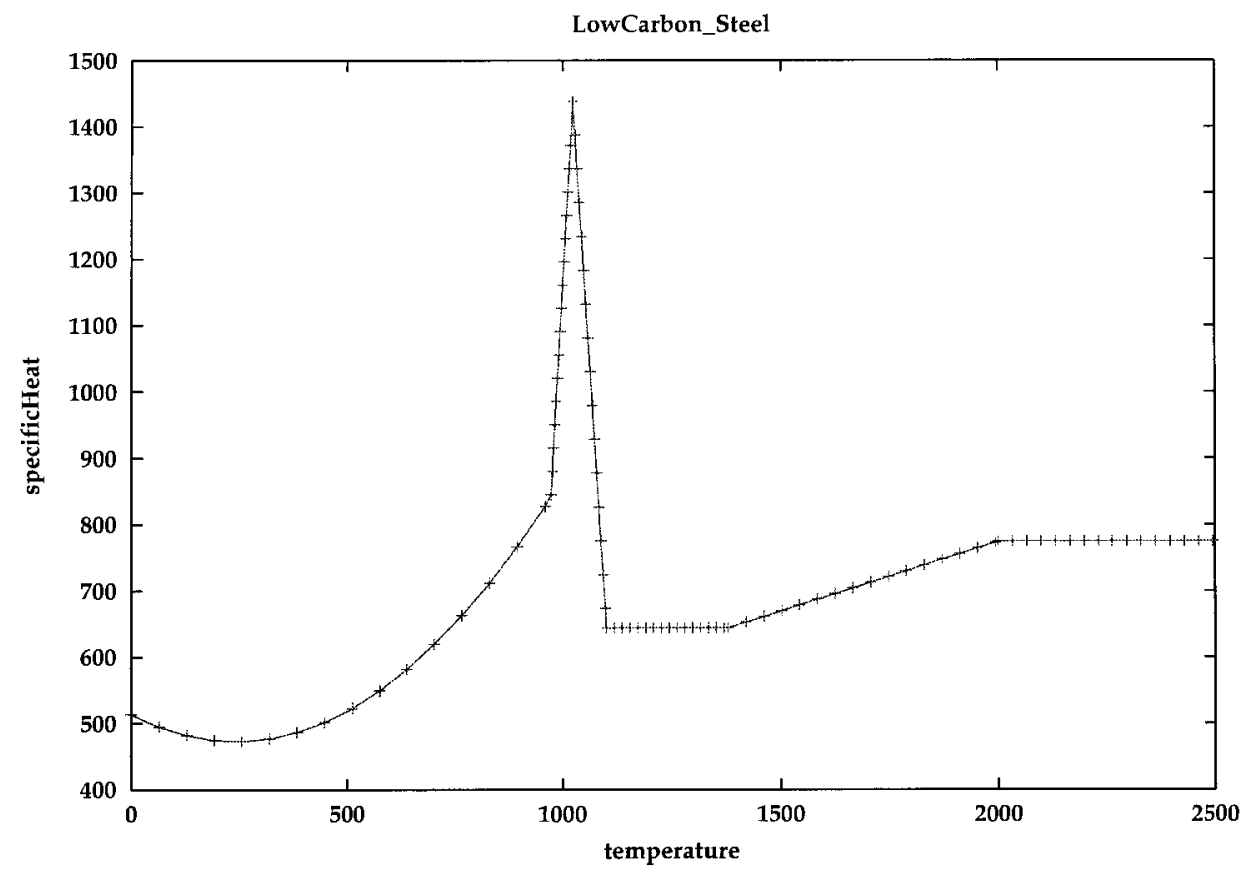

Figure A.2: Temperature-dependent specific heat [44].

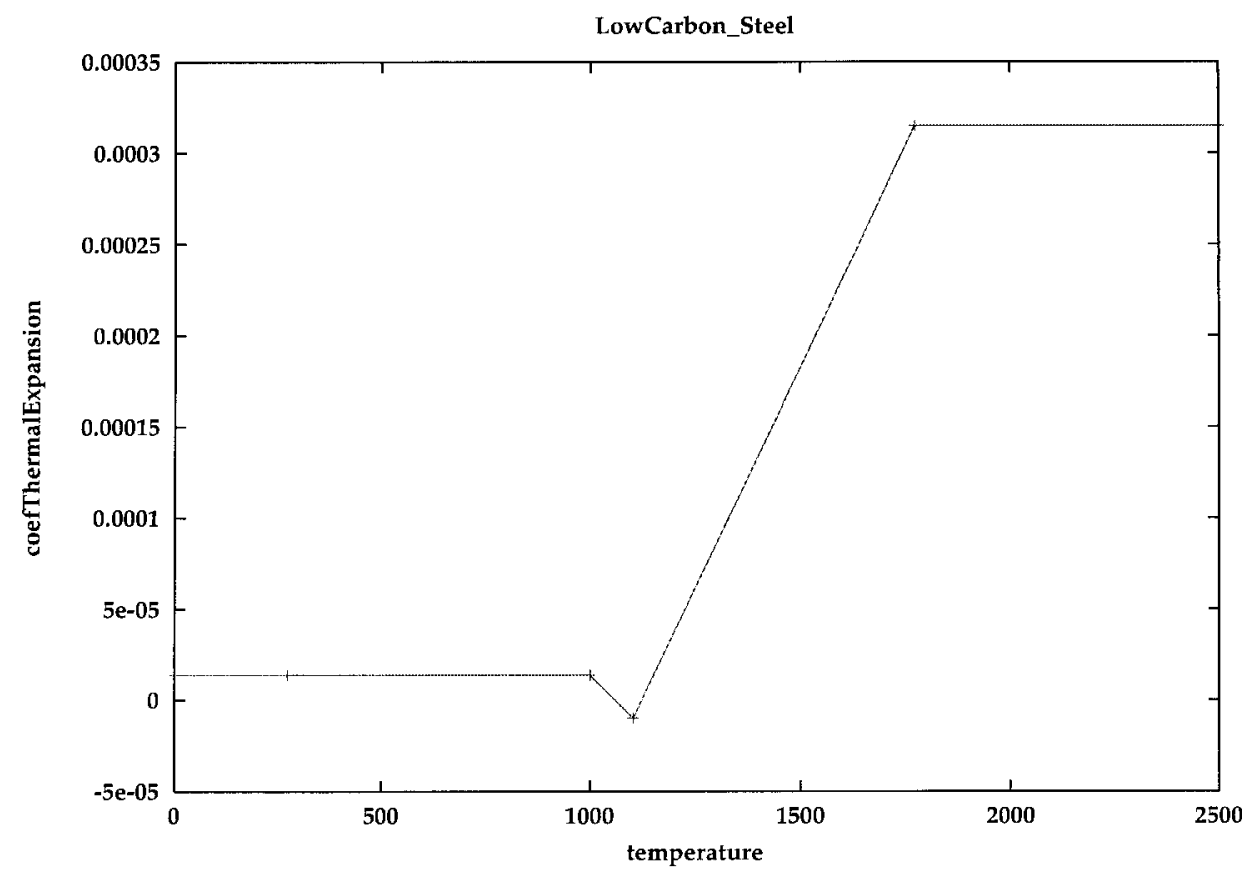

Figure A.3: Temperature-dependent coefficient of thermal expansion [45]. 


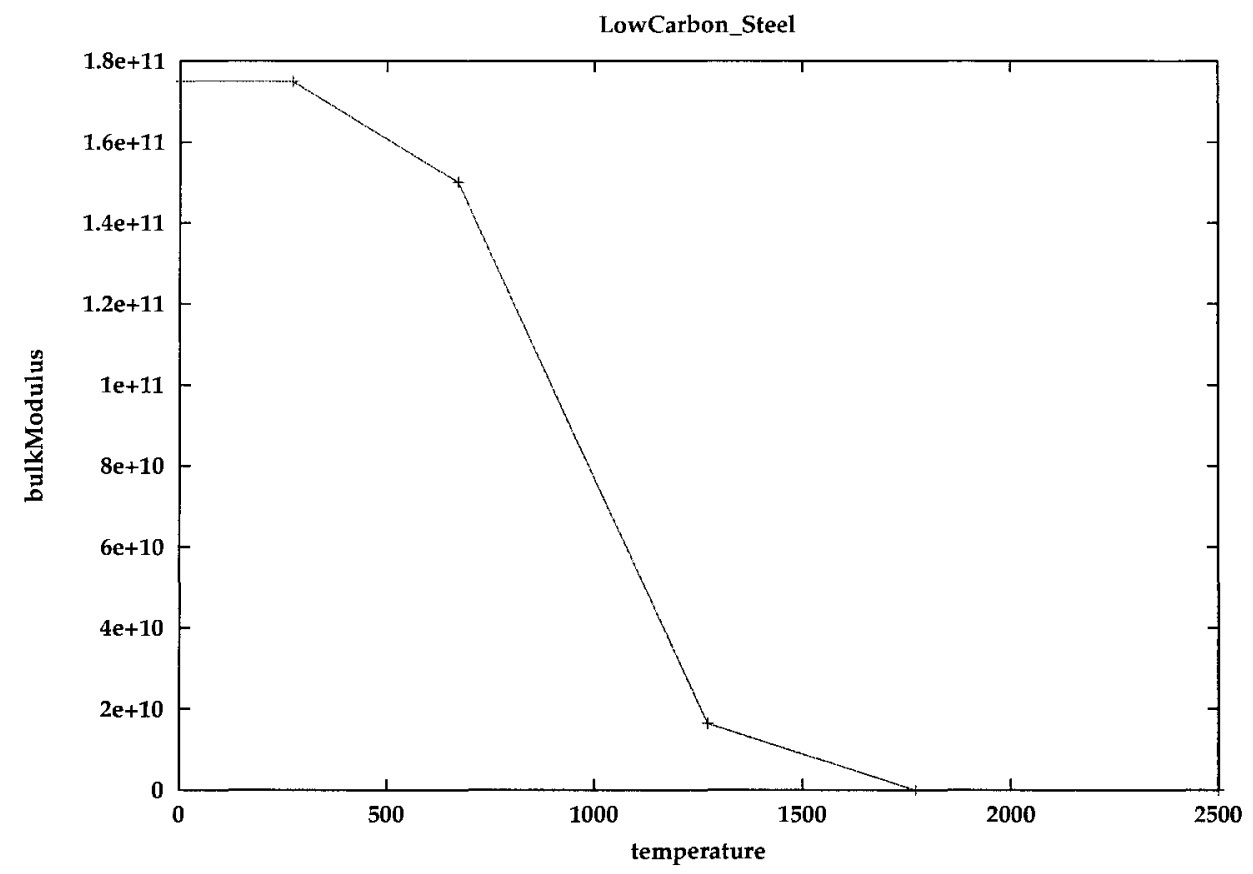

Figure A.4: Temperature-dependent bulk modulus [45].

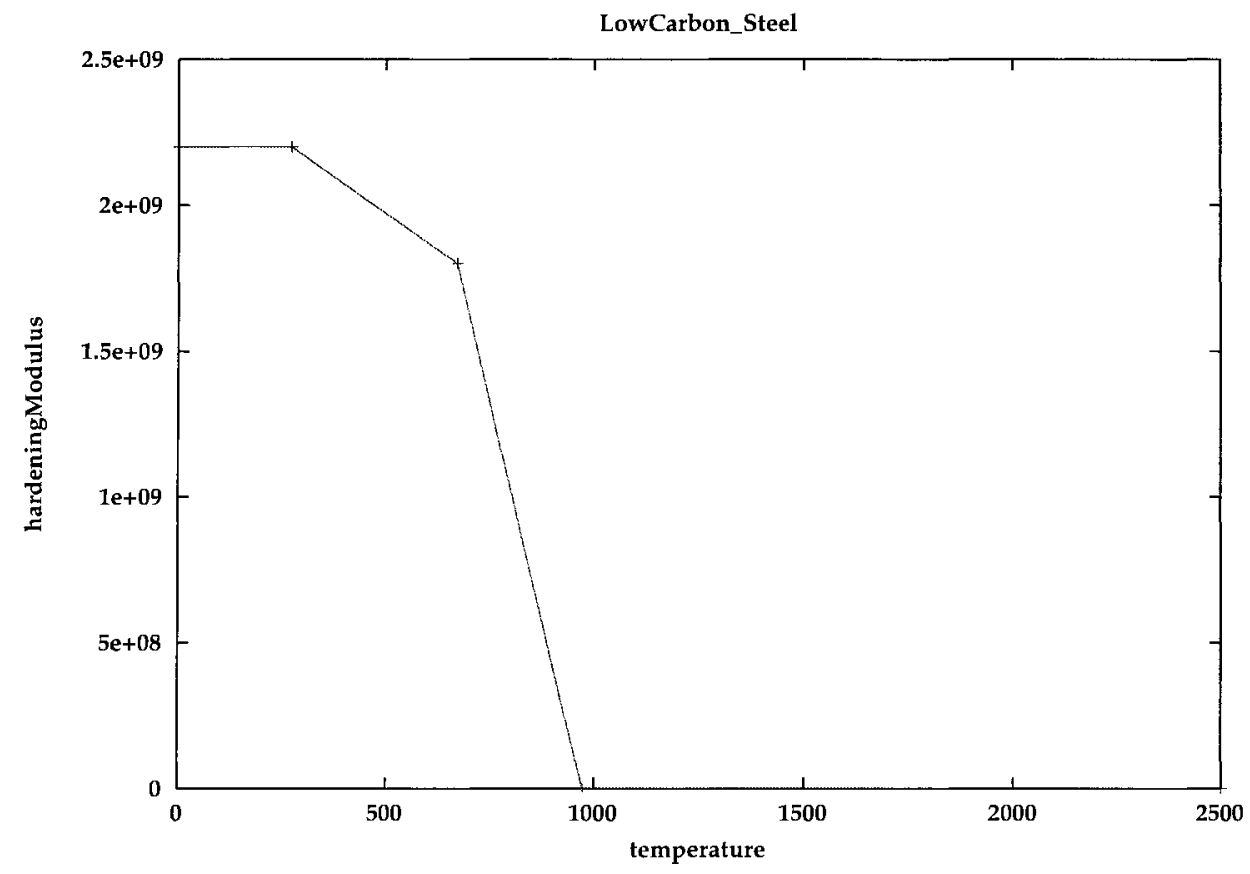

Figure A.5: Temperature-dependent hardening modulus [45] 


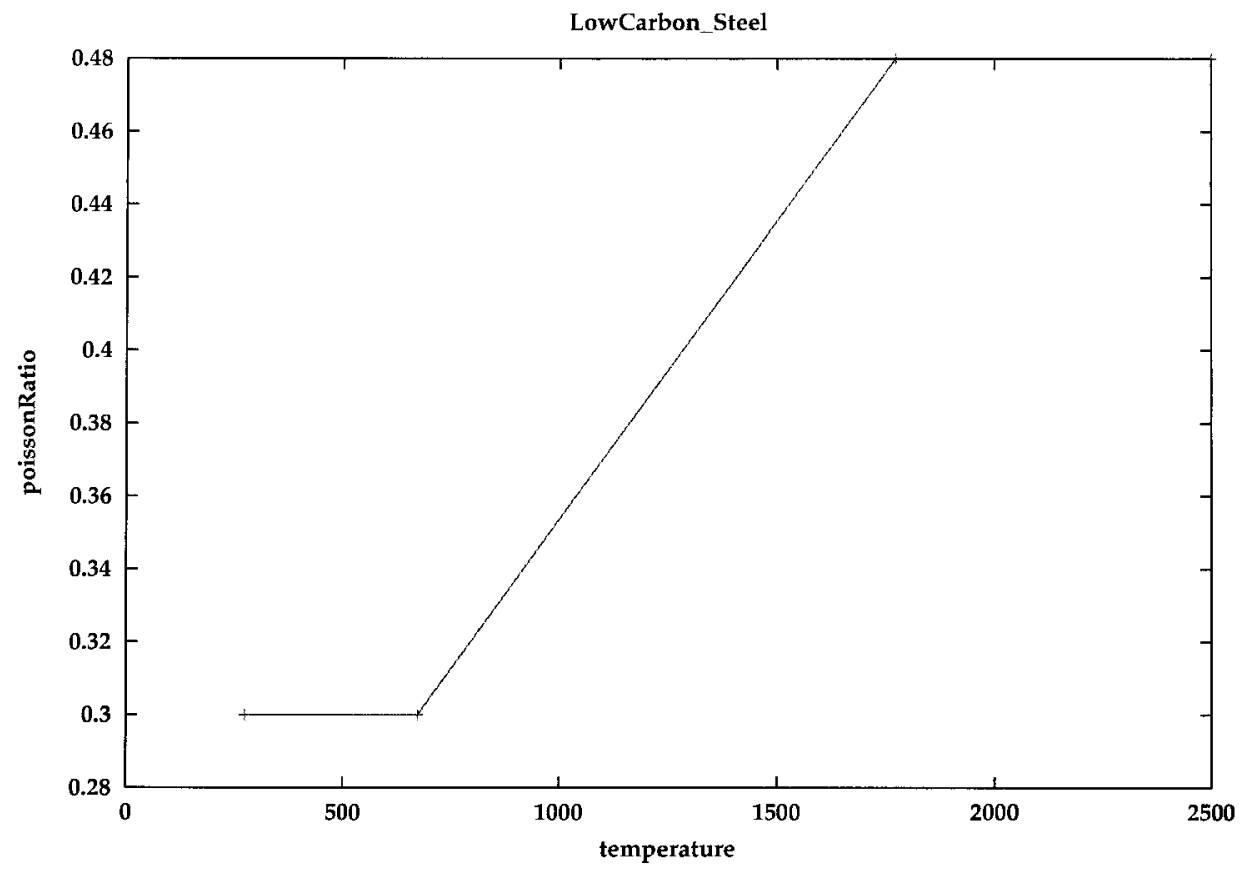

Figure A.6: Temperature-dependent Poisson's ratio [45]

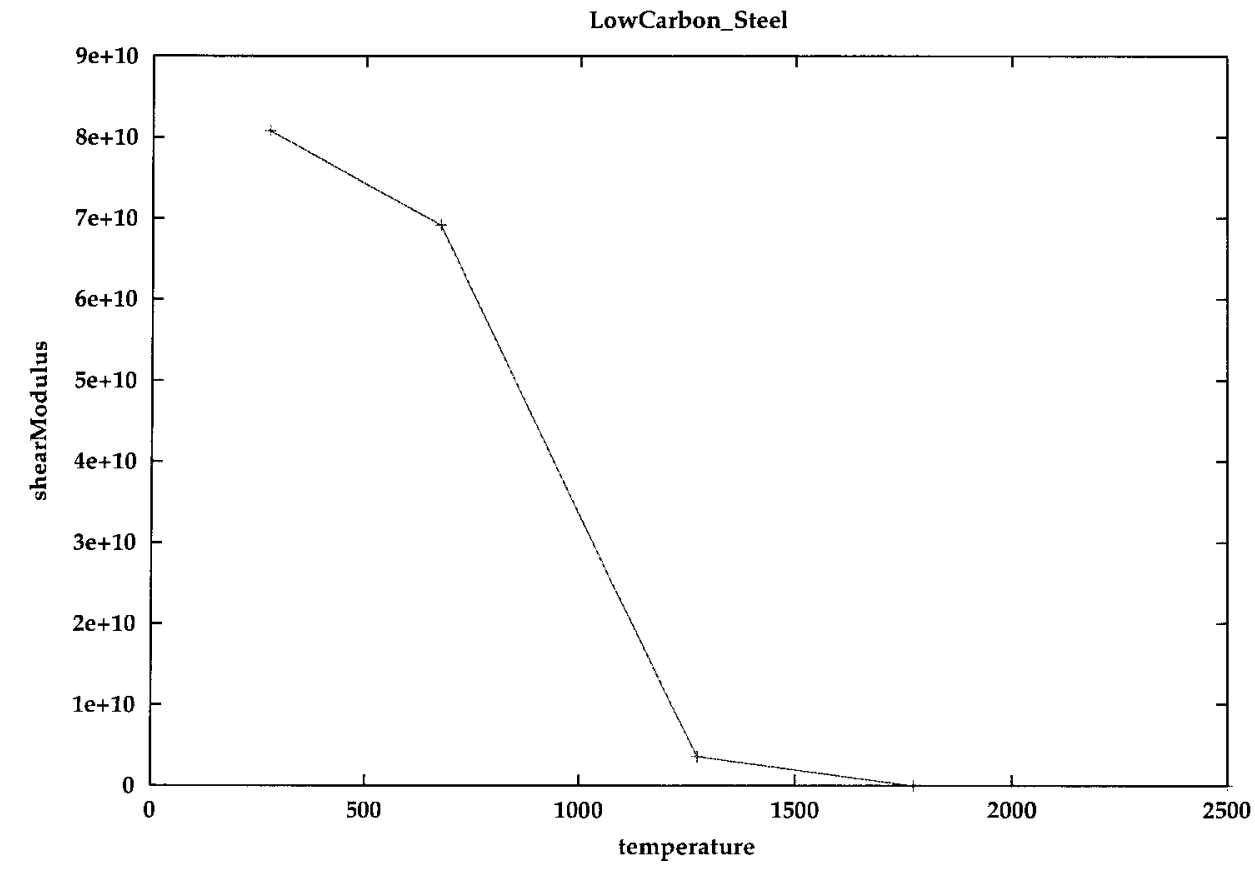

Figure A.7: Temperature-dependent shear modulus [45] 


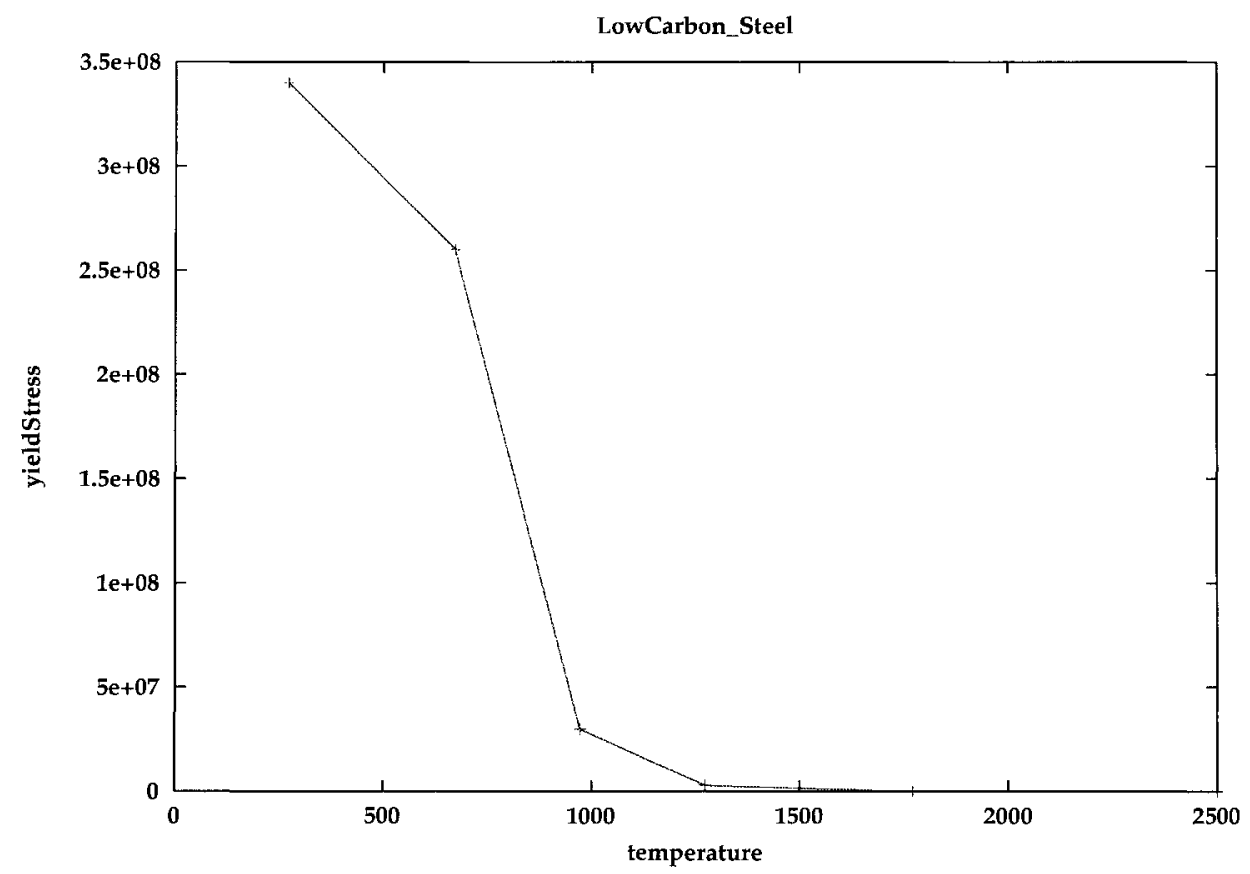

Figure A.8: Temperature-dependent yield stress [45]

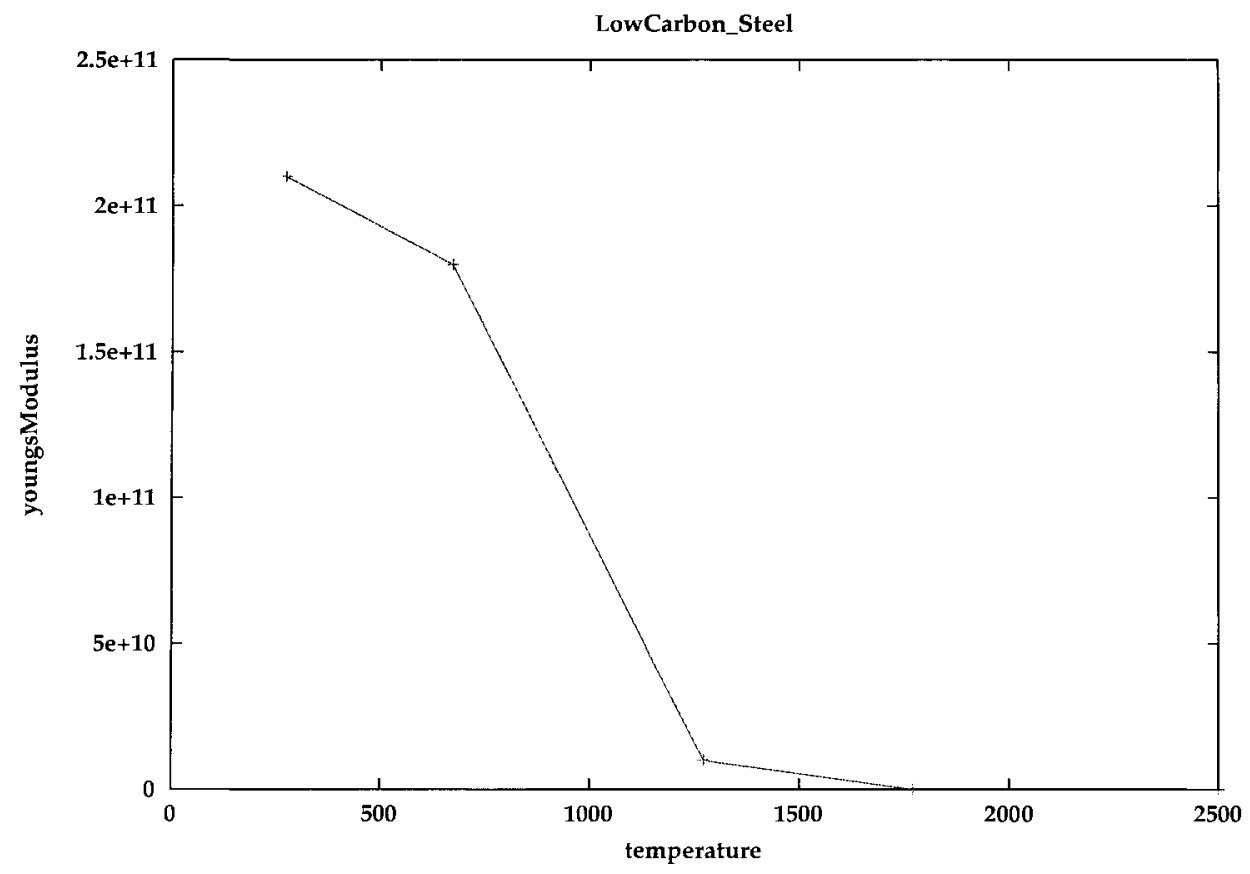

Figure A.9: Temperature-dependent Young's modulus [45] 


\section{Bibliography}

[1] Welding and allied processes - Vocabulary - Part 1: Metal welding processes, ISO 857-1, International Organization for Standardization, 1998.

[2] The Procedure Handbook of Arc Welding, the Lincoln Electric Company, 13th Ed., 1994.

[3] L. P. Connor editor, Welding Handbook, 8th Ed., American Welding Society, 1989.

[4] D. Brandon and W. D. Kaplan, Joining Process, John Wiley \& Sons Ltd., 1997.

[5] M. Hansen, Constitution of Binary Alloy, 2nd Ed., McGraw Hill, 1958.

[6] K. Mundra, T. DebRoy, S. S. Babu and S. A. David, Weld Metal Microstructure Calculation from Fundamentals of Transport Phenomena in the Arc Welding of Low-alloy Steels, Welding J. Vol. 76, No. 4, 1997, pp163s-171s. 
[7] P. Khoral, Coupling Microstructure to Heat Transfer Computation in Weld Analysis, Masters Thesis, Carleton University, 1989.

[8] H. K. D. H. Bhadeshia, Modeling the Microstructure in the Fusion Zone of Steel Weld Deposits, Recent Trends in Welding Science and Technology, ASM International, 1990, pp189-197.

[9] Sindo Kou, Welding Metallurgy, 2nd Edition, A John Wiley \& Son, Inc., 2003.

[10] J. A. Brooks and K. W. Mahin, Solidification and Structure of Welds, Welding: Theory and Practice, Edited by D. Olson, R. Dixon, and L. Liby, North-Holland Publishers, 1990.

[11] K. Easterling, Introduction to the Physical Metallurgy of Welding, Butterworths \& Co. Ltd., 1983.

[12] S. A. David and J. M. Vitek, Correlation Between Solidification Parameters and Weld Microstructures, Int. Mat. Rev. Vol. 34, No. 5, 1989, pp213-245.

[13] R. W. K. Honeycombe, Steels -Microstructure and Properties, Edward Arnold Ltd, 1981.

[14] J. A. Gianetto, Private communication, Materials Technology Laboratory - CANMET, 2005. 
[15] M. Eroglu, M. Aksoy and N. Orhan, Effect of coarse initial grain size on microstructure and mechanical properties of weld metal and $H A Z$ of a low carbon steel, Materials Science and Engineering A269, 1999, pp59-66.

[16] J. F. Lancaster, Metallurgy of welding, 4th Edition, Allen \& Unwin (Publishers) Ltd. 1987.

[17] J. Goldak, Modeling thermal stresses and distortions in welds on Recent Trends in Welding Science and Technology; ASM International, 1990.

[18] J. Goldak, A. Oddy, M. Gu, W. Ma, A. Akbar and E. Hughes, Coupling Heat Transfer, Microstructure Evolution and Thermal Stresses Analysis in weld Mechanics on Mechanical Effects of Welding, Ed. by L. Karlsson, L. -E. Lindgren and M. Jonsson, Springer-Verlag, 1992.

[19] J. Choi, J. Mazumder, Numerical and Experimental Analysis for Solidification and Residual Stress in the GMAW Process for AISI 304 Stainless Steel, J. Mater.Sci. Vol.37, 2002, pp2143-2158.

[20] K. Masubuchi, Analysis of Welded Structures, Pergamon Press Ltd, 1980.

[21] D. George, D. J. Smith, Through thickness measurement of residual stresses in a stainless steel cylinder containing shallow and deep weld repairs, Int. J. Pressure Vessels and Piping Vol. 82, 2005, pp279-287. 
[22] H. K. D. H. Bhadeshia, L. -E. Svensson and B. Gretoft A model for the Development of Microstructure in Low-alloy steel (Fe-Mn-Si-C) Weld Deposits, Acta Metall. Vol. 33 No. 7, 1985, pp1271-1283.

[23] D. F. Watt, L. Coon, M. J. Bibby, J. A. Goldak and C. Henwood, An Algorithm for Modeling Microstructural Development in Weld Heat Affected Zones, Acta Metal, Vol. 36, No.11, 1988, pp3029-3035.

[24] V. Pavlyk and U. Dilthey, Simulation of weld solidification microstructure and its coupling to the macroscopic heat and fluid flow modeling, Modeling Simula. Mater. Sci. Eng., 12, 2004, s33-s45.

[25] N. S. Boulton, H. E. Lance Martin, Residual Stresses in Arc-welded Plates, Proc. Inst. Mech. Engrs. 133, 1936, pp295-347.

[26] H. D. Hibbitt and P. V. Marcal, A Numerical, Thermo-mechanical Model for the Welding and Subsequent Loading of a Fabricated Structure, Computers and Structures, 3(5), 1973, pp1145-1174.

[27] E. F. Rybicki, A Finite Element Model for Residual Stresses in Girth-Butt Welded Pipes, Num. Model. Manuf. Process. ASME PB-025, 1977, pp131-142. 
[28] Y. Ueda, Basic Procedures in Analysis and Measurement of Welding Residual Stresses by the Finite Element Method, Int. Conf. Res. Str. Weld. Constr. (London: Weld Institute), 1977, pp27-37.

[29] L. Tall, The strength of welded built-up columns, Ph.D. Dissertation, Lehigh University, 1961.

[30] S. Fricke, E. Keim and J. Schmidt, Numerical weld modeling - a method for calculating weld-induced residual stresses, Nuclear Engineering and Design 206, 2001, pp139-150.

[31] Tso-Liang Teng and Chih-Cheng Liu, Effect of welding conditions on residual stresses due to butt welds, Inter. J. Pressure Vessels and Piping 75, 1998, pp857864.

[32] W. W. Wilkening and J.L. Snow, Analysis of Welding-induced Residual Stresses with the ADINA System, Computers and Structures Vol. 47, 4/5, 1993, pp767786.

[33] D. Rosenthal, Mathematical theory of heat distribution during welding and cutting,Welding Journal, 20(5), 1941, pp220s-234s.

[34] D. Rosenthal, The Theory of Moving Sources of Heat and Its Application Metal Treatments, Trans. ASME, Vol. 68, 1946, pp849-865. 
[35] K. Sidorowicz, Finite element analysis of laser welding induced thermal shock, Weld. J. Vol.59, 1979, pp324-329.

[36] J. Goldak, A. Chakravarti, and M. Bibby; A New Finite Element Model for Welding Heat Sources, Metall. Trans. B, V.15B, June 1984, pp299-305.

[37] J. Goldak, Computational Weld Mechanics, to be published, 2005.

[38] T. W. Eagar, An iconoclast's view of the physics of welding - rethinking old ideas, on Recent Trends in Welding Science and Technology, Edited by S. A. David and J. M. Vitek, ASM International, 1989.

[39] J. Goldak, M. Gu and L. Karlsson, Numerical Aspects of Modeling Welds, ASM Handbook, Vol. 6, ASM International, 1993, pp1131-1140.

[40] V. A. Vinokurov, Welding Stress and Distortions, Translated from Russian into English by J. E. Baker, The British Library, Lending Division, 1977, pp118-119.

[41] D. Redekop, MCG5108 - Finite Element Analysis (FEA), Lecture Notes, Ottawa University, 2003.

[42] J Goldak, B. Patel, J. Moore and M. Bibby, Computational Weld Mechanics on Advanced Joining of Aerospace Metallic Materials, North Atlantic Treaty Organization, 1985. 
[43] A. Jablonka, K. Harste and K. Schwerdtfeger, Thermomechanical properties of iron and iron-carbon alloys: density and thermal contraction, Steel research (Germany) 62, No.1, 1991, pp24-33.

[44] P. C. Zhao, C. S. Wu and Y. M. Zhang, Numerical simulation of the dynamic characteristics of weld pool geometry with step-changes of welding parameters, Modeling Simul. Mater. Sci. Eng. 12, pp765-780, 2004.

[45] B.A.B. Andersson, Thermal Stresses in a Submerged-Arc Welded Joint Considering Phase Transformations, ASME J. Engineering Materials and Technology, Vol. 100, 1978, pp356-362.

[46] S. Murugan, P. V. Kumar, B. Raj and M. S. C. Bose, Temperature distribution during multipass welding of plates, Inter. J. Pressure Vessels \& Piping, 75 1998, pp891-905.

[47] Y. S. Touloukian, R. W. Powell, C. Y. Ho and P. G. Klemens, Thermophysical properties of mater, V. 1, Purdue Research Foundation, 1970.

[48] D. R. Lide, H. V. Kehiaian, CRC Handbook of Thermophysical and Thermochemical Data, CRC Press, 1994.

[49] W. C. Leslie, The Physical Metallurgy of Steels, McGraw Hill Book Company, 1981, pp256-276. 
[50] K. W. Andrews, Journal of Iron Steel Institute, Vol. 203, 1965, pp721-728.

[51] M. F. Ashby and K. E. Easterling, A First Report on Diagrams for Grain Growth in Welds, Acta Metall. Vol.30, 1982, pp1969-1978.

[52] J. S. Kirkaldy, D. Venugipalan, Prediction of Microstructure and Hardenability in Low Alloy Steels, on Phase Transformation in Ferrous Alloys, Proceedings of the international conference, 1983.

[53] S. Babu, Acicular Ferrite and Bainite in $\mathrm{Fe}-\mathrm{Cr}-\mathrm{C}$ Weld Deposits, Ph.D thesis, University of Cambridge, 1991.

[54] E. E. Underwood, Quantitative Stereology, Addison Wesley, 1970.

[55] J. C. Ion, K. E. Easterling and M. F. Ashby, A Second Report on Diagrams of Microstructure and Hardness for Heat-affected Zones, Acta Metall. Vol.32, 1984, pp1949-1962.

[56] T. G. Gooch and P. H. M. Hart, Solid State Phase Transformations in Steel During Welding on Advances in Welding Science and Technology, Ed. by S. A. David, ASM International, 1986.

[57] Stephen Liu and J. E. Indacochea, Control of Chemical composition and microstructure in low-carbon microalloyed steel weldments, on Welding: Theory 
and Practice, Edited by D. Olson, R. Dixon, and L. Liby, North-Holland Publishers, 1990.

[58] J. W. Christian, Theory of Transformation in Metals and Alloys, 2nd Ed., part 1, Perganom Press. 1975.

[59] R. Trivedi, Growth of dendritic needles from a supercooled melt, Acta Metallurgica, Vol. 18, 1970, pp287-296.

[60] C. E. Henwood, An Analytical Model for Computing Weld Microstructure, Master thesis, Carleton University, 1987.

[61] C. Henwood, M. Bibby, J. Goldak and D. Watt, Coupled Transient Heat Transfermicrostructure Weld Computations, Part B, Acta Metallurgica, Vol. 36, 1988, pp3037-3046.

[62] D. P. Koistinen, R. E. Marburger, A General Equation Prescribing the Extent of the Austenite-martensite Transformation in Pure Iron-carbon Alloys and Plain Carbon Steels, Acta Metallurgica, Vol. 7, 1959, pp59.

[63] W. Zinn and B. Scholtes, Residual Stress Formation Processes during Welding and Joining on Handbook of Residual Stress and Deformation of Steel, Ed. by G. Totten, M. Howes and T. Inoue, ASM International, 2002. 
[64] P. Chang and T. Teng, Numerical and experimental investigations on the residual stresses of the butt-welded joints, Computational Materials Science 29, 2004, pp511-522.

[65] T. Hsu, The Finite Element Method in Thermomechanics, Allen \& Unwin, Inc., 1986.

[66] K. J. Bathe, Finite Element Procedures, Pretice-Hall, Inc., 1996, pp156-158.

[67] J. Goldak, M. Mocanita, V. Aldea, J. Zhou, D. Downey and D. Dorling, Predicting Burn-through when Welding on Pressurize Natural Gas Pipelines, Proceedings of 2000 ASME Pressure Vessels and Piping Conference, DAC-1234, Seattle, USA, 2000.

[68] B. Cheng, A Posteriori Error Estimates of Finite Element Solutions, Master thesis, Carleton University, 2003.

[69] A. Mashaie, Error Estimates for Finite Element Solutions of Elliptic Boundary Value Problems, PH.D Thesis, Carleton University, 1991. 